Carlos Gustavo Vasconcelos De Moraes

\title{
Progressão estrutural e funcional da lesão glaucomatosa na mácula
}

Tese apresentada à Faculdade de Medicina da Universidade de São Paulo para obtenção do título de Doutor em Ciências

Programa: Oftalmologia

Orientador: Prof. Dr. Remo Susanna Júnior

São Paulo

2019 
Dados Internacionais de Catalogação na Publicação (CIP)

Preparada pela Biblioteca da

Faculdade de Medicina da Universidade de São Paulo

Creprodução autorizada pelo autor

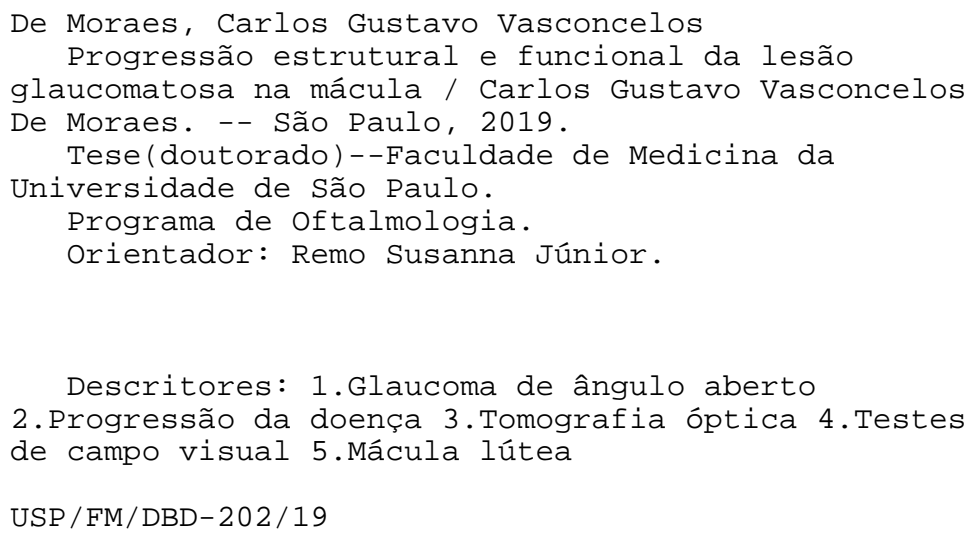


Este projeto recebe suporte financeiro do National Eye Institute (NEI) do National Institutes of Health $(\mathrm{NIH})$ dos Estados Unidos da América (Department of Health and Human Services); Identificador: EY-025253.

Este projeto está registrado no ClinicalTrials.gov; Identificador: NCT02547740 


\section{DEDICATÓRIA}

A Deus, pela vida, pela saúde; pelas coisas boas - que me fazem feliz - e pelas coisas ruins - que levam ao aprendizado.

A minha mãe, Aida, pelo amor incondicional, pela lição de vida; pelo carinho, pelo ensino da humildade.

A meu pai, Luiz Carlos, pelo amor, carinho e valorização do trabalho árduo como única forma de alcançar o sucesso.

A minha esposa, Maryanne, pelo suporte, amor e amizade, mesmo nos momentos de maior dificuldade; por nunca me permitir desistir de meus sonhos.

A meu filho Gabriel, por trazer sentido a minha vida e pela inspiração de lutar a cada dia, pelos sorrisos matinais que me lembram por que devo lutar.

A meus irmãos, Luiz Carlos, João Paulo, Ana Luiza e Ana Laura, pela amizade e suporte em todos os momentos de minha vida. 


\section{AGRADECIMENTOS}

"While life is with us, we must struggle to make our mark so that death finds little it can wipe away."

Plínio

Ao professor Remo Susanna Júnior, pela orientação desta tese e por me guiar na escolha profissional, bem como a oportunidade de vir aos Estados Unidos da América, onde não somente encontrei felicidade e sucesso profissional, mas também realização pessoal. Pelo ensino da ética, da importância do trabalho e busca incessante da qualidade e perfeição. $O$ senhor é e sempre será meu melhor exemplo de pai, profissional, educador e amigo. Conforme Plínio, sua obra nessa vida permanecerá viva, para sempre.

"All truth passes through three stages. First, it is ridiculed. Second, it is violently opposed. Third, it is accepted as being self-evident."

Arthur Schopenhauer

Ao professor Robert Ritch, pela inspiração e apoio em todos os momentos de minha vida pessoal e profissional.

Ao professor Jeffrey Liebmann, pela oportunidade profissional e mais profunda amizade. Por me receber como membro de sua família, e ser hoje meu grande amigo.

Ao professor Donald Hood, pelo ensino, rigor metodológico e por servir como modelo de cientista. 
A minha estimada Universidade de São Paulo, a qual devo minha formação em medicina, em oftalmologia e glaucoma, pela educação e formação de todos aqueles antes de mim, e todos aqueles que ainda hão por vir. 
Esta tese está de acordo com as seguintes normas, em vigor no momento desta publicação:

Referências: adaptado de International Committee of Medical Journals Editors (Vancouver)

Universidade de São Paulo. Faculdade de Medicina. Divisão de Biblioteca e Documentação. Guia de apresentação de dissertações, teses e monografias. Elaborado por Annelise Carneiro da Cunha, Maria Julia de A. L. Freddi, Maria F. Crestana, Marinalva de Souza Aragão, Suely Campos Cardoso, Valéria Vilhena. 3a ed. São Paulo: Divisão de Biblioteca e Documentação; 2011.

Abreviaturas dos títulos dos períodos de acordo com List of Journals Indexed in Index Medicus. 


\section{SUMÁRIO}

Lista de abreviaturas, símbolos e siglas

Lista de Figuras

Lista de Tabelas

Resumo

Abstract

1 INTRODUÇÃO

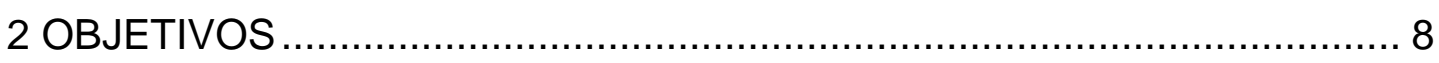

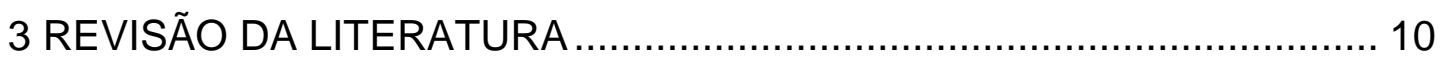

3.1 Métodos utilizados para avaliação da progressão glaucomatosa ... 11

3.1.1 Progressão funcional ..................................................... 12

3.1.2 Progressão estrutural....................................................... 18

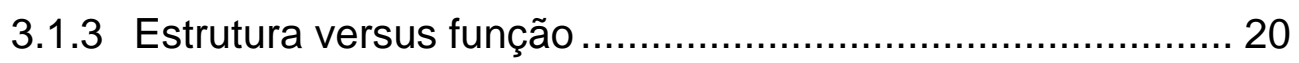

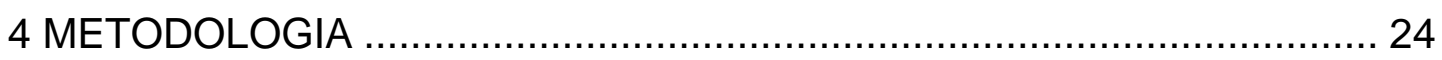

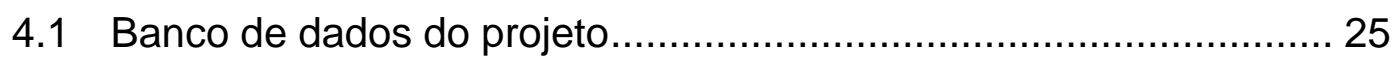

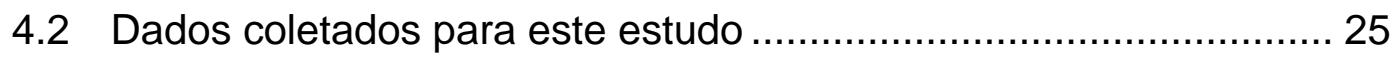

4.2.1 Tomografia de coerência óptica (OCT) .............................. 26

4.2.2 Espessura da camada de fibras nervosas e de células ganglionares da retina .................................................. 27

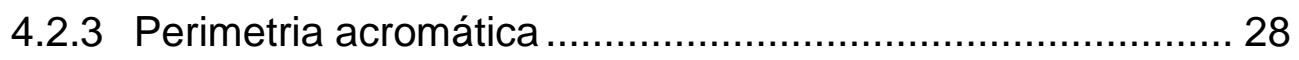

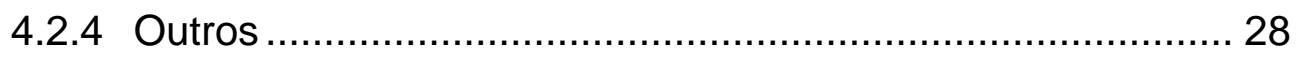

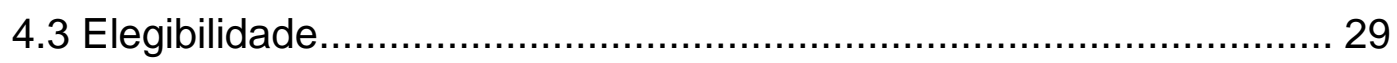

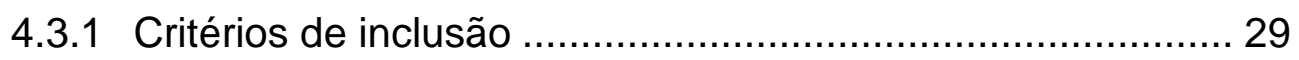

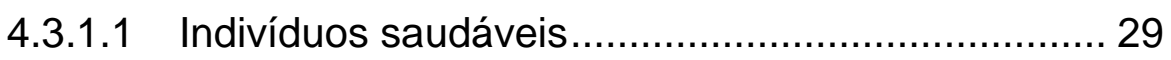

4.3.1.2 Indivíduos suspeitos de glaucoma ......................... 30

4.3.1.3 Indivíduos glaucomatosos com perda funcional inicial ........................................................ 30

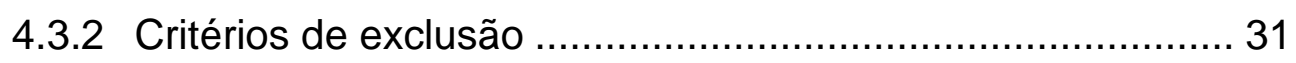

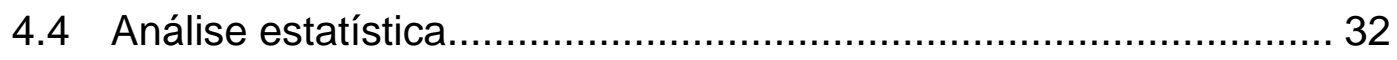

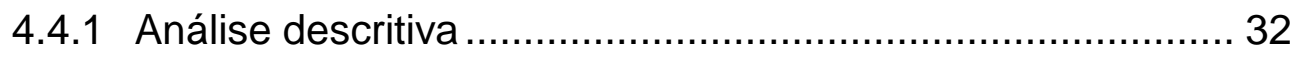

4.4.2 Avaliação da taxa de progressão ....................................... 32 
4.4.3 Combinação de parâmetros convencionais e otimizados para mácula

4.4.3.1 Obtenção da média do MD da perimetria acromática 24-2 e 10-2:

4.4.3.2 Obtenção da média de desvio de espessura da CCGR macular e CFNR peripapilar:

4.4.3.3 Modelo Bayesiano de regressão conjunta .............. 38

4.4.3.4 Modelos de simulação computacional ................... 40

5 RESULTADOS

5.1 Objetivo 1: Avaliar a taxa de progressão utilizando-se parâmetros convencionais (OCT da CFNR peripapilar e perimetria 24-2) e otimizados para mácula (OCT da CCGR e perimetria 10-2)

5.2 Objetivo 2: Avaliar a taxa de progressão glaucomatosa combinando-se parâmetros convencionais e otimizados para mácula para detecção de progressão glaucomatosa, bem como a combinação de parâmetros estruturais e funcionais em uma abordagem Bayesiana.

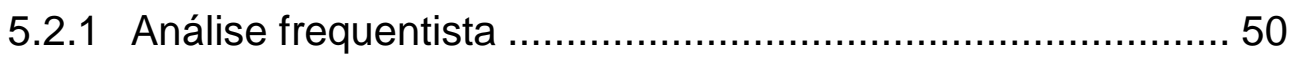

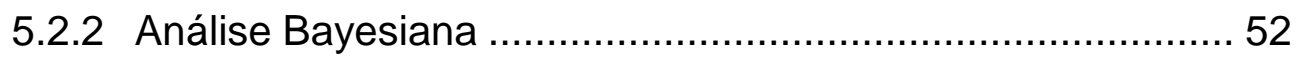

5.3 Objetivo 3: Testar a aplicabilidade da combinação de parâmetros convencionais e otimizados para mácula na prática clínica e ensaios clínicos randomizados através de um modelo de simulação computacional previamente descrito. ........................ 53

5.3.1 Paradigmas clínicos .......................................................... 53

5.3.2 Paradigma de um ensaio clínico randomizado .................... 57

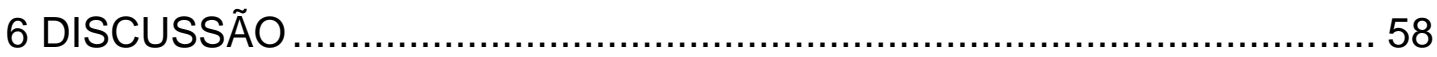

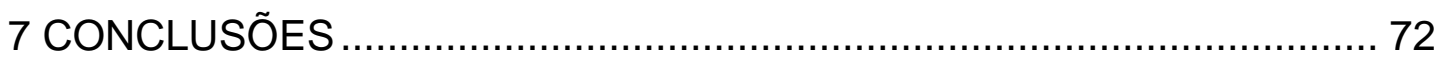

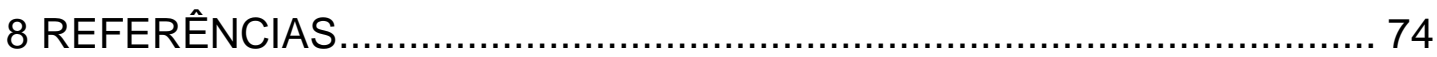




\section{LISTAS}

\section{ABREVIATURAS, SIGLAS E SÍMBOLOS}

ADAGES

AIGS

ANSWERS

CCGR

CCGRP

CFI

CFNR

CPSD

CSLO

DIC

DP

$\mathrm{dB}$

GHT

GPA

IC

IVZ
Estudo de Avaliação de Glaucoma em

Afrodescendentes, do inglês, African Descent and Glaucoma Evaluation Study

Estudo de Imagem Avançada em Glaucoma, do inglês, Advanced Imaging for Glaucoma Study

Análise com Regressão Não-estacionária do Erro de Weibull e Aprimoramento Espacial, do inglês, Analysis with Non-Stationary Weibull Error Regression and Spatial Enhancement

Camada de Células Ganglionares Retiniana, do inglês, Retinal Ganglion Cell Layer

Camada de Células Ganglionares Retiniana mais Plexiforme Interna, do inglês, Retinal Ganglion Cell Layer Plus Inner Plexiform Layer Índice De Campo Central, do inglês, Central Field Index Camada de Fibras Nervosas Retiniana, do inglês, Retinal Nerve Fiber Layer

Desvio Padrão Convencional Corrigido, do inglês, Corrected Pattern Standard Deviation

Oftalmoscopia Confocal de Varredura a Laser, do inglês, Confocal Scanning Laser Ophthalmoscopy

Critério de Informação de Desvio, do inglês, Deviance Information Criterion

Desvio Padrão

Decibel

Teste de Hemicampo do Glaucoma, do inglês, Glaucoma Hemifield Test

Análise de Progressão do Glaucoma, do inglês, Glaucoma Progression Analysis

Intervalo de Confiança

Zona Vulnerável Inferior, do inglês, Inferior Vulnerability Zone 


\begin{tabular}{|c|c|}
\hline LoGTS & $\begin{array}{l}\text { Estudo do Tratamento do Glaucoma de Pressão Baixa, } \\
\text { do inglês, Low-pressure Glaucoma Treatment Study }\end{array}$ \\
\hline LVZ & $\begin{array}{l}\text { Zona Menos Vulnerável, do inglês, Less Vulnerable } \\
\text { Zone }\end{array}$ \\
\hline MVZ & Zona Mais Vulnerável, do inglês, More Vulnerable Zone \\
\hline MAPS & $\begin{array}{l}\text { Estudo de Avaliação e Progressão Macular, do inglês, } \\
\text { Macular Assessment and Progression Study }\end{array}$ \\
\hline MaVZ & $\begin{array}{l}\text { Zona Macular de Vulnerabilidade, do inglês, Macular } \\
\text { Vulnerability Zone }\end{array}$ \\
\hline MD & Desvio Médio, do inglês, Mean Deviation \\
\hline $\mathrm{mmHg}$ & Milímetro de mercúrio \\
\hline NEI & $\begin{array}{l}\text { Instituto Nacional de Olhos, do inglês, National Eye } \\
\text { Institute }\end{array}$ \\
\hline $\mathrm{NIH}$ & $\begin{array}{l}\text { Institutos Nacionais de Saúde, do inglês, National } \\
\text { Institutes of Health }\end{array}$ \\
\hline OCT & $\begin{array}{l}\text { Tomografia de Coerência Óptica, do inglês, Optical } \\
\text { Coherence Tomography }\end{array}$ \\
\hline OLS & $\begin{array}{l}\text { Regressões Lineares De Mínimos Quadrados, do inglês, } \\
\text { Ordinary Least Squares }\end{array}$ \\
\hline OHTS & $\begin{array}{l}\text { Estudo do Tratamento da Hipertensão Ocular, do inglês, } \\
\text { Ocular Hypertension Treatment Study }\end{array}$ \\
\hline$P$ & Probabilidade segundo a hipótese nula \\
\hline PCA & $\begin{array}{l}\text { Análise de Componentes Principais, do inglês, Principal } \\
\text { Components Analysis }\end{array}$ \\
\hline PD & Desvio Convenional, do inglês, Pattern Deviation \\
\hline PSD & $\begin{array}{l}\text { Desvio Padrão Convencional, do inglês, Pattern } \\
\text { Standard Deviation }\end{array}$ \\
\hline SD & Domínio Espectral, do inglês Spectral Domain \\
\hline SITA & $\begin{array}{l}\text { Algoritmo de Limiar Interativo Sueco, do inglês, Swedish } \\
\text { Interactive Threshold Algorithm }\end{array}$ \\
\hline SLO & $\begin{array}{l}\text { Polarimetria de Varredura a Laser, do inglês, Scanning } \\
\text { Laser Polarimetry }\end{array}$ \\
\hline SS & Fonte de Varredura, do inglês, Swept Source \\
\hline TD & Desvio Total, do inglês, Total Deviation \\
\hline SVZ & $\begin{array}{l}\text { Zona Vulnerável Superior, do inglês, Superior } \\
\text { Vulnerability Zone }\end{array}$ \\
\hline UKGTS & $\begin{array}{l}\text { Estudo do Tratamento do Glaucoma do Reino Unido, do } \\
\text { inglês, United Kingdom Glaucoma Treatment Study }\end{array}$ \\
\hline
\end{tabular}


VFI

$<$

$>$

$=$

$\%$
Índice de Campo Visual, do inglês, Visual Field Index Menor que

Maior que

Igual

Percentagem 


\section{FIGURAS}

Figura 1 - Perimetria 24-2 e 10-2, em associação com OCT de alta resolução com protocolo de varredura macular. Painel superior: A região dentro do contorno azul nos campos visuais 24-2 corresponde à região nos 10 graus centrais testada pelos pontos da perimetria 10-2. Todos os campos são apresentados na projeção do olho direito. (A) Ambos os hemicampos superiores são anormais. (B) $O$ hemicampo superior é normal no 24-2, mas anormal no 102. (C) O hemicampo superior é anormal no 24-2, mas dentro da normalidade no 10-2. (D) Mapa de estruturafunção combinado mostrando a relação entre os pontos testados com 24-2 e a espessura média da CCGR da mácula. Note que apenas quatro dos 54 pontos da perimetria 24-2 testam a área que inclui até 30\% das células ganglionares. (E) Exemplo de um olho com resultados dentro da normalidade na perimetria 24-2 mas anormais na perimetria 10-2 (seta vermelha). Note que os pontos anormais na perimetria 10-2 distribuem-se no intervalo entre aqueles da perimetria 24-2 (círculos vermelhos)

Figura 2 - Defeito arqueado não detectado pelo OCT da CFNR peripapilar. A e B) são impressos de OCT desenvolvidos no laboratório do Dr. Hood usados para classificar a mácula como anormal. C e D) são impressos da região peripapilar disponível comercialmente. (A) mapa de probabilidade da espessura da CFNR do disco e mácula com pontos da perimetria 10-2 sobrepostos. (B) mapa de probabilidade de espessura da CCGR da mácula com pontos da perimetria 10-2 sobrepostos. A legenda nos painéis A e B mostra o nível de significância estatística. O círculo preto tem um raio de 8 graus. C) O perfil de espessura do CFNR (linha preta) em relação ao banco de dados normativo (fundo colorido) e apresentado como um gráfico NSTIN. (D) Gráfico de quadrantes em horas de relógio ("gráfico de pizza") com base na espessura da CFNR mostrada em C

Figura 3 - Análise de tendência em ensaios clínicos randomizados. A) Dados do LoGTS: comparação das taxas de progressão (dB/ano) do MD entre os olhos que progrediram (cinza claro) e estáveis (cinza escuro). A curva preta corresponde a uma função Gaussiana com base nas estimativas de todos os pacientes do estudo. A taxa de progressão (com base na análise de tendência) foi média \pm desvio padrão: $0,87 \pm 0,7$ versus $-0,04 \pm 0,8 \mathrm{~dB} /$ ano $(P<1 \%)$ nos olhos 
que progrediram e olhos estáveis (com base na análise de evento), respectivamente. Estes resultados confirmam a percepção de que os olhos que progrediram (baseados em evento) têm taxas mais rápidas de deterioração de sensibilidade ao longo do tempo. B) Dados OHTS: comparação entre as alterações da pressão intraocular absoluta (mm Hg, abcissa) e alterações no MD do campo visual (dB/ano, eixo y), após o tratamento. A linha preta corresponde à linha de regressão linear $(P<1 \%)$ e representa uma relação significativa entre a magnitude de redução da pressão intraocular e a mudança quantitativa na taxa de progressão

Figura 4 - Mapas de PSD de escotomas parafoveais de um banco de dados transversal. Todos os mapas de olhos foram invertidos para representar olhos direitos. Os resultados da perimetria 10-2 foram divididos em subgrupos com base na gravidade do glaucoma usando seu PSD. Os dados foram extraídos para criar um mapa de média de PSD que foi gerado pela média dos valores de mapa PSD da perimetria 10-2, ponto por ponto, dentro de cada subgrupo $(A, B, C$ e $D)$. A legenda de tons de cinza é mostrada à direita. Os defeitos superiores estão presentes $(A)$ no exame mais inicial, como um defeito arqueado difuso; (B) mais tarde, na evolução da doença, observa-se um defeito mais profundo acima do ponto de fixação (C e D). O defeito aparece mais tarde mais próximo da mancha cega e da periferia nasal, poupando a área correspondente ao feixe papilomacular

Figura 5 - Modelo estrutura-função macular de Hood et al. De acordo com o modelo de Hood, existe uma "região macular vulnerável" (VMR em inglês, em cor magenta) e uma "região macular menos vulnerável" (LVMR em inglês, em azul). A) A porção do modelo associada ao campo visual superior (retina inferior) contém uma LVMR (azul) e uma VMR (magenta). B) As regiões do disco associadas ao LVMR e VMR são indicadas pelas linhas diagonais magenta e azul, respectivamente

Figura 6 - Gráficos de Kaplan-Meier de progressão de glaucoma detectados pelo OCT e perimetria acromática 24-2 em olhos com glaucoma pré-perimétrico

Figura 7 - Impresso (Hood Report) do SD-OCT Spectralis (Heidelberg Engineering, Dossenheim, Alemanha). A) Varredura B do círculo peripapilar com delineação da CFNR; B) gráfico NSTIN com perfil da CFNR peripapilar e sua espessura relativa ao banco de dados normativo do aparelho; C) gráfico de probabilidades por setores da região peripapilar; 
D) mapa de desvio de espessura da CFNR incluindo mácula e região peripapilar; E) mapa de desvio de espessura da CCGR incluindo mácula e região peripapilar; F) e G) o mesmo que D) e F), mas, em projeção de campo, mostrando a localização dos pontos testados pela perimetria 24-2 e 10-2, respectivamente

Figura 8 - A) À esquerda, slope de valores previstos pelo modelo obtido por regressão linear de valores MD. À direita, os valores de ruído (resíduos) foram adicionados, aleatoriamente, a cada valor previsto pelo modelo baseado no bin de resíduos derivados a que o valor previsto corresponde. B) Exemplos de três bins de distribuição de resíduos de diferentes valores de MD.

Figura 9 - Paradigma de frequência de exames funcionais utilizados para simulação de ensaio clínico randomizado

Figura 10 - Distribuição dos valores médios de desvio total do Grupo Caso. Projeções de olho direito. A) Perimetria 24-2; B) Perimetria 10-2

Figura 11 - A) Perimetria 24-2C de um olho saudável; B) Perimetria 102 do mesmo olho em A), confirmando ausência de anormalidades na região macular. C) Perimetria $24-2 \mathrm{C}$ de um olho com glaucoma; D) Perimetria 10-2 do mesmo olho em C), confirmando anormalidades na região paracentral superior

Figura 12 - Estrutura-função na mácula. Um exemplo da relação estrutura-função de um paciente glaucomatoso, com uma ilustração da redução da variabilidade resultante do ajustamento para o deslocamento das células ganglionares da retina em relação aos fotorreceptores. A espessura (C) e a relação quantitativa entre todos os valores de desvio TD da perimetria 10-2 e a espessura da camada de células ganglionares + camada plexiforme externa (do inglês Retinal Ganglion Cell + Inner Plexiform [RGCP]) do paciente na região correspondente (B). Um ponto no campo visual nas coordenadas $\mathrm{x}$, y de $1^{\circ},-1^{\circ}$ (quadrado vermelho) é mostrado com o ponto de dados correspondentes no gráfico função-estrutura (quadrado verde, parte E) e na posição correspondente na área (quadrado azul, parte B). Sem considerar o deslocamento espacial de células ganglionares, a relação entre espessura e sensibilidade é fraca (B). D-F) a relação melhora e o ponto no quadrado verde agora se encontra na distribuição dos valores da estrutura-função após a contabilização do deslocamento das células ganglionares 
TABELAS

Tabela 1 - Características clínicas da população final do estudo na visita basal

Tabela 2 - Taxa de progressão dos diferentes parâmetros estruturais e funcionais no decorrer do estudo.

Tabela 3 - Taxa de progressão dos diferentes parâmetros estruturais e funcionais combinados no decorrer do estudo.

Tabela 4 - Taxa de progressão dos diferentes parâmetros estruturais e funcionais combinados no decorrer do estudo

Tabela 5 - Poder estatístico para detecção de progressão funcional confirmada (duas visitas consecutivas) em olhos seguidos a cada 4 meses

Tabela 6 - Poder estatístico para detecção de progressão funcional confirmada (duas visitas consecutivas) em olhos seguidos a cada 6 meses.

Tabela 7 - Poder estatístico para detecção de progressão estrutural confirmada (duas visitas consecutivas) em olhos seguidos a cada 4 meses.

Tabela 8 - Poder estatístico para detecção de progressão estrutural confirmada (duas visitas consecutivas) em olhos seguidos a cada 6 meses.

Tabela 9 - Tamanho mínimo da amostra por grupo para atingir poder estatístico de $80 \%$ e $90 \%$ em um ensaio clínico randomizado com efeito de $30 \%$ na taxa de progressão e erro tipo 1 de $5 \%$. 


\section{RESUMO}

De Moraes CG. Progressão estrutural e funcional da lesão glaucomatosa na mácula [Tese]. São Paulo: Faculdade de Medicina, Universidade de São Paulo; 2019.

OBJETIVOS: comparar a performance de parâmetros estruturais e funcionais convencionais (perimetria acromática 24-2 e tomografia de coerência óptica da camada de fibras nervosas retiniana peripapilar) com a dos parâmetros otimizados para a região macular (perimetria 10-2 e tomografia de coerência óptica da camada de células ganglionares retiniana macular) para detecção de progressão glaucomatosa. METODOS: análise prospectiva e longitudinal de indivíduos saudáveis e pacientes suspeitos ou portadores de glaucoma de ângulo aberto, com perda inicial de campo visual 24-2 (definida pelo desvio médio maior que $-6 \mathrm{~dB}$ ). Os participantes do estudo foram examinados com perimetria acromática 24-2 e 10-2, além de tomografia de coerência óptica de alta resolução da região peripapilar e mácula no mesmo dia. Todos os participantes foram seguidos em intervalos regulares por, no mínimo, um ano. Progressão por análise de tendência foi determinada usando-se regressão linear com modelos de efeitos mistos e estimativas Bayesianas multivariadas. Modelos de simulação computacional foram utilizados para se investigar a sensibilidade com especificidades pareadas de cada parâmetro sob diferentes frequências de exame e tempo total de seguimento. RESULTADOS: foram estudados 164 olhos de 153 participantes (49 olhos de 49 indivíduos saudáveis e 115 olhos de 104 pacientes glaucomatosos ou suspeitos de glaucoma). A média de idade foi $57,8 \pm 19,0$ (amplitude: $18-85$ ) anos. A maioria dos participantes $(86,2 \%)$ era de raça branca e do sexo feminino (54,2\%), como tempo de seguimento mediano de 2,2 (amplitude: 1 a 3) anos. Os parâmetros funcionais (perimetria 10-2) e estruturais (camada de células ganglionares retiniana) otimizados para a região macular exibiram taxas de progressão mais rápidas e com menor variância residual relativamente a seu intervalo dinâmico na análise de tendências do que parâmetros convencionais (perimetria 24-2 e camada de fibras nervosas retiniana peripapilar). A combinação de parâmetros convencionais com aqueles otimizados para a região macular resultou em redução da variabilidade. Estudos de simulação computacional indicaram um maior poder estatístico e menor tempo de seguimento para detecção de progressão glaucomatosa usando-se parâmetros otimizados para a região macular em relação aos parâmetros convencionais. Tais achados foram mais significativos ao se combinarem esses parâmetros. CONCLUSÕES: Os parâmetros estruturais e funcionais da mácula apresentaram melhor capacidade de detecção de progressão glaucomatosa do que os parâmetros convencionais, sem significativo comprometimento de especificidade. A combinação dos parâmetros (maculares e convencionais) pode apresentar aplicabilidade clínica na avaliação da progressão do glaucoma em pacientes com perda funcional inicial, com potencial implicação no desenho de ensaios clínicos randomizados em glaucoma.

Descritores: 1. Glaucoma de ângulo aberto 2. Progressão da doença 3. Tomografia óptica 4. Testes de campo visual 5. Mácula lútea 


\section{ABSTRACT}

De Moraes CG. Structural and Functional progression of glaucomatous damage to the macula [thesis]. São Paulo: "Faculdade de Medicina, Universidade de São Paulo"; 2019

OBJECTIVES: to compare the performance of conventional structural and functional parameters (24-2 achromatic perimetry and optical coherence tomography of the peripapillary retinal nerve fiber layer) with those optimized for the macular region (10-2 achromatic perimetry and optical coherence tomography of the macular ganglion cell layer) for the detection of glaucomatous progression. METHODS: prospective and longitudinal analysis of healthy subjects and patients with or suspected open-angle glaucoma with early visual field loss on the 24-2 (defined by the mean deviation greater than $-6 \mathrm{~dB}$ ). Study participants were tested with achromatic perimetry 24-2 and 10-2, in addition to high-resolution optical coherence tomography of the peripapillary region and macula on the same day. All patients were followed at regular intervals for at least one year. Trend analysis with linear mixed effects models and multivariate Bayesian estimates were employed to measure rates of progression. Computer simulation models were used to investigate the sensitivity at matched specificities for each parameter under different examination frequencies and total duration of follow-up. RESULTS: 164 eyes of 153 participants (49 eyes of 49 healthy subjects and 115 eyes of 104 glaucomatous or suspected glaucoma patients) were studied. The mean age was $57.8 \pm 19.0$ (range: 18-85) years. Most participants (86.2\%) were white and $(54.2 \%)$ female followed for a median of 2.2 (range: $1-3$ ) years. Functional (10-2 perimetry) and structural (retinal ganglion cell layer) parameters optimized for the macular region exhibited faster rates of progression and smaller residual variances relative to their dynamic range than conventional parameters (24-2 perimetry and peripapillary retinal nerve fiber layer). The combination of conventional and parameters optimized for the macular region resulted in decreased variability. Computer simulation models indicated a greater statistical power and a shorter follow-up time to detect glaucomatous progression using parameters optimized for the macular region compared to conventional parameters. These findings were more significant when these parameters were combined. CONCLUSIONS: Structural and functional parameters of the macula had improved ability to detect glaucomatous progression when compared to conventional parameters without significantly compromising specificity. The combination of these parameters (macular and conventional) may have clinical utility in the evaluation of glaucomatous progression in patients with early functional loss, with potential implication for the design of randomized clinical trials in glaucoma.

Descriptors: 1. Glaucoma, open-angle 2. Visual field tests 3. Tomography, optical 4. Disease progression 5. Macula lutea 


\section{INTRODUÇÃO}

A neuropatia óptica glaucomatosa é definida com base em alterações estruturais características que podem ou não estar associadas a anormalidades funcionais topograficamente correspondentes ${ }^{(1)}$. Na prática clínica, as alterações estruturais são, muitas vezes, avaliadas com a fotografia de disco óptico, que, nas últimas décadas, tem sido auxiliada por diferentes modalidades de imagens computadorizadas, como a tomografia de coerência óptica (do inglês Optical Coherence Tomography [OCT]). Para avaliar as anormalidades funcionais, a perimetria automatizada acromática padrão (aqui chamada perimetria acromática) com a estratégia 24-2 ou 30-2 vem sendo o padrão de referência não apenas na prática clínica, como também tem definido critérios primários de conversão e progressão glaucomatosa dos principais ensaios clínicos randomizados em glaucoma $^{(2-6)}$.

O glaucoma vem sendo, convencionalmente, considerado uma neuropatia óptica que afeta primariamente o campo visual periférico, exceto nas fases mais tardias quando então passa a estender a áreas centrais ou paracentrais próximas à fixação ${ }^{(7)}$. No entanto, há evidências estruturais e funcionais convincentes de que a lesão glaucomatosa pode ocorrer na mácula mesmo em estágios iniciais da doença ${ }^{(8)}$. Em 1969, Drance (9) apontou pela primeira vez que o campo visual central pode ser afetado mesmo nos estágios iniciais do glaucoma. Desde então, há crescente evidência de que a lesão macular é mais comum do que o anteriormente suposta ${ }^{(8,10-14)}$. Esta informação é clinicamente importante porque a mácula (aqui definida como os 8 graus centrais ao redor da fóvea) inclui cerca de $30 \%$ de todas as células da camada de células ganglionares retiniana (CCGR) (15) e fornece informação a mais de $60 \%$ do córtex visual primário ${ }^{(16)}$. Dada esta alta densidade de células ganglionares na mácula e sua grande representação no córtex visual, não é surpreendente que o dano 
à mácula afete substancialmente a qualidade de vida de pacientes com glaucoma (17-20), incluindo a habilidade de dirigir (21), leitura (22), deambulação e frequência de quedas da própria altura ${ }^{(23)}$. O desgaste psicológico agravase à medida que a qualidade visual deteriora, acompanhada do temor de cegueira, afastamento social e depressão ${ }^{(24)}$. Uma vez que o tratamento do glaucoma tem como objetivo preservar a qualidade de vida dos pacientes, conservando a função visual, sem causar os efeitos indesejáveis decorrentes do tratamento (25), a monitorização do campo visual central é parte crucial de um adequado acompanhamento clínico do paciente glaucomatoso ou suspeito de glaucoma.

Entretanto, a lesão glaucomatosa na mácula não será detectada na prática clínica se forem realizados apenas exames de perimetria com padrão 24-2 e análise da camada de fibras nervosas retiniana (CFNR) peripapilar com OCT (26, 27), como é, frequentemente, realizada. Em particular, estudos demonstram que a lesão glaucomatosa na mácula é frequente entre os pacientes com glaucoma precoce ao se empregarem ferramentas apropriadas para sua avaliação, ou seja, perimetria com padrão 10-2 (11-13, 26) e varredura macular com OCT de alta resolução ${ }^{(8,27-29)}$. Tais exames serão aqui denominados exames otimizados para avaliação da região macular.

Os dados da Figura 1 ilustram exemplos de como os exames de perimetria acromática 24-2 e 10-2 podem concordar ou discordar com relação à presença de lesão macular. Observa-se que, em razão da amostragem insuficiente da perimetria 24-2 na mácula (com espaçamento a cada 6 graus entre os pontos), a perimetria acromática convencional (24-2 ou 30-2) apresenta maior probabilidade de não detectar anormalidades centrais. Traynis et al. (11) demonstraram que até $16 \%$ dos olhos com um resultado normal na perimetria acromática 24-2 apresentaram anormalidades significativas quando analisadas com padrão 10-2 em uma amostra de pacientes com perda funcional glaucomatosa precoce, definida pelo desvio médio (do inglês Mean Deviation [MD]) maior (mais positivo) que -6 dB na perimetria acromática 24-2 ${ }^{(30)}$. Esse número é notável pois muitos dos chamados "suspeitos de glaucoma" ou "glaucoma pré-perimétrico" 
podem de fato apresentar lesão macular que agora os classificaria como "glaucoma grave", conforme sistemas de classificação existentes ${ }^{(30-32)}$. Com metodologia semelhante, Park et al. ${ }^{(12)}$ demonstraram que $74 \%$ dos olhos com glaucoma inicial apresentavam um escotoma parafoveal detectado na perimetria 10-2. Em estudo prospectivo em que todos os indivíduos realizaram exames de perimetria acromática 24-2 e 10-2 na mesma visita no decorrer de 3 anos, De Moraes et al. (33) relataram que $61 \%$ dos olhos de pacientes com MD na perimetria 24-2 maior (mais positivo) que -6 dB apresentavam alterações na perimetria 10-2 não detectadas com o padrão 24-2. Não obstante estes achados, é possível que alguns destes defeitos vistos com perimetria acromática 10-2 possam ser na verdade resultados falso-positivos ${ }^{(34)}$. A confirmação, portanto, exigiria exames de OCT de alta resolução com varredura macular mostrando anormalidades estruturais e funcionais com correspondência topográfica.

A análise convencional da CFNR peripapilar - mesmo com OCT de alta resolução - pode falhar na detecção de lesão macular definida com protocolos de varredura macular e perimetria 10-2, conforme ilustrado na Figura 2. De fato, entre os olhos classificados com anormalidade macular baseada em protocolos de varredura macular e perimetria 10-2, os quadrantes temporal e temporal inferior da CFNR peripapilar não detectaram anormalidades em até $36 \%$ dos olhos com defeitos maculares (27). Portanto, o exame com OCT deve incluir não apenas a avaliação da CFNR peripapilar, mas também avaliação de alta resolução da mácula, a fim de excluir lesão glaucomatosa e minimizar os resultados falso-positivos da perimetria acromática.

Em resposta à necessidade de se combinar estrutura e função para se minimizar o número de resultados falso-positivos que se observa quando estes exames são analisados isoladamente, De Moraes et al. ${ }^{(31)}$ avaliaram sistemas de classificação de severidade em glaucoma e observaram que a maioria dos pacientes considerados portadores de dano funcional "inicial" apresentava dano na CCGR no OCT de mácula corroborado topograficamente por alterações na perimetria 10-2. Os autores sugeriram 
que os atuais sistemas de classificação deveriam ser revisados para levar em consideração ferramentas como o OCT macular de alta resolução e a perimetria 10-2.

O presente projeto visa a expandir o conhecimento acumulado até o momento utilizando dados transversais para diagnóstico de lesão macular para sua aplicação longitudinal com o objetivo de detectar e medir a progressão glaucomatosa com parâmetros otimizados para avalição macular (CCGR macular e perimetria 10-2), bem como sua comparação com parâmetros estruturais (CFNR peripapilar) e funcionais (perimetria 24-2), convencionalmente utilizados na prática e pesquisa clínica.

A presente hipótese é que os parâmetros estruturais e funcionais otimizados para avaliação macular têm melhor performance do que a observada com parâmetros convencionais para detecção de progressão glaucomatosa em pacientes com dano funcional inicial. Além do mais, a combinação de parâmetros convencionais com parâmetros otimizados para avaliação macular pode ter significante papel complementar na prática clínica e no desenho de ensaios clínicos randomizados. 

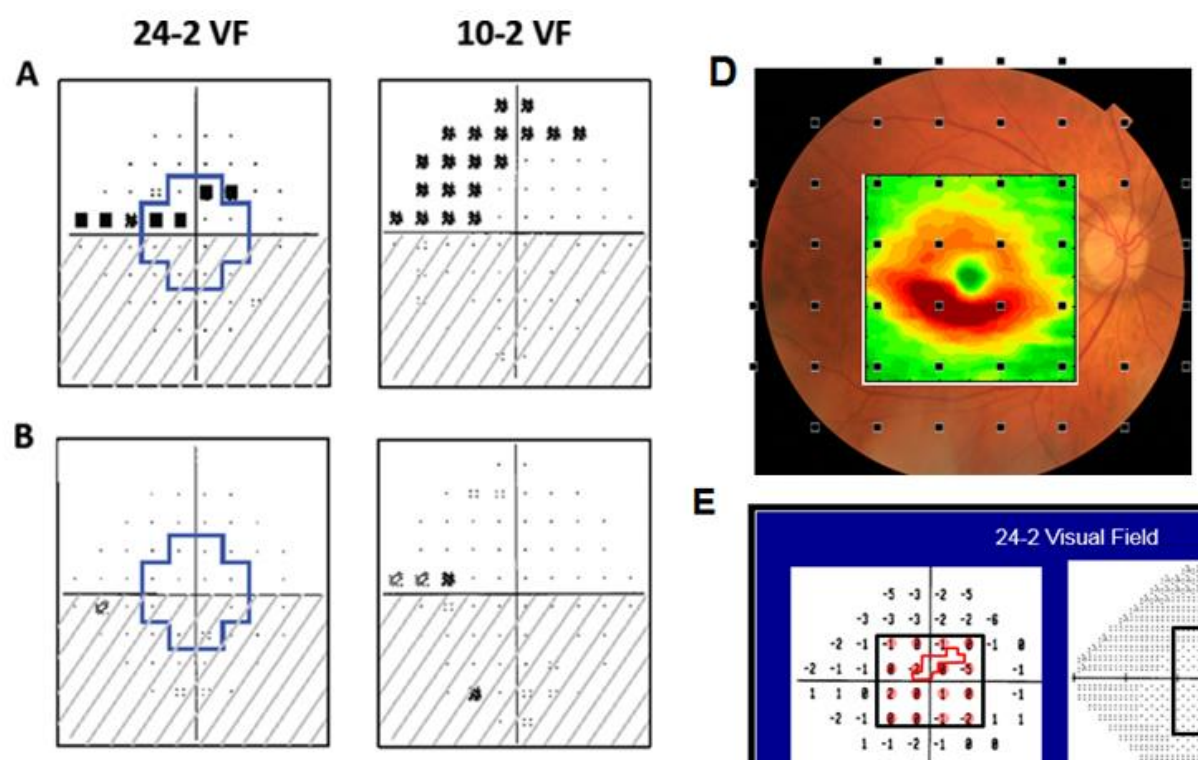

E
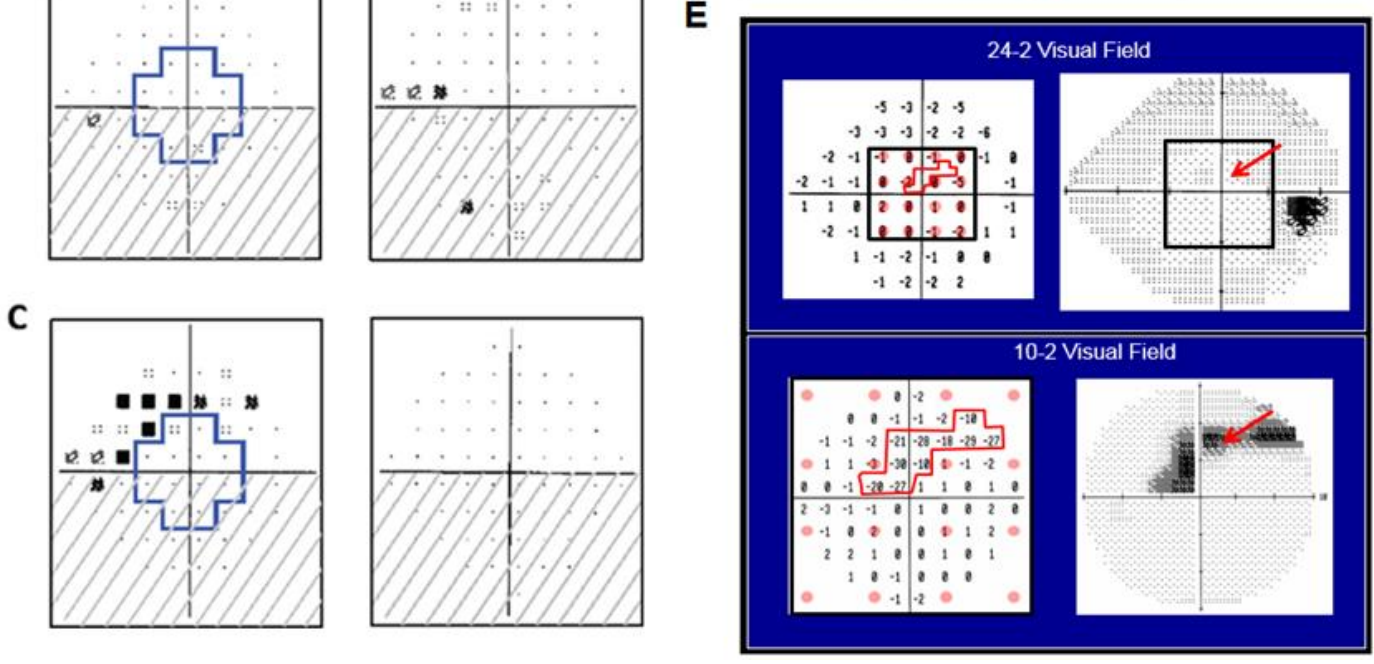

Figura 1 - Perimetria 24-2 e 10-2, em associação com OCT de alta resolução com protocolo de varredura macular. Painel superior: A região dentro do contorno azul nos campos visuais 24-2 corresponde à região nos 10 graus centrais testada pelos pontos da perimetria 10-2. Todos os campos são apresentados na projeção do olho direito. (A) Ambos os hemicampos superiores são anormais. (B) O hemicampo superior é normal no 24-2, mas anormal no 10-2. (C) O hemicampo superior é anormal no 24-2, mas dentro da normalidade no 10-2. (D) Mapa de estrutura-função combinado mostrando a relação entre os pontos testados com 24-2 e a espessura média da CCGR da mácula. Note que apenas quatro dos 54 pontos da perimetria 24-2 testam a área que inclui até 30\% das células ganglionares. (E) Exemplo de um olho com resultados dentro da normalidade na perimetria 24-2 mas anormais na perimetria 10-2 (seta vermelha). Note que os pontos anormais na perimetria 10-2 distribuem-se no intervalo entre aqueles da perimetria 24-2 (círculos vermelhos) 


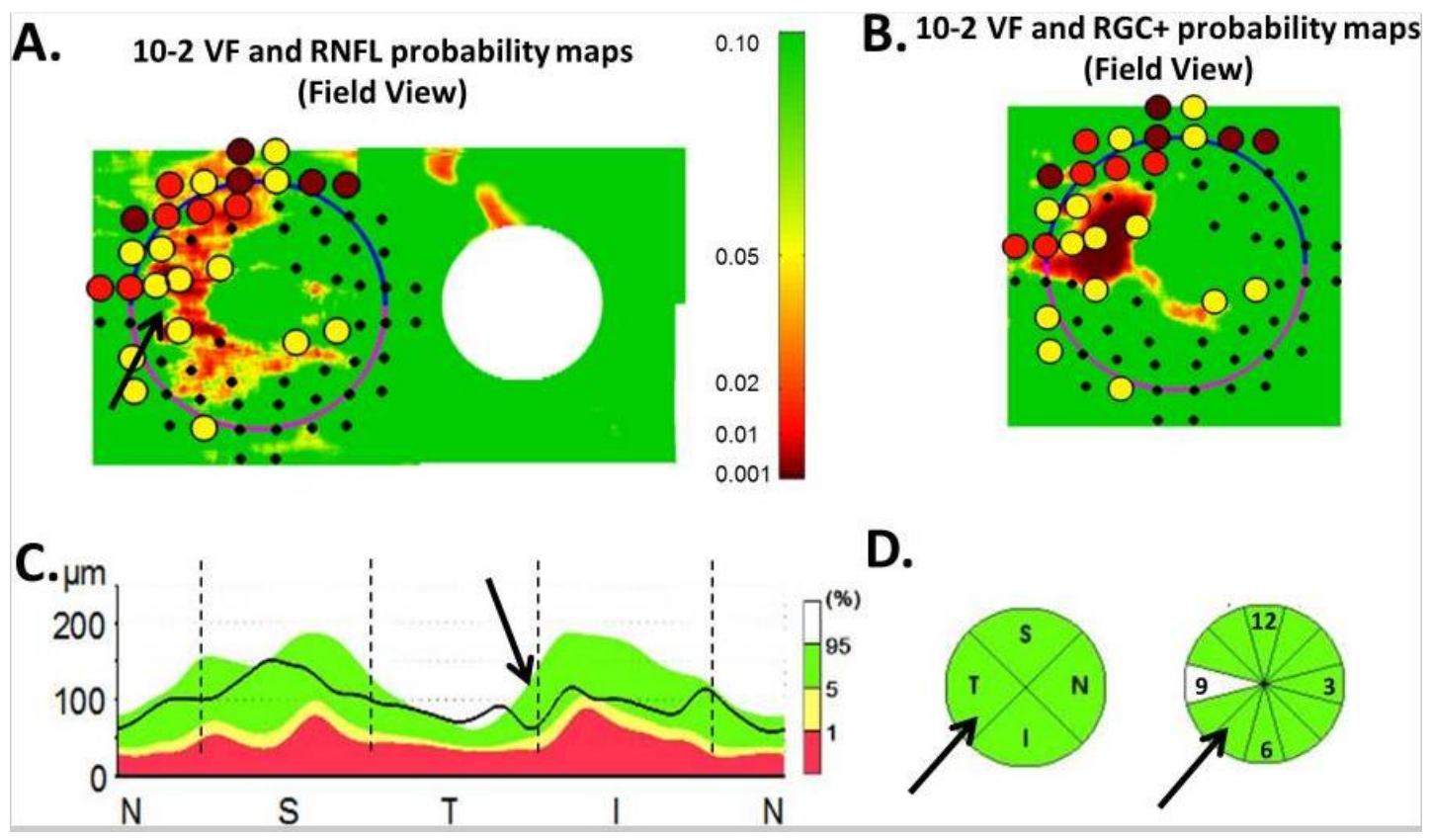

Fonte: Wang et al.(27)

Figura 2 - Defeito arqueado não detectado pelo OCT da CFNR peripapilar. A e B) são impressos de OCT desenvolvidos no laboratório do Dr. Hood usados para classificar a mácula como anormal. C e D) são impressos da região peripapilar disponível comercialmente. (A) mapa de probabilidade da espessura da CFNR do disco e mácula com pontos da perimetria 10-2 sobrepostos. (B) mapa de probabilidade de espessura da CCGR da mácula com pontos da perimetria 10-2 sobrepostos. A legenda nos painéis $A$ e $B$ mostra o nível de significância estatística. $\mathrm{O}$ círculo preto tem um raio de 8 graus. C) O perfil de espessura do CFNR (linha preta) em relação ao banco de dados normativo (fundo colorido) e apresentado como um gráfico NSTIN. (D) Gráfico de quadrantes em horas de relógio ("gráfico de pizza") com base na espessura da CFNR mostrada em C 
2 OBJETIVOS 


\section{OBJETIVOS}

O presente estudo tem por objetivos:

2.1 Avaliar a taxa de progressão glaucomatosa utilizando-se parâmetros convencionais (OCT da CFNR peripapilar e perimetria 24-2) e otimizados para mácula (OCT da CCGR macular e perimetria 10-2);

2.2 Avaliar a taxa de progressão glaucomatosa combinando-se parâmetros convencionais e otimizados para mácula para detecção de progressão glaucomatosa, bem como a combinação de parâmetros estruturais e funcionais em uma abordagem Bayesiana; e

2.3 Testar a aplicabilidade da combinação de parâmetros convencionais e otimizados para mácula na prática clínica e ensaios clínicos randomizados por meio de um modelo de simulação computacional previamente descrito. 


\section{REVISÃO DA LITERATURA}

\subsection{Métodos utilizados para avaliação da progressão glaucomatosa}

Embora exista um amplo conjunto de evidências que apoiem o uso de ferramentas otimizadas para avaliar o dano macular no diagnóstico do glaucoma, pouco se sabe sobre sua utilidade na avaliação de alterações longitudinais, ou seja, a progressão glaucomatosa na mácula. O conhecimento da taxa de progressão da doença é fundamental para preservação da função visual em pacientes com glaucoma, uma vez que determinará seu tratamento ${ }^{(35)}$. Dada a importância da mácula ${ }^{(8)}$, é notável que pouco se saiba até o presente sobre a progressão nesta região.

As diretrizes do primeiro Consenso da Associação Mundial de Glaucoma estabeleceram que uma avaliação precisa de progressão do glaucoma requer uma combinação de testes estruturais e funcionais ${ }^{(36)}$. Em particular, para a tomada de decisão e ajuste terapêutico, o oftalmologista deve procurar sinais objetivos de progressão auxiliada por softwares com algoritmos automatizados (36). O desenvolvimento de exames necessários para avaliação de progressão macular requer um banco de dados de exames estruturais e funcionais coletados a curto e longo prazos. O primeiro (curto prazo) tem por objetivo entender os limites de variabilidade testereteste, e o segundo (longo prazo) auxilia na validação de critérios de progressão. Até o presente momento, não há este tipo de banco de dados publicado ou comercialmente disponível, não permitindo, assim, uma análise estatisticamente mais precisa e objetiva de progressão glaucomatosa na mácula e sua comparação com medidas convencionais. O presente estudo incluiu a coleta de dados contendo informação sobre a variabilidade a curto e longo prazos que possam ser úteis nessa avaliação. 


\subsubsection{Progressão funcional}

Em indivíduos saudáveis e glaucomatosos, os parâmetros da perimetria acromática não são totalmente reprodutíveis, visto que pontos individuais do exame apresentam variações de sensibilidade a curto e longo prazos ${ }^{(37)}$. Esta variabilidade é maior no glaucoma ${ }^{(38,39)}$ e pode confundir a detecção de perda progressiva real daquela decorrente de variabilidade (ruído) da função visual. Distinguir a perda progressiva real do campo visual glaucomatoso em relação a variabilidade do exame representa, portanto, uma tarefa complexa. Os procedimentos utilizados para detecção da progressão perimétrica do glaucoma podem ser agrupados em quatro categorias: (1) julgamento clínico, que consiste em observação subjetiva simples de resultados de exames sequenciais; (2) sistemas de classificação de defeitos, que especificam os critérios usados para estratificar a perda perimétrica por meio de um sistema de pontuação e definem progressão baseada na mudança dessa pontuação ao longo do tempo; (3) análises de evento, que identificam eventos únicos de mudança significativa em relação à média de dois exames de referência (basais); (4) análises de tendência, que se baseiam na taxa de progressão (ou declive, do inglês slope), utilizando-se todos os testes (desde que confiáveis e elegíveis) realizados ao longo do tempo.

Nas análises de evento, primeiramente, definem-se os testes basais a serem utilizados para comparação. Dependendo da variabilidade testereteste (definida a curto prazo, já que progressão real é improvável em tão curto intervalo), definem-se os limites de variabilidade (tradicionalmente com percentis 5 e 95) ajustados para excentricidade e grau de severidade (uma vez que a variabilidade aumenta do centro para a periferia e com a piora da severidade funcional) (37-39). Por exemplo, usando-se of impresso do Glaucoma Progression Analysis do perímetro Humphrey (GPA, Carl Zeiss Meditec, Inc., Dublin, CA, Estados Unidos da América), caso a mudança do valor de sensibilidade exceda o limite inferior dessa variabilidade ajustada em, pelo menos, três pontos em dois exames consecutivos, a progressão é 
considerada "possível". Caso se confirme no terceiro exame seguinte, a progressão passa a ser "provável".

Nas análises de tendência, avaliam-se os parâmetros do teste, sequencialmente, para determinar os padrões temporais que possam existir nos dados. Esta análise é capaz de determinar as tendências a longo prazo usando as informações de todos os exames de perimetria (confiáveis e elegíveis) realizados em um paciente. Portanto, este método tem o potencial de discriminar perda progressiva mesmo na presença de considerável variabilidade nos testes. É possível empregar este método com qualquer variável contínua que quantifique a informação perimétrica, projetando-se os valores em relação ao tempo e encontrando-se a linha de melhor ajuste (isto é, aquela que minimiza o quadrado dos resíduos da regressão linear). A análise de tendência tem alta sensibilidade e especificidade para a detecção de progressão funcional, desde que haja um número suficiente de exames $(40,41)$. Apesar desse número mínimo de exames depender da variabilidade do campo de cada paciente, da frequência de exames e tempo de seguimento (41), a literatura, geralmente, recomenda o mínimo de cinco a seis exames $(40,42-45)$. Além disso, a análise de tendência é menos influenciada pela variabilidade a curto e longo prazos do que os métodos baseados em evento ${ }^{(46)}$. Outra vantagem é que, em lugar de um resultado binário (progressão versus estável) fornecido por métodos baseados em evento, a análise de tendência fornece uma variável contínua (em dB/ano ou \%/ano, por exemplo) que permite medidas objetivas de progressão e de efeitos do tratamento. Por exemplo, a análise de tendência permite a determinação do quanto da perda de $\mathrm{dB}$ representa uma progressão "clinicamente significativa". Para fins deste estudo, todas as análises de progressão serão baseadas em análise de tendência com regressão linear. Embora haja discussão sobre o uso de métodos de regressão não lineares para sensibilidades perimétricas pontuais $(47,48)$, a regressão linear é amplamente utilizada e considerada robusta para análises de índices globais e com períodos de seguimento relativamente curtos (de 1 a 5 anos) ${ }^{(41,45,49)}$. 
De Moraes e colaboradores publicaram vários estudos usando a análise de tendência para detectar progressão na perimetria 24-2 e 30-2, bem como testando a relação entre as taxas de progressão, fatores de risco do glaucoma e efeitos do tratamento clínico e cirúrgico ${ }^{(42-44,50-59)}$. Por exemplo, em estudo com Demirel et al. (44) o grupo avaliou o banco de dados de perimetria acromática 30-2 do Estudo do Tratamento da Hipertensão Ocular (do inglês Ocular Hypertension Treatment Study [OHTS]) e, pela primeira vez, relatou as taxas de progressão do MD do campo visual nos grupos tratados e não tratados desse ensaio clínico randomizado. Além disso, De Moraes et al. ${ }^{(51)}$ relataram que o benefício do tratamento neste estudo foi significativo, tanto entre os participantes que não converteram baseados no $M D(-0,17 \pm 0,6$ vs. $-0,01 \pm 0,5 \mathrm{~dB} /$ ano, $P<1 \%)$ como entre aqueles que converteram em glaucoma $(-0,51 \pm 0,8$ vs. vs. $-0,27 \pm 0,7$ $\mathrm{dB} /$ ano, $\mathrm{P}<1 \%$ ), conforme os critérios originais do estudo. Como exemplo das vantagens do uso de medidas quantitativas da progressão do campo visual com análise de tendência, os autores relataram que para cada $1 \mathrm{~mm}$ $\mathrm{Hg}$ de diminuição na pressão intraocular, a taxa de progressão reduziu a magnitude de $0,1 \mathrm{~dB} / \mathrm{ano}^{(51)}$. Estes estudos foram importantes, entre outras razões, porque uma das preocupações com os resultados do OHTS foi que, uma vez que o desvio padrão convencional corrigido (do inglês Corrected Pattern Standard Deviation [CPSD]) da perimetria 30-2 foi um fator preditivo na conversão para glaucoma ${ }^{(6)}$, poder-se-ia argumentar que a inclusão de pacientes com doença limítrofe poderia ter influenciado seus resultados. Em outras palavras, os participantes do OHTS cujos campos visuais eram mais severos e mais próximos do limiar inferior do CPSD estavam obviamente mais propensos a desenvolver perda perimétrica manifesta, uma vez que os critérios do OHTS exigiam um CPSD normal ( $P>5 \%$ ) para inclusão no estudo ${ }^{(6)}$. Nesse estudo, a análise de tendências foi importante, portanto, para esclarecer o papel da severidade funcional basal na taxa de progressão futura.

Por fim, em pacientes com glaucoma manifesto no Estudo do Tratamento do Glaucoma de Pressão Baixa (do inglês Low-pressure 
Glaucoma Treatment Study [LoGTS]), De Moraes et al. (43) observaram um efeito semelhante da terapia de redução da pressão intraocular na taxa de progressão medida com análise de tendência (Figura 3). Portanto, oftalmologistas podem agora estimar a magnitude de redução da pressão intraocular necessária para prevenir a progressão da cegueira de pacientes baseada em sua expectativa de vida e nível de dano funcional basal ${ }^{(60)}$.

A

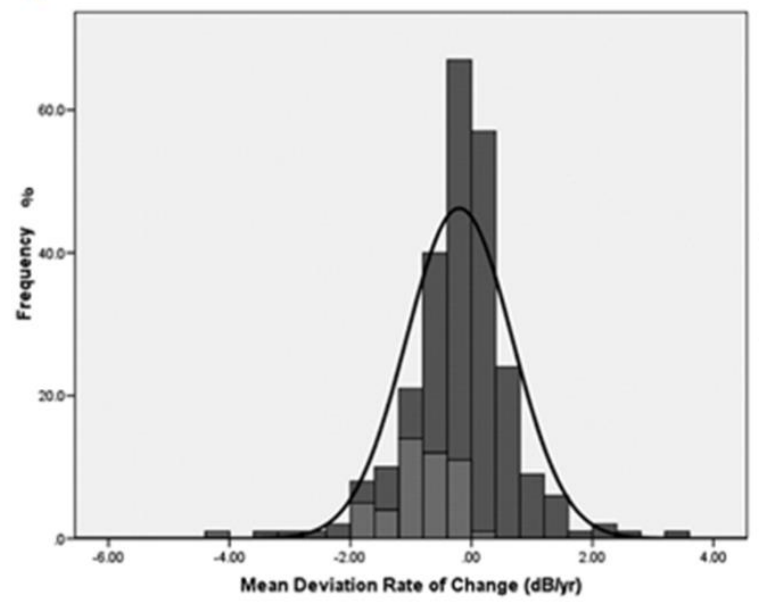

B

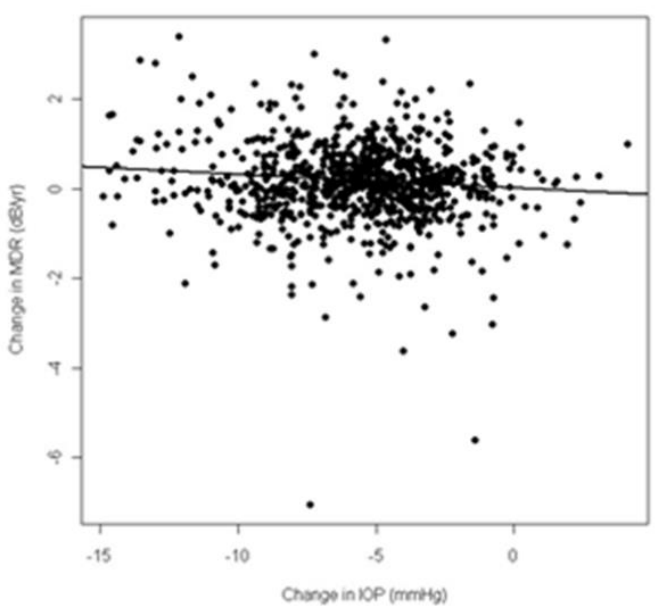

Fontes: De Moraes et al.(43), De Moraes et al. ${ }^{(44)}$,

Figura 3 - Análise de tendência em ensaios clínicos randomizados. A) Dados do LoGTS: comparação das taxas de progressão (dB/ano) do MD entre os olhos que progrediram (cinza claro) e estáveis (cinza escuro). A curva preta corresponde a uma função Gaussiana com base nas estimativas de todos os pacientes do estudo. A taxa de progressão (com base na análise de tendência) foi média \pm desvio padrão: $-0,87 \pm 0,7$ versus $-0,04 \pm 0,8 \mathrm{~dB} /$ ano $(P<1 \%)$ nos olhos que progrediram e olhos estáveis (com base na análise de evento), respectivamente. Estes resultados confirmam a percepção de que os olhos que progrediram (baseados em evento) têm taxas mais rápidas de deterioração de sensibilidade ao longo do tempo. B) Dados OHTS: comparação entre as alterações da pressão intraocular absoluta (mm Hg, abcissa) e alterações no MD do campo visual (dB/ano, eixo y), após o tratamento. A linha preta corresponde à linha de regressão linear $(P<1 \%)$ e representa uma relação significativa entre a magnitude de redução da pressão intraocular e a mudança quantitativa na taxa de progressão 
Em relação à perimetria acromática 10-2, estudos recentes investigaram o padrão e as taxas de progressão perimétrica em bancos de dados retrospectivos $(52,58,61)$. Foi descrito, por exemplo, um padrão de progressão na perimetria 10-2 similar ao observado em estudos utilizando-se a perimetria 30-2 realizada há mais de 30 anos ${ }^{(38)}$. Como ilustrado nos dados da Figura 4, os olhos com defeitos de hemicampo superior na perimetria 10-2 apresentam um padrão arqueado, aproximadamente, 3 a 5 graus acima da fixação, que se torna mais profundo (com valores pontuais mais negativos) com a progressão da doença. À medida que a gravidade aumenta, o escotoma, então, alonga-se em direção à mancha cega e estende-se em direção à periferia nasal, poupando a área correspondente ao feixe papilomacular. Para defeitos de hemicampo inferior, observou-se um padrão semelhante, embora ligeiramente mais distante da fixação (61).
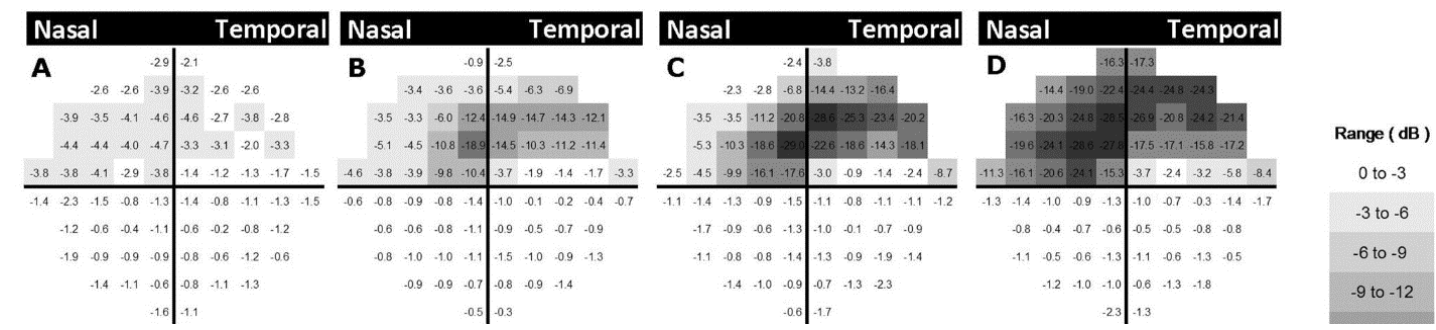

Fonte: Su et al. ${ }^{(61)}$

Figura 4 - Mapas de PSD de escotomas parafoveais de um banco de dados transversal. Todos os mapas de olhos foram invertidos para representar olhos direitos. Os resultados da perimetria 10-2 foram divididos em subgrupos com base na gravidade do glaucoma usando seu PSD. Os dados foram extraídos para criar um mapa de média de PSD que foi gerado pela média dos valores de mapa PSD da perimetria 10-2, ponto por ponto, dentro de cada subgrupo ( $A, B, C$ e $D)$. A legenda de tons de cinza é mostrada à direita. Os defeitos superiores estão presentes $(A)$ no exame mais inicial, como um defeito arqueado difuso; (B) mais tarde, na evolução da doença, observa-se um defeito mais profundo acima do ponto de fixação (C e D). O defeito aparece mais tarde mais próximo da mancha cega e da periferia nasal, poupando a área correspondente ao feixe papilomacular 
Hood et al. (62) avaliaram um modelo anatômico de lesão glaucomatosa na mácula com dados de perimetria de alta densidade. A parte do modelo associada ao campo visual superior (retina inferior) é mostrada nos dados da Figura 5. O modelo previu com precisão uma "zona mais vulnerável" e uma "zona menos vulnerável" na mácula (do inglês, More Vulnerable Zone [MVZ] e Less Vulnerable Zone [LVZ], respectivamente). Observa-se que há uma correspondência entre essas regiões de vulnerabilidade e o padrão de dano perimétrico descrito nos dados da Figura 4.

A

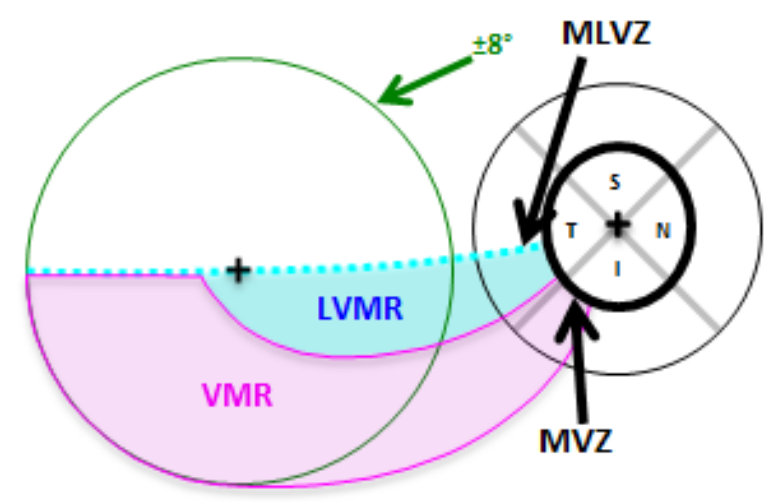

B

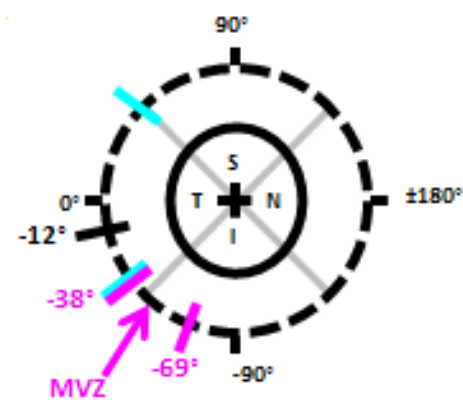

Figura 5 - Modelo estrutura-função macular de Hood et al. De acordo com o modelo de Hood, existe uma "região macular vulnerável" (VMR em inglês, em cor magenta) e uma "região macular menos vulnerável" (LVMR em inglês, em azul). A) A porção do modelo associada ao campo visual superior (retina inferior) contém uma LVMR (azul) e uma VMR (magenta). B) As regiões do disco associadas ao LVMR e VMR são indicadas pelas linhas diagonais magenta e azul, respectivamente

Uma vez definido o padrão de dano glaucomatoso usando-se a perimetria 10-2, pesquisadores investigaram os critérios baseados em análise de tendência que resultassem em melhor sensibilidade e especificidade para detecção da progressão glaucomatosa ${ }^{(52,58)}$. Decorrente da falta de um banco de dados de referência com dados de teste-reteste, De Moraes et al. (58) utilizaram uma definição pautada no pressuposto de que slopes positivos (isto é, sugerindo melhora perimétrica) representavam 
resultados falso-positivos, pois o glaucoma é, por definição, uma doença progressiva. Utilizando a análise dos componentes principais (do inglês Principal Components Analysis [PCA]), os autores definiram setores da perimetria 10-2 onde os conglomerados de pontos em progressão foram observados com maior frequência e com slopes mais negativos ${ }^{(58)}$. Deve-se salientar que esses setores apresentaram boa concordância com as zonas de vulnerabilidade da perimetria 10-2 representadas nos dados das Figuras 4 e 5 .

De Moraes et al. (52) investigaram se a perimetria 10-2 detectaria progressão com maior frequência do que a perimetria convencional 24-2 em uma coorte de dados retrospectivos. Ao comparar as taxas de progressão do índice de campo visual (do inglês Visual Field Index [VFI]) da perimetria 24-2 com o índice de campo central (do inglês Central Field Index [CFI]) da perimetria 10-2 desenvolvido pelos autores, as taxas de progressão usandose o 10-2 foram até duas vezes mais rápidas do que as correspondentes ao 24-2 realizadas nos mesmos olhos no mesmo período de seguimento. Como parte do Objetivo 2, será investigada a utilidade clínica da combinação dos parâmetros convencionais e otimizados para mácula para detecção de progressão glaucomatosa, utilizando-se um banco de dados prospectivo e longitudinal.

\subsubsection{Progressão estrutural}

Alterações estruturais podem preceder alterações funcionais em muitos pacientes com glaucoma. A fotografia de disco óptico vem sendo amplamente utilizada para deteç̧ão da doença, bem como a monitorização de progressão glaucomatosa estrutural na prática clínica, incluindo-se ensaios clínicos randomizados ${ }^{(2,6)}$. Entretanto, esta técnica apresenta baixa concordância intra- e entre-observadores ${ }^{(63)}$. Para superar esta limitação, as últimas duas décadas observaram uma rápida evolução de exames de imagem computadorizados que auxiliem na detecção e monitorização do dano estrutural glaucomatoso de forma mais objetiva e reprodutível. Entre 
estas modalidades de exames, a que obteve maior aceitação e difusão entre clínicos e pesquisadores foi o OCT, particularmente, na última década com o advento do OCT de alta resolução com tecnologias de domínio espectral (do inglês spectral domain [SD]) e fonte de varredura (do inglês swept source [SS]).

Vários estudos vêm demonstrando a utilidade dessa tecnologia não só para diagnóstico de glaucoma como também detecção de progressão ${ }^{(64-}$ 66). A maior parte destes estudos baseou-se em medidas da CFNR peripapilar em vista da importância dessa região já longamente conhecida no campo de estudo das neuropatias ópticas. Recentemente, atenção maior vem sendo dada à região macular em decorrência de achados de estudos discutidos acima ${ }^{(67-69)}$. Uma recente metanálise sugeriu que a performance para detecção de lesão glaucomatosa estrutural é semelhante entre protocolos de varredura da CFNR peripapilar e CCGR macular (70). Este é um achado marcante, uma vez que o padrão de referência utilizado em estudos de performance diagnóstica para definição do glaucoma ser a fotografia de disco óptico e a perimetria 24-2, ambos insuficientes para avaliação macular.

A comparação da utilidade destes dois parâmetros estruturais para a progressão do glaucoma em estudos prospectivos é escassa. Utilizando-se dados do multicêntrico Estudo de Imagem Avançada em Glaucoma (do inglês Advanced Imaging for Glaucoma Study [AIGS]), Zhang et al. (71) não observaram significância estatística na comparação da performance da CFNR peripapilar e CCGR macular para detecção de progressão em indivíduos com ou suspeitos de glaucoma. No entanto, entre aqueles com glaucoma mais avançado, a CCGR macular apresentou melhor performance, possivelmente, em vista de seu maior intervalo dinâmico (definido como a diferença entre os valores máximo e mínimo, ou seus intervalos de confiança). Quando comparado com a perimetria acromática 24-2, no entanto, tanto o OCT da CFNR peripapilar como CCGR macular detectaram progressão com maior frequência e, em média, 2 anos antes que a perimetria, mesmo após ajuste para especificidade (Figura 6). 
Em estudo retrospectivo de 151 pacientes coreanos, Kim et al. (72) observaram que, em olhos com glaucoma inicial, a alteração progressiva da CCGR macular foi detectada com maior frequência antes da alteração correspondente da CFNR peripapilar. Mais recentemente, Marshall et al. (73) relataram que pacientes tratados com glaucoma de pressão intraocular mais baixa apresentaram progressão estrutural mais precoce na CCGR macular do que CFNR peripapilar. Em conjunto, estes estudos sugerem que, pelo menos em alguns pacientes, atenção mais detalhada deve ser dada à região macular para detecção de sinais de progressão da doença.

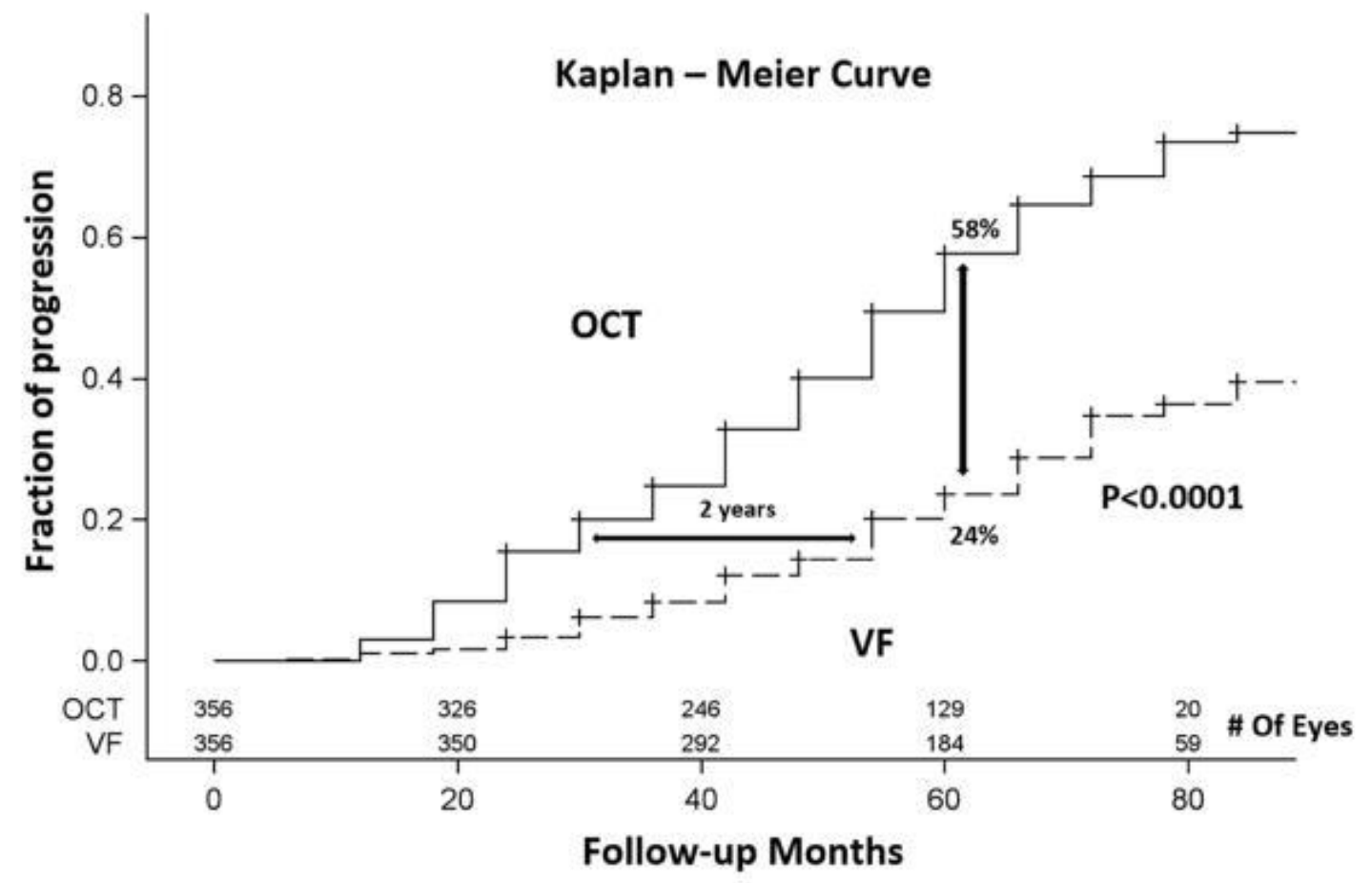

Fonte: Zhang et al.(71)

Figura 6 - Gráficos de Kaplan-Meier de progressão de glaucoma detectados pelo OCT e perimetria acromática 24-2 em olhos com glaucoma pré-perimétrico

\subsubsection{Estrutura versus função}

Atualmente, as principais técnicas utilizadas na prática clínica para se detectar a progressão glaucomatosa são, no Brasil, a fotografia do disco óptico ${ }^{(74)}$ (ou OCT nos EUA ${ }^{(75)}$ ) e a perimetria acromática 24-2. No entanto, 
a forma como estas técnicas são utilizadas hoje é, com frequência, de natureza subjetiva e estudos vêm demonstrando que a concordância entre oftalmologistas na definição de progressão usando esses métodos é, no máximo, moderada $(63,76,77)$. Esta é uma observação perturbadora uma vez que o manejo adequado do glaucoma depende da capacidade de medir a progressão de forma objetiva $(35,36)$.

Para superar estas limitações, estudos recentes $(78,79)$ que integraram os resultados dos testes estruturais e funcionais para aprimorar a detecção de progressão glaucomatosa, adotaram abordagens estatísticas Bayesianas, em grande parte em razão do crescente avanço da capacidade computacional. Esta abordagem é consistente com as diretrizes do primeiro Consenso da Associação Mundial de Glaucoma (36), isto é, uma avaliação precisa da progressão do glaucoma requer uma combinação de testes estruturais e funcionais. Medeiros et al. (78) usaram um modelo conjunto de efeitos aleatórios mistos multivariados dentro de uma estrutura de modelagem hierárquica Bayesiana para integrar informações das medidas longitudinais do VFI da perimetria 24-2 e espessura média da CFNR peripapilar medida com polarimetria de varredura laser (do inglês Scanning Laser Polarimetry [SLP]) em um estudo longitudinal. Os autores observaram que o novo método aprimorou a detecção de progressão do glaucoma em comparação com a regressão linear convencional do VFI, disponível comercialmente com o GPA.

De forma semelhante, Russell et al. (79) aplicaram regressão linear Bayesiana em uma amostra de pacientes com hipertensão ocular e utilizaram medidas da área do anel neurorretiniano obtidas pela oftalmoscopia confocal de varredura a laser (do inglês, Confocal Scanning Laser Ophthalmoscopy [CSLO], como informação estrutural a priori, para prever mudanças funcionais ao longo do tempo (a posteriori). Comparado com a regressão linear convencional, o método Bayesiano demonstrou que as taxas de progressão perimétrica podem ser estimadas com maior precisão. No entanto, ambos os estudos aqui descritos utilizaram parâmetros globais, tais como o VFI e MD para análises de tendência e não exploraram 
as informações contidas nas correlações espaciais entre pontos da perimetria e medidas de espessura da CCGR (disponíveis com a OCT de alta resolução). Portanto, idealmente, os modelos de progressão deveriam incluir informações espaciais (isto é, a relação entre os pontos de perimetria e as medidas da OCT) para minimizar o efeito negativo decorrente da variabilidade (ou ruído).

Seguindo esta recomendação, Zhu et al. (80) descrevem um modelo estatístico inferencial chamado análise com Regressão Não-estacionária do Erro de Weibull e Aprimoramento Espacial (do inglês Analysis with NonStationary Weibull Error Regression and Spatial Enhancement [ANSWERS]). Em contraste com os modelos de regressão linear convencionais, ANSWERS incorpora a correlação espacial de medidas usando uma estrutura Bayesiana. O modelo detectou progressão significativamente mais precoce do que os métodos convencionais, com taxas de resultados falsopositivos semelhantes ${ }^{(80)}$. No Objetivo 2, será aplicado um modelo Bayesiano multivariado conjunto incorporando-se o OCT com varredura macular e peripapilar em conjunto com a perimetria 24-2 e 10-2 com o objetivo de aprimorar a sensibilidade e a especificidade para detectar progressão glaucomatosa.

Tomados em conjunto, os estudos citados acima forneceram evidência de que uma abordagem Bayesiana pode melhorar a acurácia para detectar progressão clinicamente significativa de glaucoma. No entanto, até a presente data, as técnicas descritas acima vêm sendo limitadas a laboratórios e não foram traduzidas para a prática diária. Muitas vezes, os oftalmologistas não têm o conhecimento ou tempo para realizar estas análises estatísticas avançadas. Na prática, fazem diferentes exames diagnósticos (perimetria, fotografia de disco e OCT) com o intuito de aumentar a sensibilidade de detecção de dano glaucomatoso e/ou sua progressão. No entanto, sua combinação sem ajustes estatísticos adequados pode resultar no aumento desproporcional de resultados falsopositivos (i.e., redução da especificidade), que, por sua vez, pode ser tão prejudicial quanto a não detecção (resultados falso-negativos, ou baixa 
sensibilidade). Como alternativa à análise Bayesiana, o presente estudo também investigará a frequência de aumento de resultados falso-positivos quando todos os quatro exames são utilizados (i.e., OCT macular e peripapilar, perimetria 24-2 e 10-2) e como se comparam quando ajustados para a mesma especificidade.

Combinando-se os métodos estatísticos acima mencionados, e tendo em vista estudos preliminares descrevendo seu desempenho, será testada a hipótese de que a combinação de medidas convencionais àquelas otimizadas para avaliação da região macular pode aumentar a sensibilidade sem excessivo aumento de resultados falso-positivos (ou redução da especificidade) na detecção de progressão glaucomatosa, com ou sem modelos Bayesianos. Caso confirmada, os resultados poderão servir de base para o melhor entendimento de como empregar estes exames (de forma mais racional) na prática clínica e em futuros ensaios clínicos, reduzindo a duração e os custos de pesquisa, além de auxiliar no cuidado de pacientes nos níveis individual e personalizado. 
4 METODOLOGIA 


\section{METODOLOGIA}

\subsection{Banco de dados do projeto}

No presente estudo, longitudinal e prospectivo, a participação de indivíduos foi voluntária e acompanhada de assinatura do Termo de Consentimento Livre e Esclarecido aprovado pelo Comitê de Ética em Pesquisa do Centro Médico da Universidade de Columbia. O estudo foi executado em conformidade com os princípios da Declaração de Helsinki. O estudo incluiu participantes do Estudo de Avaliação e Progressão Macular (do inglês Macular Assessment and Progression Study [MAPS]) financiado pelo Instituto Nacional de Olhos (do inglês National Eye Institute [NEI]) dos Institutos Nacionais de Saúde (do inglês National Institutes of Health [NIH]) dos Estados Unidos da América (Investigador Principal: Carlos Gustavo de Moraes). O estudo foi registrado no site clinicaltrials.gov sob o número de inscrição NCT02547740. O estudo iniciou-se em outubro de 2015 e continua em andamento na presente data.

\subsection{Dados coletados para este estudo}

Os dados coletados em dois centros colaboradores em Nova lorque (Centro Médico da Universidade de Columbia e Laboratório de Ciências Visuais do Dr. Hood na Universidade de Columbia) foram incluídos. Utilizouse o mesmo dispositivo de OCT (Spectralis SD-OCT, Glaucoma Module Premium Edition software; Heidelberg Engineering, Dossenheim, Alemanha) nos dois centros, além do equipamento de perimetria acromática (Humphrey Field Analyzer II / III, Carl Zeiss, Meditec, Inc., Dublin, CA, Estados Unidos da América). 


\subsubsection{Tomografia de coerência óptica (OCT)}

O dispositivo de OCT Spectralis foi usado como modalidade de imagem (Figura 7). Todos os indivíduos foram submetidos à: varredura de linha horizontal e vertical da mácula, círculo peripapilar, mácula tridimensional. Para o presente estudo, apenas os dados de círculo peripapilar (com $3.5 \mathrm{~mm}$ de diâmetro, com referência no centro da Abertura da Membrana de Bruch) e mácula tridimensional (61 linhas horizontais x 15 verticais [volumes de $30 \times 25$ graus de varredura centrados na fóvea]) foram analisados. As imagens foram adquiridas usando o software de alinhamento automático Anatomic Positioning System (TruTrack; Heidelberg Engineering, Heidelberg GmbH, Heidelberg, Alemanha).

A

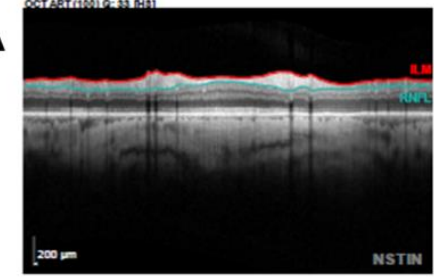

B

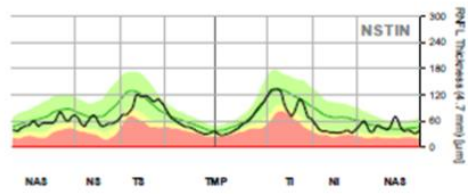

C

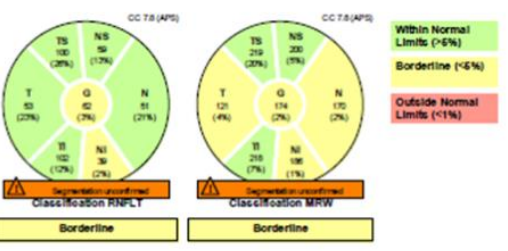

D

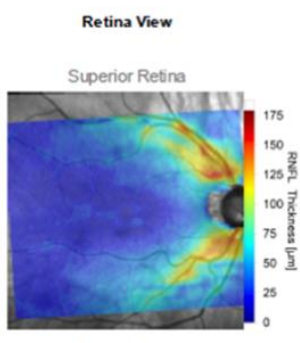

Inferior Retina

Superior Retina

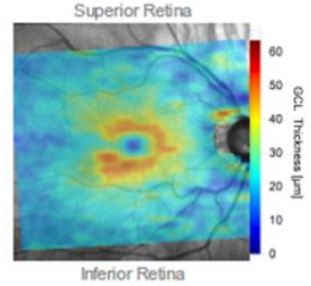

Figura 7 - Impresso (Hood Report) do SD-OCT Spectralis (Heidelberg Engineering, Dossenheim, Alemanha). A) Varredura B do círculo peripapilar com delineação da CFNR; B) gráfico NSTIN com perfil da CFNR peripapilar e sua espessura relativa ao banco de dados normativo do aparelho; C) gráfico de probabilidades por setores da região peripapilar; D) mapa de desvio de espessura da CFNR incluindo mácula e região peripapilar; E) mapa de desvio de espessura da CCGR incluindo mácula e região peripapilar; F) e G) o mesmo que D) e F), mas, em projeção de campo, mostrando a localização dos pontos testados pela perimetria 24-2 e 10-2, respectivamente 


\subsubsection{Espessura da camada de fibras nervosas e de células ganglionares da retina}

A segmentação do algoritmo do Spectralis define a CFNR como o intervalo entre as linhas que delimitam a membrana limitante interna e a CCGR. Esta medida ao redor do disco gera um mapa em dupla-corcova (chamado TSNIT ou NSTIN), em razão da maior espessura dessa camada nos pólos superior e inferior do disco óptico. O presente estudo utilizou a medida global (média) de 360 graus ao redor do disco. Estudos de estruturafunção em glaucoma demonstraram uma correlação linear moderada entre essa medida global (ou por quadrantes, em escala linear [micra]) e aquelas obtidas pela perimetria 24-2 (em escala logarítmica [dB]) em regiões correspondentes $(81,82)$. Esta correlação torna-se mais forte quando a estrutura e a função são ambas medidas em escala linear (micra e Lambert, respectivamente) (83).

A melhor resolução dos atuais dispositivos de OCT de alta resolução incentivou pesquisadores a examinarem a espessura local da CCGR como uma medida alternativa, ou adjuvante, da estrutura retiniana. Diferentes empresas fabricantes de OCT calculam a espessura das camadas internas da mácula de distinta maneira, ora medindo-se a CCGR isoladamente, ora em combinação com a CFNR ou camada plexiforme interna. No presente estudo, utilizou-se a medida da espessura (em micra) da CCGR medida isoladamente. O Laboratório de Ciências Visuais Dr. Hood tem disponível o software para exportar estas medidas da CFNR e CCGR, após correção semiautomática da segmentação.

Em todos os participantes do estudo, exames com varreadura de nervo óptico e mácula foram realizados em 2 ou 4 dias diferentes no intervalo de 2 meses, para se definir o estado estrutural basal (aqui chamada sessão teste-reteste basal). Em indivíduos saudáveis (ver descrição abaixo), as visitas de seguimento foram realizadas a cada 6 meses. Em indivíduos glaucomatosos ou suspeitos de glaucoma, as visitas de seguimento foram realizadas a cada 4 meses. 


\subsubsection{Perimetria acromática}

Os exames de perimetria acromática foram obtidos com o Humphrey Field Analyzer II ou III (Carl Zeiss Meditec, Inc., Dublin, CA, Estados Unidos da América) utilizando os programas 10-2 e 24-2 com a estratégia padrão (do inglês Swedish Interactive Threshold Algorithm [SITA]). Tecnólogos treinados e certificados realizaram os exames no mesmo dia, com intervalo de 20 minutos para minimizar fadiga. Em cada visita, programas 10-2 e 24-2 foram realizados em sequência aleatória para se minimizar viés de sequência que poderia resultar em exames de pior qualidade realizados em segundo lugar.

No presente estudo, a variável dependente utilizada foi o MD, que representa o desvio médio das sensibilidades medidas na perimetria acromática (10-2 ou 24-2) após o ajuste (pela média ponderada) dando-se maior peso aos valores mais centrais por apresentarem menor variância $\left(\sigma^{2}\right)$ e, portanto, maior precisão $\left(1 / \sigma^{2}\right)$.

Em todos os participantes do estudo, tanto a perimetria 10-2 como 242 foram realizadas em 2 ou 4 dias diferentes no intervalo de 2 meses para se definir o estado funcional basal (sessão teste re-reteste). Em indivíduos saudáveis, as visitas de seguimento foram realizadas a cada 6 meses. Assim como para o OCT, em indivíduos glaucomatosos ou suspeitos de glaucoma, as visitas de seguimento foram realizadas a cada 4 meses. Todos os participantes do estudo já possuíam experiência prévia na realização de exames perimétricos com, pelo menos, três exames confiáveis e sem evidência de efeito aprendizado, antes das visitas basais do presente estudo.

\subsubsection{Outros}

Todos os participantes do estudo foram submetidos a exame oftalmológico completo que incluiu acuidade visual corrigida, exame biomicroscópico, e fotografia do disco óptico obtido com câmara de fundo midriática Nidek 3-Dx (Nidek, Inc., Japão). A pressão intraocular foi medida 
por oftalmologistas treinados utilizando-se tonometria de aplanação de Goldmann (Haag Streit, GmBH, Koniz, Suíça). A espessura central da córnea foi medida por paquimetria ultrassônica (DGH-550; DGH Technology, Inc., Exton, PA, Estados Unidos da América).

\subsection{Elegibilidade}

Os critérios de elegibilidade seguiram a metodologia do Estudo de Avaliação de Glaucoma em Afrodescendentes (do inglês African Descent and Glaucoma Evaluation Study [ADAGES]), conforme descritos na literatura (84). Todos os participantes do estudo apresentavam melhor acuidade visual corrigida na tabela de Snellen $\geq 20 / 40$ no olho de estudo. Se ambos os olhos preenchessem todos os critérios de elegibilidade, ambos foram incluídos no estudo.

\subsubsection{Critérios de inclusão}

\subsubsection{Indivíduos saudáveis}

- Fotografia tridimensional de disco óptico normal baseada na interpretação de dois especialistas em glaucoma (Jeffrey M. Liebmann e Carlos Gustavo de Moraes). Em caso de discordância, a decisão final descrita no prontuário médico foi utilizada para classificação;

- Perimetria acromática 24-2 confiável com Glaucoma Hemifield Test (GHT) dentro dos limites da normalidade e Pattern Standard Deviation (PSD) com $\mathrm{P}>5 \%$ em dois exames consecutivos;

- Confiabilidade definida pela presença de resultados falsonegativos $<33 \%$, falso-positivos $<15 \%$ e perdas de fixação $<20 \%$; 
- Pressão intraocular $<22 \mathrm{mmHg}$ com tonometria de Goldmann em, pelo menos, dois dias diferentes (mínimo 7 e máximo 30 dias).

\subsubsection{Indivíduos suspeitos de glaucoma}

- Fotografia tridimensional de disco óptico sugestiva de neuropatia óptica glaucomatosa baseada na interpretação de dois especialistas em glaucoma;

- Perimetria acromática 24-2 confiável com GHT dentro dos limites da normalidade e PSD com $\mathrm{P}>5 \%$ em dois exames consecutivos;

- Pressão intraocular $<22 \mathrm{mmHg}$ com tonometria de Goldmann em, pelo menos, 2 dias diferentes (mínimo 7 e máximo 30 dias);

- Olho contralateral com glaucoma a perda funcional (ver abaixo).

\subsubsection{Indivíduos glaucomatosos com perda funcional inicial}

- Fotografia tridimensional de disco óptico sugestiva de neuropatia óptica glaucomatosa baseada na interpretação de dois especialistas em glaucoma;

- Perimetria acromática 24-2 confiável com GHT fora dos limites da normalidade ou PSD com P <5\% em dois exames consecutivos;

- Desvio médio (MD) da perimetria 24-2 >-6 dB no exame basal;

Em todos os grupos acima, o ângulo era aberto na gonioscopia (pelo menos, trabeculado anterior visível nos quatro quadrantes) na ausência de iridotomia a laser. Todos os pacientes glaucomatosos apresentavam diagnóstico de Glaucoma Primário de Ângulo Aberto, Glaucoma Pigmentar ou Glaucoma Pseudoesfoliativo.

Para fins deste estudo, indivíduos saudáveis foram denominados grupo Controle, e suspeitos de glaucoma e pacientes com glaucoma, grupo 
Caso, conforme a metodologia do ADAGES (84). Apenas indivíduos com, ao menos, seis visitas de estudo em, pelo menos, um ano de seguimento foram incluídos no presente estudo. Todos os pacientes glaucomatosos ou suspeitos de glaucoma foram tratados no decorrer do estudo conforme determinação subjetiva do especialista em glaucoma responsável pelo paciente. Indivíduos saudáveis permaneceram não tratados.

\subsubsection{Critérios de exclusão}

Tanto para o grupo Controle como grupo Caso, participantes do estudo foram excluídos se apresentassem alterações oculares que, potencialmente, afetassem a interpretação dos exames diagnósticos, tais como:

- catarata significante (resultando em melhor acuidade visual corrigida $<20 / 40$ );

- erro refrativo maior que 6 dioptrias esféricas ou 3 dioptrias cilíndricas;

- doenças neuro-oftalmológicas;

- alterações retinianas como retinopatia diabética de qualquer severidade;

- degeneração macular relacionada à idade de qualquer severidade;

- edema macular ou membrana epirretiniana de qualquer etiologia;

- oclusão de veia ou artéria central da retina ou seus ramos; e

- distrofias ou cicatrizes retinianas;

Pacientes glaucomatosos em decorrência de causas secundárias (excluindo-se Glaucoma Pigmentar e Glaucoma Pseudoesfoliativo) também foram excluídos. Resultados de exames de perimetria acromática (24-2 e 102) que não preenchessem os critérios de confiabilidade descritos acima no 
decorrer do estudo não foram analisados. Exames de OCT com qualidade menor que $15 \mathrm{~dB}$ também foram excluídos.

\subsection{Análise estatística}

A análise computadorizada foi realizada com os seguintes softwares: STATA (versão 14.2; StataCorp LP, College Station, Texas, Estados Unidos) e R [R Core Team (2013). R: A language and environment for statistical computing. R Foundation for Statistical Computing, Vienna, Austria. URL http://www.R-project.org/]. A probabilidade de erro tipo 1 (a) foi definida em $5 \%$.

\subsubsection{Análise descritiva}

Variáveis categóricas são descritas como proporções e percentagens. A comparação entre grupos foi feita com o teste exato de Fisher bicaudal.

Estimativas de centro de variáveis contínuas são descritas como média ou mediana, dependendo de sua distribuição (paramétrica ou não paramétrica, respectivamente). Estimativas de dispersão de variáveis contínuas são descritas com desvio padrão (DP) ou intervalo interquartílico, dependendo de sua distribuição (paramétrica ou não paramétrica, respectivamente). $O$ teste de Kolmogorov-Smirnov foi utilizado para acessar a normalidade de distribuição de cada variável. A comparação entre grupos foi feita com modelos lineares generalizados (que ajustam para inclusão de ambos os olhos do mesmo individuo) com teste bicaudal.

\subsubsection{Avaliação da taxa de progressão}

Tanto para as medidas de perimetria acromática como do OCT, a taxa de progressão por unidade de tempo (ano) foi calculada utilizando-se modelos de efeitos mistos lineares. 
Modelos de efeitos mistos lineares são uma extensão de modelos lineares simples para permitir efeitos fixos e aleatórios e, particularmente, são usados quando há interdependência nos dados, como surge de uma estrutura hierárquica e longitudinal. Por exemplo, ambos os olhos podem ser amostrados de um mesmo indivíduo e para cada olho múltiplas medidas são obtidas no decorrer do seguimento. Embora sejam amplamente utilizados pela indústria e pesquisadores, modelos lineares simples não são recomendados quando há mais de uma medida dentro da mesma hierarquia (como no caso de dois olhos do mesmo individuo) ou quando há interdependência entre os resíduos (como no caso de múltiplas medidas no mesmo olho no decorrer do tempo) ${ }^{(85)}$. Modelos de efeitos mistos lineares permitem, portanto, ajustar para inclusão de ambos os olhos do mesmo paciente ao mesmo tempo que levam em consideração medidas repetidas; por esse motivo, vêm sendo amplamente utilizados em pesquisa oftalmológica, particularmente, em estudos de progressão glaucomatosa ${ }^{(86-}$ 88).

O princípio básico dos modelos mistos é que eles incorporam efeitos fixos e aleatórios na regressão. Um efeito fixo é um parâmetro que não varia, como por exemplo, a linha de regressão (slope) da população, $\beta$, para qual se tem uma estimativa, $\beta$ '. Em contraste, efeitos aleatórios são parâmetros que variam entre indivíduos. Por exemplo, pode-se dizer que $\beta$ é distribuída como variável aleatória com média $\mu$ e desvio padrão $\sigma$, ou em forma de equação:

$$
\beta \sim N(\mu, \sigma)
$$

Essa relação é análoga à observada na regressão linear simples, onde assumimos que os dados são variáveis aleatórias, mas os parâmetros são efeitos fixos. Em modelos mistos, os dados e os parâmetros são variáveis aleatórias, mas são fixos no nível mais alto (por exemplo, média geral da população, $\mu$ ). 
Em modelos mistos, temos:

$$
y=X \beta+Z u+\varepsilon
$$

Onde y é a variável dependente com um vetor com $N \times 1$ colunas; $X$ são as variáveis preditoras de uma matriz de dimensões $N \times p$; $\beta$ é um vetor com $p \times 1$ colunas com os coeficientes de regressão de efeitos fixos ( $\beta \mathrm{s}$ ); $Z$ é a matriz $\mathrm{N} \times q$ para os q efeitos aleatórios (o complemento aleatório para o $X$ ); u é um vetor $q \times 1 \mathrm{com}$ efeitos aleatórios (o complemento aleatório de $\beta$ ); e $\varepsilon$ é um vetor $N \times 1$ dos resíduos (isto é, a diferença entre o valor previsto pelo modelo, $X \beta+Z u$, e o dado observado).

No entanto, em estatística clássica, não se estima u. Em vez disso, assume-se que:

$$
\mathrm{u} \sim \mathrm{N}(0, \mathrm{G})
$$

Isto é, u é distribuído como variável de distribuição normal com média zero e variância $G$, onde $G$ é a matriz de variância-covariância dos efeitos aleatórios. Como se estimam diretamente os efeitos fixos, incluindo o valor estimado basal (do inglês intercept) do efeito fixo, os complementos de efeitos aleatórios são avaliados no modelo como desvios do efeito fixo e, portanto, têm zero de média. Os efeitos aleatórios são apenas desvios em torno do valor de $\beta$.

Várias parametrizações e restrições permitem simplificar o modelo como, por exemplo, assumindo que os efeitos aleatórios são independentes, o que implicaria que a estrutura seja:

$$
\mathbf{G}=\left[\begin{array}{cc}
\sigma_{\text {int }}^{2} & 0 \\
0 & \sigma_{\text {slope }}^{2}
\end{array}\right]
$$


No entanto, no glaucoma a relação entre intercepts e slopes é usualmente correlacionada (isto é, quanto mais severo o valor basal do MD, mais rápida a taxa de progressão, em média) ${ }^{(89)}$. Para os modelos no presente estudo, assume-se uma covariação a ao invés de zero, sendo que a é estimado empiricamente baseado nos dados observados através de uma matriz de covariância não estruturada (do inglês Unstructured Covariance Matrix).

O elemento final do modelo misto é a matriz de variância-covariância dos resíduos, $\varepsilon$, que segue:

$$
\mathrm{R}=\mathrm{I} \sigma^{2} \varepsilon
$$

Onde I é uma matriz de identidade (matriz diagonal com valor 1) e $\sigma^{2} \varepsilon$ é a variância dos resíduos. É importante notar que $\sigma^{2} \varepsilon$ reflete 0 grau de variabilidade não explicado pelo modelo, tendo, portanto, efeito na detecção de progressão estatisticamente significativa (isto é, quanto maior $\sigma^{2} \varepsilon$, mais exames serão necessários para se detectar a progressão).

Para os resultados das análises utilizando-se modelos mistos, são descritos a taxa de progressão média (slope) da população e seu intervalo de confiança (IC) de 95\%. Para comparação entre Controles e Casos, o modelo permite testar sua diferença ao se adicionar ao modelo linear misto a interação Grupo x Tempo. Caso valor P do coeficiente desta interação seja significante, rejeita-se a hipótese nula e conclui-se que Controles e Casos progridem a taxas diferentes. 


\subsubsection{Combinação de parâmetros convencionais e otimizados para mácula}

\subsubsection{Obtenção da média do MD da perimetria acromática 24-2 e 10-2}

Para combinação dos dados funcionais convencionais e otimizados para mácula, a média de sensibilidade de todos os pontos dos exames 24-2 e 10-2 foi calculada. Primeiramente, os valores de TD de cada teste (52 pontos do 24-2, após exclusão dos pontos acima abaixo da mancha-cega, e 68 pontos do 10-2) foram exportados automaticamente dos perímetros. Como os valores de sensibilidade são fornecidos em escala logarítmica (dB), primeiramente, cada valor foi convertido em escala linear (Lambert, L), usando-se a equação:

$$
d B=10 * \log (1 / L)]
$$

A seguir, a média aritmética ponderada dos 120 pontos combinados foi calculada para cada par de exames (24-2 e 10-2) realizados no mesmo dia. Os pesos das médias ponderadas são derivados da precisão de cada ponto $\left(1 / \sigma^{2}\right)$, conforme realizado no Humphrey ${ }^{(90)}$. Como estes dados são proprietários da empresa (Carl Zeiss) e não disponíveis em domínio público, utilizaram-se os dados obtidos na sessão teste-reteste deste estudo (isto é, duas ou quatro visitas no intervalo de 2 meses). $O$ valor médio ponderado foi então convertido em dB, usando-se a mesma equação acima. Esta variável dependente passa a ser aqui denominada Função Combinada e tem a mesma interpretação que o MD do 24-2 ou 10-2 (isto é, quanto em média a sensibilidade global desvia-se em relação à média de indivíduos controles de mesma faixa etária). 


\subsubsection{Obtenção da média de desvio de espessura da CCGR macular e CFNR peripapilar}

A combinação dos dados estruturais convencionais e otimizados para mácula tem maiores desafios do que utilizando-se os dados de perimetria acromática. Embora sejam medidas na mesma unidade (micra), trata-se de estruturas diferentes com distintos intervalos dinâmicos (CFNR peripapilar e CCGR macular). Portanto, a simples média das duas camadas não seria adequada. Uma abordagem diferente e nova foi aqui adotada para se calcular a média global de espessuras da região macular e peripapilar. Primeiramente, os valores globais da CCGR macular e CFNR peripapilar foram exportados automaticamente do aparelho de OCT. Em analogia aos valores de TD, calculamos o desvio médio dos valores globais, usando-se a equação:

$$
D_{N E_{i j}}=\left(\mu-E_{i j}\right) / \sigma
$$

Onde $\mathrm{DNE}_{\mathrm{i}}$ é o desvio normalizado de espessura do olho i do paciente j; $\mu$ é a espessura média do banco de dados normativo do aparelho para o mesmo grupo etário; $\mathrm{E}_{\mathrm{ij}}$ e a espessura medida do olho i do paciente j; e $\sigma$ é o desvio padrão do banco de dados normativo do aparelho (os valores do banco de dados normativo foram generosamente cedidos pela Heidelberg). Inicialmente, os cálculos acima foram realizados para a espessura da CCGR e da CFNR separadamente.

Finalmente, a média ponderada aritmética de DNE da CCGR e da CFNR foi calculada para cada par de varreduras (macular e peripapilar) realizadas no mesmo dia. Os pesos foram derivados da medida de precisão $\left(1 / \sigma^{2}\right)$ das medidas teste-reteste (semelhante ao realizado para perimetria). Note que esse valor final não tem unidade e será aqui referido ' $U$ ', sendo o parâmetro final aqui denominado Estrutura Combinada. 


\subsubsection{Modelo Bayesiano de regressão conjunta}

Para combinação dos dados estruturais e funcionais, um modelo de regressão conjunta foi implementado utilizando-se uma estrutura de modelo hierárquica Bayesiana para integrar as quatro medidas longitudinais, isto é, estrutural (OCT da CFNR peripapilar e CCGR macular) e funcional (perimetria 10-2 e 24-2). Detalhes desta abordagem podem ser encontrados na literatura (78). Em uma abordagem conjunta usando-se modelos hierárquicos, são assumidos efeitos aleatórios para cada parâmetro e os diferentes parâmetros são associados impondo uma distribuição multivariada conjunta nos efeitos aleatórios. Esta abordagem tem grande flexibilidade e permite combinar modelos para medidas de diferentes intercepts e também com distintos números de observações por indivíduos. No primeiro nível, cada parâmetro é descrito usando um modelo linear:

$$
\begin{gathered}
Y_{1 i}=\alpha_{1 j[i]}+\beta_{1 j[i]} x \text { time }+\varepsilon_{1 i}, \varepsilon_{1 i} \sim N\left(0, \delta_{1 y^{2}}\right) \\
Y_{2 i}=\alpha_{2 j[i]}+\beta_{2 j[i]} x \text { time }+\varepsilon_{2 i}, \quad \varepsilon_{2 i} \sim N\left(0, \delta_{2 y^{2}}\right) \\
Y_{3 i}=\alpha_{3[i]}+\beta_{3 j[i]} x \text { time }+\varepsilon_{3 i}, \varepsilon_{3 i} \sim N\left(0, \delta_{3 y^{2}}\right) \\
Y_{4 i}=\alpha_{4 j[i]}+\beta_{4 j[i]} x \text { time }+\varepsilon_{4 i,} \varepsilon_{4 i} \sim N\left(0, \delta_{4 y^{2}}\right) \\
\text { Para i }=1,2,3,4 \ldots, n
\end{gathered}
$$

Onde Y1i, Y2i, Y3i e Y4i representam as medidas longitudinais de MD do 242, MD do 10-2, espessura da CFNR peripapilar e CCGR macular, respectivamente, para um olho j tomado no instante i; $\alpha 1$, $\alpha 2$, $\alpha 3$ e $\alpha 4$ correspondem aos intercepts aleatórios, respectivamente, para cada parâmetro; $\beta 1, \beta 2, \beta 3$ e $\beta 4$ correspondem aos slopes aleatórios para cada parâmetro; $\varepsilon 1, \varepsilon 2$, $\varepsilon 3$ e $\varepsilon 4$ são os termos de erro de cada equação e assumese que seguem uma distribuição normal com média 'zero' e variância $\delta 1^{2}$, $\delta 2^{2}, \delta 2^{3}$ e $\delta 2^{4}$, respectivamente. As trajetórias de resposta de cada 
parâmetro são conectadas por meio de uma distribuição multivariada de efeitos aleatórios. Ou seja, no modelo Bayesiano, os intercepts e slopes devem seguir uma distribuição t multivariada e esta distribuição multivariada atua como dados a priori para a estimação de intercepts e slopes a posteriori para cada olho individualmente.

Os parâmetros desta distribuição multivariada podem ser estimados empiricamente. As estimativas das distribuições posteriores dos parâmetros de interesse podem ser obtidas por procedimentos de Monte Carlo Markov Chain. Após estimativas das distribuições posteriores, calculam-se medidas sumárias, como média e intervalos de credibilidade (em estatística Baysiana não se denominam intervalos de confiança). Utilizando metodologia semelhante, Medeiros et al. ${ }^{(78)}$ encontraram uma relação mais precisa entre os slopes da perimetria e as medidas da oftalmoscopia de varredura confocal calculadas pelo modelo de regressão da conjunta Bayesiana em comparação com o método regressão linear convencional. Além disso, verificaram que o erro quadrático médio das previsões de regressão linear convencional foi menor que os das previsões Bayesianas. Estes resultados suportam a importância de se combinar dados estruturais e funcionais para avaliação da progressão glaucomatosa, que pode determinar medidas de slope mais próximas à "real" e menos afetadas por variabilidade perimétrica. No presente estudo, a função mvglmer do pacote estatístico JMbayes do programa $R^{\left({ }^{(91)}\right.}$ Os parâmetros adotados na presente análise são aqueles definidos como padrão (do inglês default) descritos na referência. ${ }^{(91)}$ Para testar a hipótese de que o modelo Bayesiano apresentou melhor acurácia, comparou-se o índice de goodness-of-fit denominado critério de informação de desvio (do inglês deviance information criterion [DIC]) com aquele obtido quando apenas o MD do 24-2 foi estudado. Esse índice é particularmente útil em problemas de seleção de modelos Bayesianos onde as distribuições posteriores dos modelos foram obtidas pela simulação de Monte Carlo Markov Chain. A ideia é que os modelos com menor DIC são superiores aos modelos com maior DIC. O DIC é penalizado pelo número de parâmetros testados, ou seja, ele é ajustado para fato de que modelos com um maior 
número de variáveis teriam uma melhor acurácia em relação a modelos mais simples.

\subsubsection{Modelos de simulação computacional}

Esta abordagem vem sendo adotada por diferentes investigadores (34, 49, 92, 93) pois permite uma maior flexibilidade de ajuste de parâmetros (como frequência de exames e duração de seguimento), além de ajustar-se para definição de progressão baseada na especificidade do parâmetro em questão. Por exemplo, quanto maior o tempo de seguimento e frequência de exames, maior a probabilidade de se detectar progressão com um determinado parâmetro (41). Ao mesmo tempo, a observação de um parâmetro mais sensível à detecção de progressão (i.e., aquele que detecta mais pacientes progredindo do que outro a despeito do mesmo tempo de seguimento e frequência de exames) pode ser decorrente de uma maior taxa de resultados falso-positivos (ou detecção de progressão em excesso). Modelos de simulação permitem estabelecer uma predeterminada especificidade (100 - \% falso-positivos), como por exemplo 95\% (100 - 5\%), e testar qual parâmetro realisticamente tem melhor performance. $\mathrm{O}$ modelo aqui adotado foi baseado no estudo publicado por Wu e Medeiros ${ }^{(93)}$.

Em resumo, utilizaram-se dados estruturais e funcionais do presente banco de dados longitudinal (aqui denominado "real", pois foi extraído da coorte incluída neste estudo) para se extrair as taxas de progressão (slopes) dos diferentes parâmetros ao longo do tempo. Além disso, o banco de dados "real" foi utilizado para se extrair informação sobre a variabilidade (resíduos) dos parâmetros.

O primeiro passo para desenvolver o modelo foi calcular a taxa de progressão dos parâmetros estruturais e funcionais ao longo do tempo (ou "sinal") por meio de regressões lineares de mínimos quadrados (do inglês Ordinary Least Squares [OLS]) no banco de dados "real". A variabilidade (ou "ruído") foi então estimada pelos resíduos do modelo OLS, que foram 
obtidos subtraindo-se os valores observados dos valores estimados pelo modelo.

As estimativas de variabilidade foram então agrupadas em intervalos (do inglês bins) de mesmo tamanho, a cada $1 \mathrm{~dB}$ ou 10 micra, de acordo com os valores estimados pelo modelo. Para se reconstruir o parâmetro "real" (estrutural ou funcional) em cada ponto do seguimento, o parâmetro "real" foi determinado pelo slope e intercept estimado para cada olho. O componente "ruído" (ou resíduo) foi, então, selecionado aleatoriamente da distribuição do bin correspondente, sendo adicionado ao valor "real"; ilustrações deste procedimento são mostradas na Figura 8. Este tipo de análise permite levar em consideração o fato de que a variabilidade (resíduo) aumenta com a severidade da doença em glaucoma (39). Apesar da Figura 8 exemplificar a avaliação do MD do 24-2, os mesmos princípios foram utilizados para o MD do 10-2, espessura da CFNR, CCGR e parâmetros combinados. 

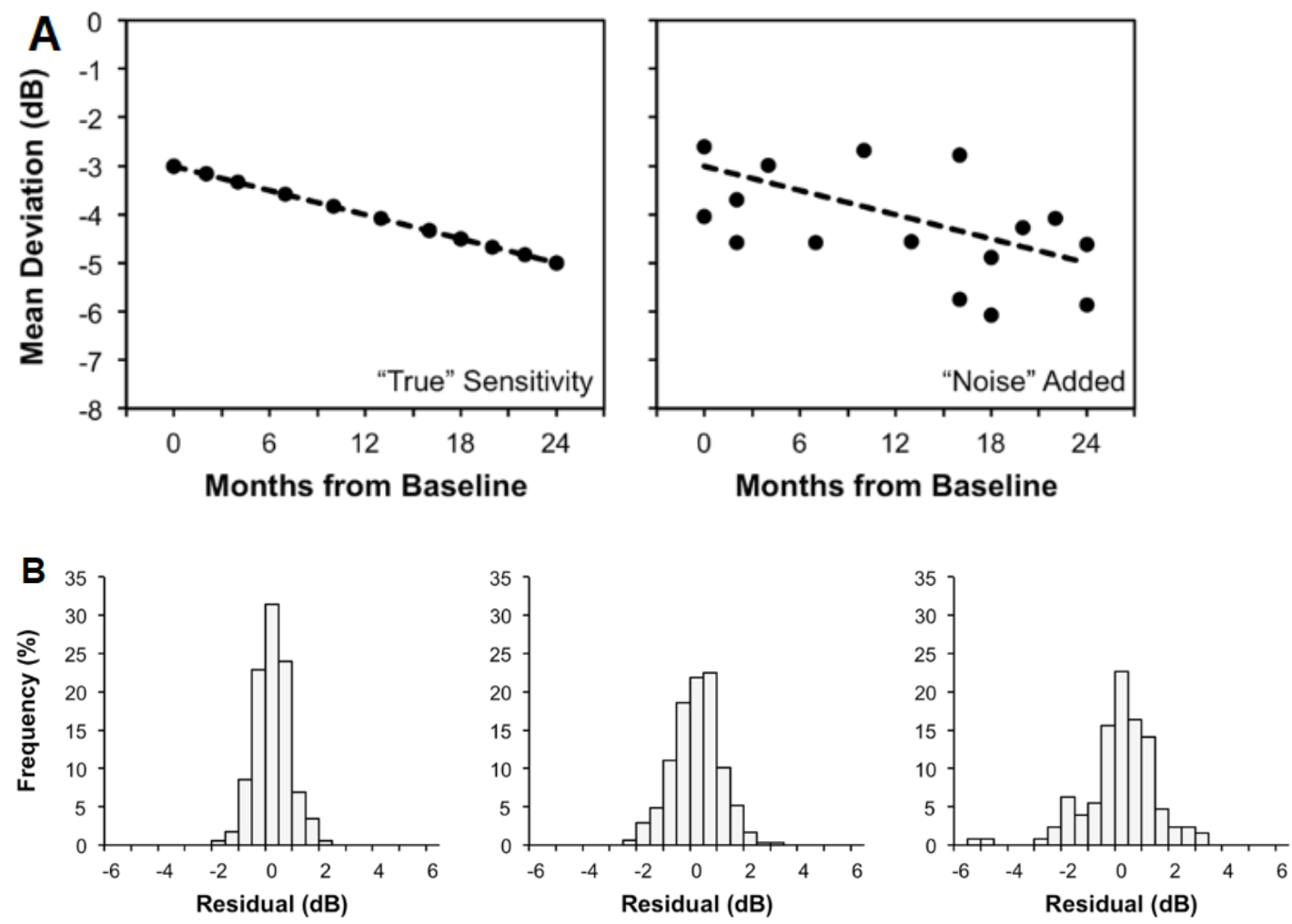

Fonte: Wu e Medeiros(93)

Figura 8 - A) À esquerda, slope de valores previstos pelo modelo obtido por regressão linear de valores MD. À direita, os valores de ruído (resíduos) foram adicionados, aleatoriamente, a cada valor previsto pelo modelo baseado no bin de resíduos derivados a que o valor previsto corresponde. B) Exemplos de três bins de distribuição de resíduos de diferentes valores de MD

Três tipos de paradigma de frequência de testes foram testados, dois refletindo a prática clínica e o terceiro um potencial ensaio clínico randomizado.

Para os paradigmas da prática clínica, simularam-se (A) dois exames basais seguidos de exames de seguimento a cada 4 meses por um período de 5 anos, com um total de 17 exames, além de (B) dois exames basais seguidos de exames de seguimento a cada 6 meses por um período de 5 anos, com um total de 12 exames. Para se determinar o poder estatístico de cada parâmetro (funcional ou estrutural) na prática clínica (testados a cada 4 ou 6 meses), a progressão foi avaliada pela realização de análises de 
regressão linear para cada olho simulado nos diferentes momentos ao longo do estudo. Em todas as análises, exigiu-se confirmação em dois exames consecutivos. Para se garantir a comparabilidade entre os diferentes parâmetros investigados, as especificidades foram pareadas em 95\%. Para tal fim, foram realizadas simulações gerando-se parâmetros estruturais e funcionais de 10.000 olhos seguidos conforme cada paradigma, assumindose que o slope fosse de $0 \mathrm{~dB} /$ ano (ou 0 micra/ano); isto é, que os olhos eram de fato estáveis do ponto de vista do glaucoma. A variabilidade obtida de cada parâmetro do banco de dados "real" foi então adicionada de forma semelhante àquela descrita nos dados da Figura 8. Em seguida, obtiveramse pontos de corte para os valores de $\mathrm{P}$ que asseguraram a especificidade correspondente $(95 \%)$.

Para o paradigma de ensaio clínico randomizado, simularam-se seis exames basais (no decorrer de um mês), dois exames no $8^{\circ}$ mês, dois exames no $16^{\circ}$ mês e seis exames no final (no decorrer de um mês), por um período de 2 anos, com um total de 16 exames (Figura 9). Esta frequência de exames foi escolhida para fins de concordância com o trabalho de Wu e Medeiros ${ }^{(93)}$, que se basearam no trabalho de simulação de Garway-Heath e Crabb (92) que demonstrou uma melhor capacidade de detecção de progressão glaucomatosa quando se agrupam exames no começo e fim de estudo (do inglês Wait-and-See Approach). Na avaliação do tamanho de amostra e poder estatístico para um ensaio clínico hipotético, apenas os parâmetros funcionais (24-2, 10-2 e Função Combinada) foram avaliados em decorrência de nos Estados Unidos da América (e na maior parte do mundo hoje) as agências regulatórias apenas aceitarem o dados funcionais como variável principal (do inglês endpoint) em ensaios clínicos (94). Por simplicidade, investigou-se o tamanho de amostra necessária para se detectar o efeito de tratamento que resultasse em $30 \%$ de redução nas taxas médias de progressão funcional. No entanto, sabe-se que, para efeitos maiores (e.g.: 40 ou $50 \%$ ), o tamanho da amostra seria menor, mantendo-se fixos os demais parâmetros ${ }^{(93)}$. 


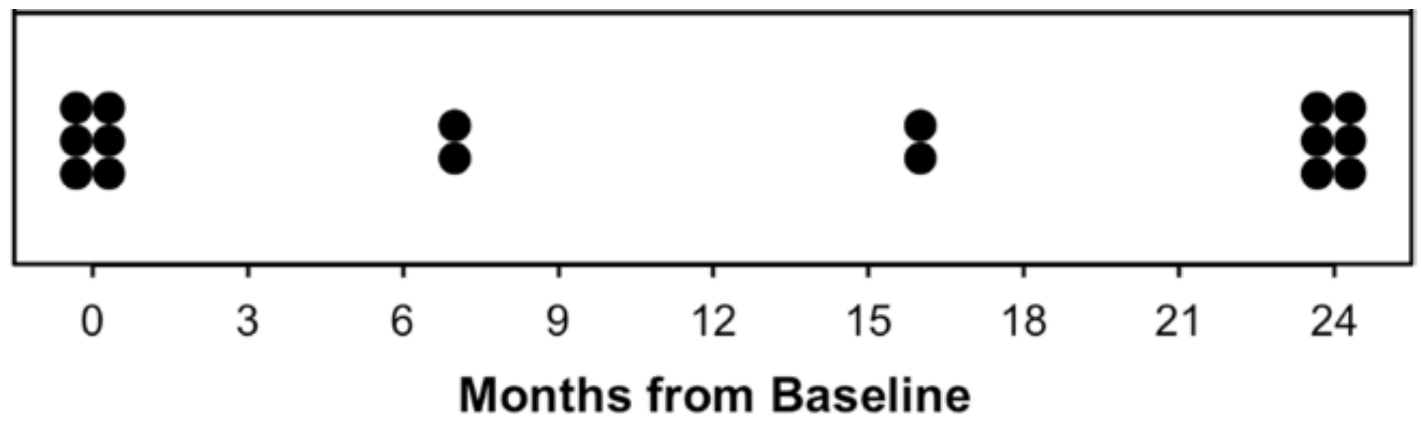

Fonte: Wu e Medeiros ${ }^{(93)}$

Figura 9 - Paradigma de frequência de exames funcionais utilizados para simulação de ensaio clínico randomizado

As estimativas de tamanho da amostra necessárias para um ensaio clínico foram obtidas pela simulação de 10.000 sequências para cada parâmetro funcional. Durante cada simulação, olhos com diferentes valores de MD basais e taxa de progressão foram selecionados aleatoriamente sem substituição, e um grupo com mesmas características, mas com efeito de tratamento de $30 \%$ nos slopes, foi simulado para refletir o grupo tratado. Para cada ensaio simulado, o efeito benéfico do novo tratamento foi avaliado usando-se modelos lineares de efeitos mistos aleatórios para se determinar a diferença de slope ao longo do tempo entre os grupos. A significância estatística do efeito do tratamento foi determinada examinando-se a interação entre a variável Grupo X Tempo (em outras palavras, se houve uma diferença significativa na taxa de progressão entre os dois grupos). A probabilidade de erro tipo 1 de $5 \%$ com teste bicaudal foi aplicada. A estimativa do tamanho da amostra necessária para cada desenho foi obtida observando-se 0 tamanho da amostra onde um efeito benéfico estatisticamente significativo poderia ser detectado em $80 \%$ ou $90 \%$ das sequências simuladas, ou seja, com poder (100\% - erro tipo 2) de $80 \%$ ou $90 \%{ }^{(93)}$. 
5 RESULTADOS 


\section{RESULTADOS}

A população inicial incluiu 376 olhos de 198 indivíduos, dos quais 257 olhos de 137 indivíduos tinham glaucoma ou suspeita de glaucoma e 119 olhos de 61 indivíduos foram classificados como saudáveis. Após aplicados os critérios de inclusão e exclusão, os dados de 115 olhos de 104 Casos e 49 olhos de 49 Controles que completaram pelo menos seis visitas e, pelo menos, um ano de seguimento foram analisados. Os dados da Tabela 1 descrevem as características dos participantes. A maioria dos indivíduos do estudo foi do sexo feminino $(54,2 \%)$ e raça branca $(86,2 \%)$. A idade média ( \pm DP) na visita basal foi 57,8 $\pm 19,0$ anos (amplitude: 18-85), e a mediana do tempo de seguimento foi 2,2 anos (intervalo interquartílico: 1,3 a 2,5; amplitude: 1 a 3 anos).

Os dados da Figura 10 mostram a distribuição da média dos valores de TD da perimetria 24-2 e 10-2 na vista basal do Grupo Caso. Nota-se uma distribuição de pontos com maior severidade correspondente à zona de maior vulnerabilidade descrita por Hood et al.(8), como descrito nos dados das Figuras 4 e 5. Três olhos (6,1\%) no Grupo Controle e $42(36,5 \%)$ no Grupo Caso apresentavam anormalidade na perimetria 10-2 (definida como PSD $<5 \%$ ) na visita basal. Na varredura peripapilar do OCT, nenhum olho no Grupo Controle apresentava anormalidade na zona de vulnerabilidade macular (definida pela presença de áreas com probabilidade $<1 \%$ no gráfico TSNIT da CFNR), e 60 (52,1\%) o apresentavam no Grupo Caso. Embora a varredura macular do OCT Spectralis não forneça probabilidades até o presente momento, notou-se que todos os olhos com alteração na zona de vulnerabilidade macular apresentavam regiões de afilamento na CCGR em formato arqueado. 
Tabela 1 - Características clínicas da população final do estudo na visita basal

\begin{tabular}{|c|c|c|c|}
\hline Parâmetros & $\begin{array}{c}\text { Casos } \\
\text { (115 olhos de } 104 \\
\text { indivíduos) }\end{array}$ & $\begin{array}{l}\text { Controles } \\
\text { (49 olhos de } 49 \\
\text { indivíduos) }\end{array}$ & $P$ \\
\hline Idade (Anos) & $67,2(11,6)$ & $36,1(15,1)$ & $<0,001$ \\
\hline Sexo (Feminino) & 55 & 28 & 0,728 \\
\hline Raça (Branca) & 92 & 40 & 0,314 \\
\hline $\begin{array}{l}\text { Pressão intraocular } \\
\quad(\mathrm{mmHg})\end{array}$ & $14,5(3,5)$ & $14,1(4,2)$ & 0,652 \\
\hline $\begin{array}{c}\text { Número de } \\
\text { medicações } \\
\text { antiglaucomatosas }\end{array}$ & $1(0 \text { a } 3)^{*}$ & $0(0 \text { a } 0)^{*}$ & $<0,001$ \\
\hline $\begin{array}{l}\text { Espessura central da } \\
\text { córnea (micra) }\end{array}$ & $532,8(39,2)$ & $550,2(38,0)$ & 0,012 \\
\hline MD 24-2 (dB) & $-2,0(2,4)$ & $-1,1(1,8)$ & 0,031 \\
\hline MD 10-2 (dB) & $-2,2(2,8)$ & $-1.2(1,5)$ & 0,021 \\
\hline $\begin{array}{l}\text { Espessura média da } \\
\text { CFNR (micra) }\end{array}$ & $75,7(18,5)$ & $100,2(9,3)$ & $<0,001$ \\
\hline $\begin{array}{l}\text { Espessura média da } \\
\text { CCGR (micra) }\end{array}$ & $25,6(3,7)$ & $31,0(2,3)$ & $<0,001$ \\
\hline Número de visitas & $8(6 \text { a } 10)^{*}$ & $6(6 \text { a } 8)^{*}$ & $<0,001$ \\
\hline
\end{tabular}

* Valores correspondem à mediana (intervalo interquartílico).

Demais valores correspondem à média (DP).

A

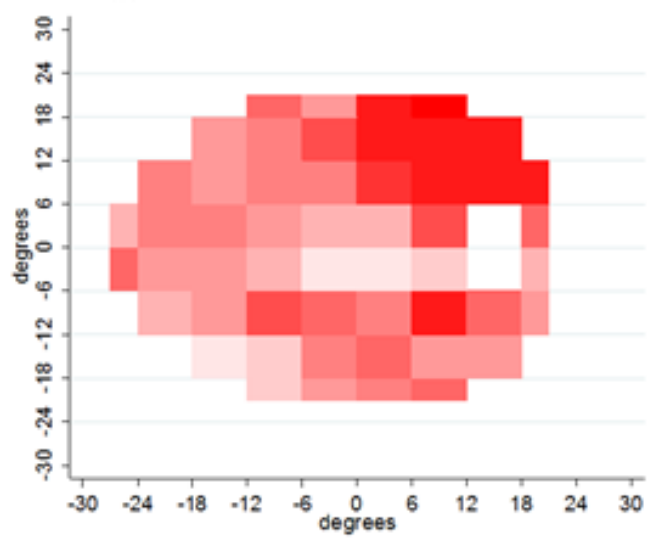

B

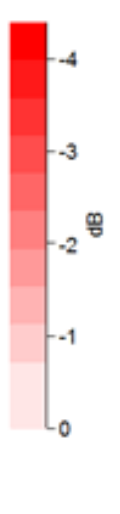

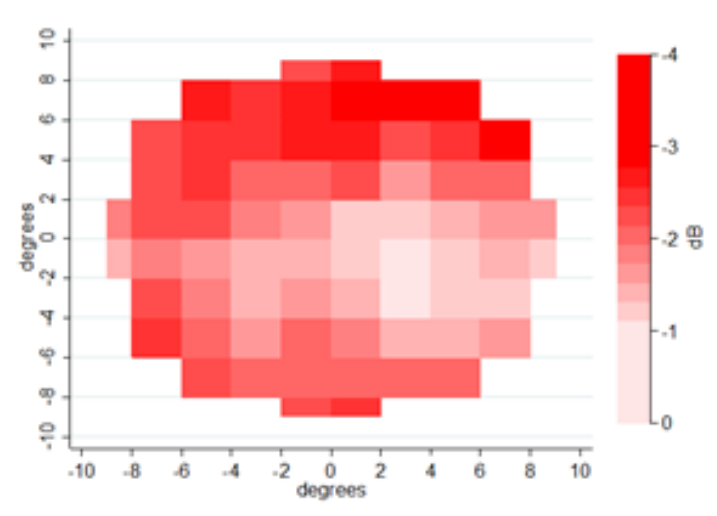

Figura 10 - Distribuição dos valores médios de desvio total do Grupo Caso. Projeções de olho direito. A) Perimetria 24-2; B) Perimetria 10-2 


\subsection{Objetivo 1: Avaliar a taxa de progressão glaucomatosa utilizando- se parâmetros convencionais (OCT da CFNR peripapilar e perimetria 24-2) e otimizados para mácula (OCT da CCGR e perimetria 10-2)}

As taxas de progressão (slopes) baseadas em cada parâmetro são descritas nos dados da Tabela 2. Nota-se que, para todos os parâmetros investigados, o IC de 95\% no grupo Caso não incluiu o valor zero, o que sugere que esse grupo sofreu perda progressiva significante no período do estudo. No entanto, no grupo Controle, o IC de $95 \%$ dos mesmos parâmetros incluiu o valor zero, o que sugere que não houve progressão significante nesse grupo. Para todos os parâmetros investigados, $\mathrm{O}$ valor $\mathrm{P}$ da interação Grupo $X$ Tempo foi estatisticamente significante $(P<5 \%$, modelo de efeitos lineares mistos), o que sugere que Casos (glaucoma e suspeitos) progrediram mais rapidamente que Controles (saudáveis).

Nota-se que a taxa de progressão do MD do 10-2 foi mais negativa (isto é, mais distante da hipótese nula) do que o MD do 24-2, ao mesmo tempo em que apresentaram menores variâncias dos resíduos. Nota-se ainda que os parâmetros estruturais apresentaram menores variâncias de resíduos relativamente ao intervalo dinâmico de suas medidas quando comparados aos parâmetros funcionais.

Estes achados sugerem, pelo menos potencialmente, uma melhor performance na detecção de progressão glaucomatosa utilizando-se medidas da perimetria acromática 10-2 e OCT da CCGR. Esta hipótese será testada de forma mais sistemática no Objetivo 3 por meio de modelos de simulação que permitam ajustar para especificidades, frequência de testes e tempo de seguimento. 
Tabela 2 - Taxa de progressão dos diferentes parâmetros estruturais e funcionais no decorrer do estudo

\begin{tabular}{|c|c|c|c|c|c|}
\hline Parâmetros & Casos & Controles & $\begin{array}{l}90 \% \text { do } \\
\text { intervalo } \\
\text { dinâmico }\end{array}$ & $\begin{array}{l}\text { Variância } \\
\text { dos } \\
\text { resíduos }\end{array}$ & $\begin{array}{c}\text { Variância } \\
\text { dos } \\
\text { resíduos/ } \\
90 \% \\
\text { intervalo } \\
\text { dinâmico }\end{array}$ \\
\hline $\begin{array}{l}\text { MD 24-2 } \\
\text { (dB/ano) }\end{array}$ & $\begin{array}{c}-0,20 \\
(-0,31 \text { a }-0,10)\end{array}$ & $\begin{array}{c}-0,04 \\
(-0,09 \text { a } 0,01)\end{array}$ & $-5,2$ a 1,4 & 0,77 & 0,11 \\
\hline $\begin{array}{l}\text { MD 10-2 } \\
\text { (dB/ano) }\end{array}$ & $\begin{array}{c}-0,37 \\
(-0,55 a-0,19)\end{array}$ & $\begin{array}{c}-0,02 \\
(-0,15 \text { a } 0,11)\end{array}$ & $-6,5$ a 1,0 & 0,68 & 0,09 \\
\hline $\begin{array}{c}\text { Espessura da } \\
\text { CFNR } \\
\text { (micra/ano) }\end{array}$ & $\begin{array}{c}-0,68 \\
(-1,00 \text { a }-0,35)\end{array}$ & $\begin{array}{c}0,81 \\
(-0,20 \text { a } 1,8)\end{array}$ & 54,6 a 110,9 & 3,20 & 0,05 \\
\hline $\begin{array}{c}\text { Espessura da } \\
\text { CCGR } \\
\text { (micra/ano) }\end{array}$ & $\begin{array}{c}-0,20 \\
(-0,31 \text { a }-0,08)\end{array}$ & $\begin{array}{c}0,10 \\
(-0,05 \text { a } 0,25)\end{array}$ & 19,9 a 34,1 & 0,18 & 0,01 \\
\hline
\end{tabular}

(Os valores em parênteses correspondem ao intervalo de confiança de 95\% da média). 
5.2 Objetivo 2: Avaliar a taxa de progressão glaucomatosa combinando-se parâmetros convencionais e otimizados para mácula para detecção de progressão glaucomatosa, bem como a combinação de parâmetros estruturais e funcionais em uma abordagem Bayesiana

\subsubsection{Análise frequentista}

Quando se definiu progressão funcional pela presença de MD com slope negativo e $\mathrm{P}<5 \%$ no Grupo Caso, 16 olhos (13,9\%) progrediram no 24-2 e 23 (20,0\%) no 10-2. Ao definir-se pela progressão no 24-2 ou 10-2, este número foi 28 olhos (24,3\%). No Grupo Controle (como estimativa de resultados falso-positivos), estes valores foram 4 (8,1\%), 7 (14,2\%) e 8 olhos $(16,3 \%)$.

Usando-se as definições semelhantes para dados estruturais (slope negativo e $\mathrm{P}<5 \%$ ), 23 olhos (20,0\%) progrediram na CFNR e $14(12,1 \%)$ na CCGR. Ao definir-se pela progressão na CFNR ou CCGR, o número foi 26 olhos (22,6\%). No Grupo Controle, estes valores foram 6 (12,2\%), $3(6,1 \%)$ e 7 (14,2\%). Nota-se, portanto, que a combinação de parâmetros convencionais e otimizados para a região macular aumentou a sensibilidade, mas ao custo de piora da especificidade neste tipo de análise.

Os dados da Tabela 3 mostram os valores da taxa progressão utilizando-se os parâmetros combinados funcionais (MD do 24-2 + MD do 10-2, ou Função Combinada) e estruturais (espessura da CFNR + espessura da CCGR macular, ou Estrutura Combinada), conforme descrita na Metodologia. Em ambas as análises, diferenças de taxas de progressão de Casos e Controles foram estatisticamente significantes ( $P<5 \%$, modelo de efeitos lineares mistos).

Nota-se uma redução na variância dos resíduos relativamente ao intervalo dinâmico das novas medidas quando comparados aos parâmetros individuais (Tabela 2). 
Nas análises acima, algumas das limitações são o curto intervalo de seguimento e um tamanho de amostra relativamente pequeno. Estas limitações resultam em intervalos de confiança amplos, além de baixo poder estatístico para se detectar diferenças entre os métodos (que, portanto, não foram testadas neste momento). Além disso, em razão da falta de um padrão-ouro para se definir progressão glaucomatosa, as proporções acima observadas não podem ser adequadamente comparadas sem uma análise de especificidade pareada. Enquanto a avaliação de indivíduos saudáveis permite acessar taxas de resultados falso-positivos para fins diagnósticos, ela não é adequada para avaliação de resultados falso-positivos no que se refere à progressão (os valores fornecidos acima tiveram fins descritivos). Para uma adequada avaliação de progressão, é necessário um grupo de pacientes (Casos) sabidamente estáveis no decorrer do seguimento. Tal definição é, portanto, dependente de um padrão-ouro do qual não se dispõe em glaucoma. Para superar estas limitações, modelos de simulação computacional foram aplicados para se comparar os diferentes métodos no presente estudo (Objetivo 3).

Tabela 3 - Taxa de progressão dos diferentes parâmetros estruturais e funcionais combinados no decorrer do estudo

\begin{tabular}{|c|c|c|c|c|c|}
\hline Parâmetros & Casos & Controles & $\begin{array}{l}90 \% \text { do } \\
\text { intervalo } \\
\text { dinâmico }\end{array}$ & $\begin{array}{l}\text { Variância } \\
\text { dos } \\
\text { resíduos }\end{array}$ & $\begin{array}{c}\begin{array}{c}\text { Variância } \\
\text { dos }\end{array} \\
\text { resíduos/ } \\
90 \% \\
\text { intervalo } \\
\text { dinâmico }\end{array}$ \\
\hline $\begin{array}{l}\text { Função } \\
\text { Combinada } \\
\text { (dB/ano) }\end{array}$ & $\begin{array}{c}-0,22 \\
(-0,30 a-0,15)\end{array}$ & $\begin{array}{c}-0,05 \\
(-0,10 \text { a } 0,01)\end{array}$ & $-4,2$ a 1,3 & 0,45 & 0,08 \\
\hline $\begin{array}{l}\text { Estrutura } \\
\text { Combinada } \\
\text { (U/ano) }\end{array}$ & $\begin{array}{c}-0,04 \\
(-0,07 \text { a }-0,02)\end{array}$ & $\begin{array}{c}0,02 \\
(-0,01 \text { a } 0,04)\end{array}$ & $-3,2$ a 0,1 & 0,01 & 0,001 \\
\hline
\end{tabular}

(Os valores em parênteses correspondem ao intervalo de confiança de 95\% da média). 


\subsubsection{Análise Bayesiana}

Os dados da Tabela 4 sumarizam os resultados da análise multivariada Bayesiana, incluindo os quatro parâmetros em estudo, bem como o resultado ao analisar-se a perimetria acromática 24-2 isoladamente. Nota-se que a taxa de progressão do MD do 24-2 foi mais negativa (isto é, mais distante da hipótese nula) na análise multivariada do que univariada, sugerindo que a análise do 24-2, isoladamente, subestimou a taxa de progressão glaucomatosa quando comparada à combinação de parâmetros estruturais e funcionais. Para se determinar qual das abordagens seria mais correlacionada à "real", observa-se que o DIC foi menor quando houve combinação de parâmetros do que o 24-2 isoladamente, o que sugere que o primeiro teve melhor goodness-of-fit e, portanto, deve refletir melhor 0 estado "real" de progressão da população em estudo.

Tabela 4 - Taxa de progressão dos diferentes parâmetros estruturais e funcionais combinados no decorrer do estudo

\begin{tabular}{|c|c|c|c|c|c|c|}
\hline & & \multirow{2}{*}{$\begin{array}{l}\text { Média } \\
\text { Posteriori }\end{array}$} & \multicolumn{2}{|c|}{$\begin{array}{c}\text { Intervalo de } \\
\text { credibilidade Bayesiano }\end{array}$} & \multirow[t]{2}{*}{$P$} & \multirow{2}{*}{ DIC } \\
\hline & & & $2,5 \%$ & $97,5 \%$ & & \\
\hline \multirow{2}{*}{ Multivariado } & $\begin{array}{l}\text { Intercept } \\
\text { (dB) }\end{array}$ & $-1,96$ & $-2,53$ & $-1,40$ & $<0,001$ & \\
\hline & $\begin{array}{c}\text { Slope } \\
\text { (dB/ano) }\end{array}$ & $-0,22$ & $-0,39$ & $-0,03$ & 0,026 & 1991,37 \\
\hline \multirow{2}{*}{ Univariado } & $\begin{array}{l}\text { Intercept } \\
\quad(\mathrm{dB})\end{array}$ & $-1,73$ & $-2,30$ & $-1,15$ & $<0,001$ & \\
\hline & $\begin{array}{c}\text { Slope } \\
\text { (dB/ano) }\end{array}$ & $-0,20$ & $-0,35$ & $-0,01$ & 0,04 & 2328,56 \\
\hline
\end{tabular}




\subsection{Objetivo 3: Testar a aplicabilidade da combinação de parâmetros convencionais e otimizados para mácula na prática clínica e ensaios clínicos randomizados por meio de um modelo de simulação computacional previamente descrito}

\subsubsection{Paradigmas clínicos}

Testou-se o poder (100\% - erro tipo 2) para detecção de progressão estatisticamente significante, após pareamento para especificidade, conforme a metodologia acima descrita. Os dados das Tabelas 5 e 6 mostram o número de olhos com progressão perimétrica, confirmada no decorrer do tempo de seguimento de 5 anos no modelo de simulação em que os exames foram realizados a cada 4 ou 6 meses, respectivamente. Como esperado, o poder de detecção aumenta à medida que mais testes são realizados no decorrer do tempo. Nota-se ainda que a perimetria 10-2 apresentou maior sensibilidade que a perimetria 24-2. Por sua vez, a Função Combinada foi mais sensível que as duas modalidades analisadas isoladamente.

Baseado em uma frequência de exames a cada 6 meses, o tempo médio para detecção de progressão funcional de 0,50 dB/ano (considerada clinicamente significante segundo De Moraes et al. ${ }^{(95)}$ ) para um poder estatístico de 80 e $90 \%$, usando-se o MD do 24-2, foi de 5,2 e 5,8 anos; com 10-2 foi 4,6 e 5,2 anos; com a Função Combinada foi 3,8 e 4,5 anos, respectivamente.

Resultados semelhantes foram observados com os dados estruturais (Tabelas 7 e 8). Baseado em uma frequência de exames a cada 6 meses, o tempo médio para deteç̧ão de progressão estrutural correspondente àquela observada na perimetria com poder estatístico de $80 \%$ e $90 \%$, usando-se a espessura da CFNR peripapilar foi 4,4 e 4,8 anos; com CCGR macular foi 3,5 e 3,8 anos; com a Função Combinada foi 2,9 e 3,3 anos, respectivamente. 
De modo geral, as medidas do OCT detectariam progressão com maior poder estatístico que as médias correspondentes na perimetria acromática; para um mesmo poder estatístico, a progressão seria detectada, em média, de 6 a 12 meses antes com OCT do que com a perimetria, com um efeito ainda mais pronunciado com parâmetros combinados. Vale ressaltar que os resultados acima são ajustados para especificidade, o que adiciona informação aos resultados descritos na análise frequentista do Objetivo 2. 
Tabela 5 - Poder estatístico para detecção de progressão funcional confirmada (duas visitas consecutivas) em olhos seguidos a cada 4 meses

\begin{tabular}{cccccc}
\hline & $\begin{array}{c}\text { Taxa de } \\
\text { progressão } \\
\text { (dB/ano) }\end{array}$ & 2 & 3 & 4 & 5 \\
\hline \multirow{2}{*}{$24-2$} & $-0,25$ & 4,69 & 10,18 & 20,06 & 36,38 \\
& $-0,5$ & 11,92 & 33,93 & 66,7 & 91,39 \\
& $-1,0$ & 42,94 & 89,84 & 99,84 & 100,00 \\
& $-0,25$ & 4,84 & 10,91 & 22,46 & 40,34 \\
& $-0,5$ & 13,63 & 38,4 & 72,7 & 94,7 \\
& $-1,0$ & 48,55 & 93,38 & 100,00 & 100,00 \\
& $-0,25$ & 7,14 & 18,28 & 37,24 & 62,78 \\
& $-0,5$ & 22,78 & 61,53 & 92,17 & 99,72 \\
& $-1,0$ & 72,42 & 99,48 & 100,00 & 100,00 \\
\hline
\end{tabular}

Tabela 6 - Poder estatístico para detecção de progressão funcional confirmada (duas visitas consecutivas) em olhos seguidos a cada 6 meses

\begin{tabular}{cccccc}
\hline & $\begin{array}{c}\text { Taxa de } \\
\text { progressão } \\
\text { (dB/ano) }\end{array}$ & 2 & 3 & 4 & 5 \\
\hline $24-2$ & $-0,25$ & 3,85 & 7,55 & 14,69 & 26,48 \\
(dB/ano) & $-0,5$ & 9,85 & 25,82 & 52,09 & 79,74 \\
& $-1,0$ & 34,59 & 78,88 & 98,37 & 99,99 \\
$10-2$ & $-0,25$ & 3,92 & 7,96 & 15,71 & 28,76 \\
(dB/ano) & $-0,5$ & 10,59 & 28,29 & 56,08 & 83,94 \\
& $-1,0$ & 37,31 & 82,4 & 99,01 & 99,99 \\
Função Combinada & $-0,25$ & 5,75 & 12,88 & 26,94 & 47,71 \\
(dB/ano) & $-0,5$ & 17,54 & 47,17 & 81,2 & 97,61 \\
& $-1,0$ & 59,08 & 96,51 & 100,00 & 100,00 \\
\hline
\end{tabular}


Tabela 7 - Poder estatístico para detecção de progressão estrutural confirmada (duas visitas consecutivas) em olhos seguidos a cada 4 meses

\begin{tabular}{cccccc}
\hline & Taxa de progressão & \multicolumn{4}{c}{ Tempo (anos) } \\
& & 2 & 3 & 4 & 5 \\
\hline CFNR & $-0,65$ & 5,74 & 13,79 & 29,82 & 53,21 \\
(micra/ano) & $-1,3$ & 15,78 & 45,81 & 82,98 & 98,21 \\
& $-2,6$ & 57,4 & 97,21 & 99,99 & 100,00 \\
CCGR & $-0,2$ & 9,06 & 23,59 & 49,62 & 77,18 \\
(micra/ano) & $-0,4$ & 30,01 & 75,34 & 97,81 & 99,98 \\
& $-0,8$ & 85,48 & 99,95 & 100,00 & 100,00 \\
Estrutura Combinada & $-0,03$ & 12,34 & 34,78 & 68,33 & 92,31 \\
(U/ano) & $-0,06$ & 45,28 & 90,65 & 99,87 & 100,00 \\
& $-0,12$ & 96,19 & 100,00 & 100,00 & 100,00 \\
\hline
\end{tabular}

Tabela 8 - Poder estatístico para deteç̧ão de progressão estrutural confirmada (duas visitas consecutivas) em olhos seguidos a cada 6 meses

\begin{tabular}{cccccc}
\hline & Taxa de progressão & \multicolumn{4}{c}{ Tempo (anos) } \\
& & 2 & 3 & 4 & 5 \\
\hline CFNR & $-0,65$ & 4,41 & 10,19 & 20,41 & 36,65 \\
(micra/ano) & $-1,3$ & 12,77 & 36,05 & 68,94 & 92,52 \\
& $-2,6$ & 45,98 & 90,94 & 99,83 & 100,00 \\
CCGR & $-0,2$ & 14,15 & 25,33 & 43,53 & 67,25 \\
(micra/ano) & $-0,4$ & 33,12 & 67,27 & 93,36 & 99,68 \\
& $-0,8$ & 78,88 & 99,61 & 100,00 & 100,00 \\
Estrutura Combinada & $-0,03$ & 16,07 & 32,89 & 58,07 & 83,25 \\
(U/ano) & $-0,06$ & 41,35 & 82,5 & 99,11 & 100,00 \\
& $-0,12$ & 90,55 & 99,98 & 100,00 & 100,00 \\
\hline
\end{tabular}




\subsubsection{Paradigma de um ensaio clínico randomizado}

Investigou-se o tamanho de amostra necessário para se detectar o efeito de $30 \%$ nas taxas de progressão dos diferentes parâmetros funcionais (MD do 24-2, MD do 10-2, e Função Combinada) em um estudo de 2 anos com aglomerados de testes do início e final do estudo (conforme "Wait-andSee Aproach" (92)). Os dados da Tabela 9 mostram os resultados referentes ao número mínimo de pacientes por grupo (em desenho balanceado 1 para 1) para um poder estatístico de $80 \%$ ou $90 \%$.

Nota-se que, para uma população com características similares a deste estudo (i.e.: suspeitos de glaucoma ou glaucomatosos com dano funcional inicial), o uso do MD do 10-2 como endpoint requer um número menor de pacientes do que o 24-2, mesmo com especificidades pareadas. Além disso, a combinação de parâmetros funcionais permitiria reduzir esses números em $10 \%$ a $20 \%$ em estudo com duração relativamente curta, desde que seguindo a frequência de testes aqui definida. Por exemplo, para um poder estatístico de 90\%, o número mínimo necessário de olhos/pacientes por grupo (tratamento versus placebo) seria 230, 180 e 160 para o MD do 24-2, 10-2, e Função Combinada, respectivamente.

Tabela 9 - Tamanho mínimo da amostra por grupo para atingir poder estatístico de $80 \%$ e $90 \%$ em um ensaio clínico randomizado com efeito de $30 \%$ na taxa de progressão e erro tipo 1 de $5 \%$

\begin{tabular}{ccc}
\hline & $80 \%$ & $90 \%$ \\
\hline $24-2$ & 170 & 230 \\
$10-2$ & 110 & 180 \\
Função Combinada & 100 & 160 \\
\hline
\end{tabular}




\section{DISCUSSÃO}

O presente estudo teve por objetivos: (i) avaliar a taxa de progressão, utilizando-se parâmetros convencionais e otimizados para mácula; (ii) avaliar a taxa de progressão combinando-se parâmetros convencionais e otimizados para mácula; (iii) testar a aplicabilidade da combinação de parâmetros convencionais e otimizados para mácula na prática clínica e ensaios randomizados por meio de um modelo de simulação computacional previamente descrito.

Com base nos resultados aqui descritos: (i) pacientes com ou suspeitos de glaucoma progridem a taxas de progressão estrutural e funcional mais rápidas que aquelas observadas em indivíduos saudáveis, mesmo durante um tempo de seguimento relativamente curto, o que foi consistente, tanto ao utilizar-se parâmetros convencionais como aqueles otimizados para mácula; além disso, parâmetros otimizados para mácula exibiram variâncias de resíduos menores relativamente ao intervalo dinâmico; (ii) a combinação dos parâmetros convencionais e otimizados para mácula confirmou as diferenças nas taxas de progressão entre pacientes com ou suspeitos de glaucoma e indivíduos saudáveis ao mesmo tempo que reduziu ainda mais a variância dos resíduos observados na regressão linear; além disso, um modelo Bayesiano que combina dados estruturais e funcionais melhorou a acurácia da medida de taxa de progressão da perimetria 24-2, atualmente considerada o padrão de referência para avaliação de progressão funcional; e (iii) modelos de simulação computacional demonstraram maior sensibilidade dos parâmetros estruturais e funcionais otimizados para mácula em relação aos parâmetros convencionais na detecção de progressão glaucomatosa, mesmo após ajuste para especificidade e levando-se em consideração diferentes frequências de exames; estes resultados foram aprimorados ao se combinar os parâmetros otimizados para mácula com os parâmetros 
convencionalmente usados na prática clínica, sugerindo ainda sua potencial utilidade no desenho de ensaios clínicos randomizados em glaucoma.

Estudos comparando exames estruturais e funcionais (maculares ou não) são escassos até o presente o momento. No estudo AIGS, os autores relataram uma melhor performance de parâmetros estruturais (CNFR peripapilar e CCGR macular) que funcionais (MD do 24-2) na detecção de progressão em indivíduos com glaucoma inicial ${ }^{(71)}$. Em pacientes do Estudo de Tratamento do Glaucoma no Reino Unido (do inglês United Kingdom Glaucoma Treatment Study [UKGTS]), Garway-Heath et al. (96) relataram que métodos que combinam dados de perimetria acromática e OCT identificaram progressão mais precoce do que métodos baseados na perimetria isoladamente, além de resultarem em estimativas mais precisas da taxa de progressão. Abe et al. (97) avaliaram uma coorte com 462 olhos com glaucoma em diferentes estágios da doença e 62 controles seguidos por um tempo médio de 3,8 anos e concluíram que, em olhos com doença menos avançada, progressão foi detectada com maior frequência na CFNR do OCT do que no MD da perimetria acromática 24-2; com o piora na gravidade da doença, progressão foi detectada com maior frequência na perimetria 24-2 que no OCT. Para cada $1 \mathrm{~dB}$ mais positivo no MD, houve um aumento de $5 \%$ na chance de se detectar progressão por OCT do que pela perimetria 24-2 (97). Embora haja resultados concordantes entre os estudos acima e o presente no que se refere às vantagens do OCT, este foi o primeiro a incorporar dados maculares (estruturais e funcionais) na avaliação de progressão glaucomatosa de forma prospectiva e longitudinal.

Susanna et al. ${ }^{(35)}$ descreveram as causas mais relevantes que levam à cegueira por glaucoma no mundo, entre elas (i) o não diagnóstico ou diagnóstico tardio da doença e (ii) avaliação inadequada da taxa de progressão. O presente projeto aborda ambas as causas de forma direta ou indireta. Primeiro, conforme demonstrado por vários autores utilizando-se dados transversais $(12,13,28)$, incluindo-se estudos realizados por De Moraes e colaboradores que serviram de premissa para o presente estudo $(8,11,26,27$, 31), o uso exclusivo de perimetria acromática 24-2 e OCT de CFNR 
peripapilar pode levar a não detecção de dano funcional e estrutural na mácula. Por exemplo, De Moraes et al. (31) demonstraram que a perimetria 24-2 pode não detectar lesão funcional e estrutural na mácula em até $70 \%$ dos pacientes considerados suspeitos de glaucoma ou portadores de glaucoma inicial. A detecção de dano funcional central nesses pacientes não só altera seu diagnóstico (de suspeito ou pré-perimétrico para glaucoma manifesto), como também os classifica como tendo defeito avançado (30), com provável impacto em sua qualidade de vida (18-20). A avaliação inadequada da taxa de progressão pode levar ao tratamento insuficiente ou excessivo, ambos com importante repercussão clínica. A inclusão da perimetria acromática 10-2 e OCT da CCG macular no seguimento podem, potencialmente, fornecer uma melhor estimativa da velocidade de progressão estrutural e funcional. Por sua vez, esta combinação de exames poderá fornecer dados mais objetivos que auxiliem na decisão de tratamento clínico ou cirúrgico. Finalmente, medidas mais precisas de progressão que incluam a avaliação estrutural e funcional da mácula possam auxiliar no desenho de futuros ensaios clínicos testando-se novas modalidades terapêuticas no glaucoma. A mácula concentra mais de $30 \%$ de todas as células da CCGR, apesar de corresponder a uma área relativamente pequena ( $2 \%$ da retina) ${ }^{(15)}$. Esta alta densidade de células neurais, que podem ser avaliadas do ponto de vista funcional e estrutural, não têm outro equivalente em medicina, daí seu potencial foco em neuroproteção ${ }^{(95)}$. Com o crescente interesse em novas terapias neuroprotetoras, a avaliação macular poderá se mostrar útil na definição de taxas de progressão, auxiliando no cálculo da amostra e do tempo necessário de seguimento em ensaios clínicos. Com a redução de custos, estes ensaios clínicos poderão se tornar mais frequentes e com potencial aceleração do desenvolvimento de novas drogas (com efeito hipotensor ou não) efetivas para tratamento do glaucoma. Com melhor habilidade de deteç̧ão da doença, métodos mais sensíveis e específicos para monitorização de progressão e novas formas de terapia, a taxa de cegueira por glaucoma no mundo poderia ser significativamente reduzida ${ }^{(35)}$. 
Uma forma de se avaliar a generalização dos presentes resultados é compará-los a outros estudos que adotaram metodologia semelhante. Em relação ao MD do 24-2, Wu et al. (49) encontraram que o tempo necessário para se detectar progressão estatisticamente significante em pacientes progredindo a $-0,50 \mathrm{~dB} /$ ano testados a cada 6 meses com poder de $80 \%$ e $90 \%$ foi 5,7 e 6,5 anos. No presente estudo, encontrou-se 5,2 e 5,8. Para taxas de progressão mais rápidas (-1,00 dB/ano), Wu et al encontraram 3.6 e 4.2 anos, mas o presente estudo mostrou 3,2 e 3,9 anos, respectivamente. Embora seja uma diferença pequena, esta poderia ser em razão do fato de que os pacientes examinados no presente estudo possuírem glaucoma com dano funcional inicial (MD melhor que $-6 \mathrm{~dB}$ ), os quais sabidamente têm menor variabilidade de testes funcionais. O estudo de Wu et al. (49) incluiu olhos com dano até $-15 \mathrm{~dB}$ no MD do 24-2, nos quais a detecção de progressão funcional pode ser mais demorada pela maior variabilidade ${ }^{(41)}$. Referente ao MD do 10-2 em uma população diferente à do estudo anterior, agora testada com 24-2 e 10-2 no mesmo dia e com severidades semelhantes ao do presente estudo, Wu et al. (34) encontraram que, em pacientes progredindo a $-0,50 \mathrm{~dB} /$ ano testados a cada 6 meses, progressão significante pode ser detectada em 4,5 e 5,0 anos com poder de $80 \%$ e $90 \%$, respectivamente. Estes valores foram bastante semelhantes aos do presente estudo (4,6 e 5,2 anos). No entanto, os autores não avaliaram os resultados do 24-2 global, que seriam necessários para a comparação direta entre os estudos. Em outro estudo de Wu e Medeiros ${ }^{(93)}$, avaliando o tamanho da amostra necessário para um ensaio clínico randomizado sob frequência de testes semelhantes à atual (16 testes em 2 anos), para um efeito do tratamento de $30 \%$, os autores encontraram um mínimo de 237 pacientes/olhos por grupo; o presente estudo encontrou 230 pacientes/olhos. Mais uma vez, a diferença pode ser decorrente das diferenças em severidade das populações estudadas e seu impacto na variabilidade perimétrica. Não há, até o momento, estudos que permitam a comparação desses números, usando-se o MD do 10-2 ou parâmetros derivados do OCT 
(peripapilares ou maculares) para fins de comparação, sendo a presente análise a primeira a abordar este tema.

Uma potencial implicação dos presentes resultados refere-se ao desenvolvimento de novas estratégias perimétricas incorporando mais pontos centrais à grade do 24-2. Embora muitos pesquisadores e clínicos concordem com a importância de se avaliar a mácula mesmo no glaucoma inicial ou suspeito, dificuldades práticas e logísticas impedem sua ampla utilização. Exames de perimetria acromática são, em geral, demorados e altamente dependentes do estado de atenção do paciente. A realização de exame 24-2 e 10-2 no mesmo dia ou em dias próximos tem grande peso aos pacientes, bem como ao médico e sistema de saúde. Wu et al. (34) demonstraram que a perimetria 10-2 pode detectar progressão entre 4 e 7 meses antes que a região central do 24-2, mas discutiram que esse benefício talvez não seja justificável do ponto de vista socioeconômico. A nova estratégia 24-2-C, a ser em breve disponibilizada no mercado brasileiro (mas já disponível nos Estados Unidos da América), foi baseada em estudos transversais para diagnóstico de dano macular $(8,12-14)$ e adiciona mais 10 pontos aos 10 graus centrais do 24-2 (Figura 11). O uso desta estratégia pode ser uma alternativa para os desafios acima descritos. No entanto, futuros estudos ainda são necessários para se determinar sua performance em relação aos exames 24-2 e 10-2 (isolados ou em associação).

O presente estudo apresenta limitações que devem ser levadas em consideração. Primeiro, não se pode extrapolar os resultados funcionais e estruturais a pacientes com perda funcional mais severa, uma vez que os critérios de inclusão aqui aplicados exigiram MD melhor que -6 dB. É possível que as medidas de variabilidade, tanto da perimetria como do OCT sejam maiores (e talvez mais significativas para detecção de progressão) em pacientes com MD mais severo, conforme comparações com os estudos descritos acima $(34,49,93)$. O tempo de seguimento aqui também foi relativamente curto. Uma determinação de taxas de progressão e variabilidade mais próximas às "reais" (seja para estimação empírica ou 
modelo de simulação) beneficiar-se-ia de tempo de seguimento mais longo com essas modalidades de exames.

Nota-se também que a diferença de idade média de indivíduos Controle e Casos foi estatisticamente significante, com uma diferença média de 30 anos. Apesar de diferenças de idade serem relevantes para fins diagnósticos (uma vez que a comparação com bancos de dados normativos ser com frequência pareada para grupo etário), não se sabe qual seu papel na comparação de taxas de progressão, sejam elas estruturais e funcionais. Mais importante, o foco principal do presente estudo foi a comparação da performance de exames realizados nos mesmos indivíduos, no mesmo intervalo de tempo, sob mesma frequência; portanto, para efeitos comparativos no mesmo indivíduo, o efeito da idade é insignificante. 
A

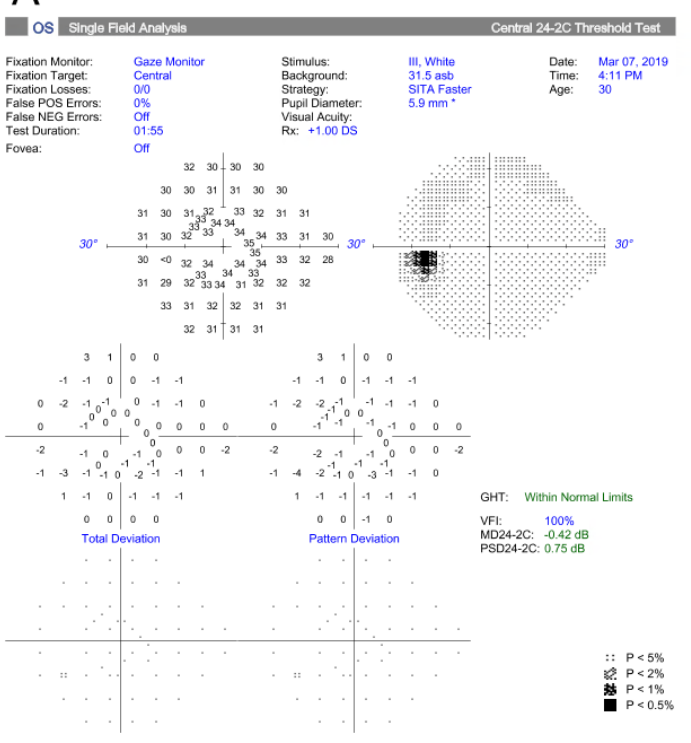

C

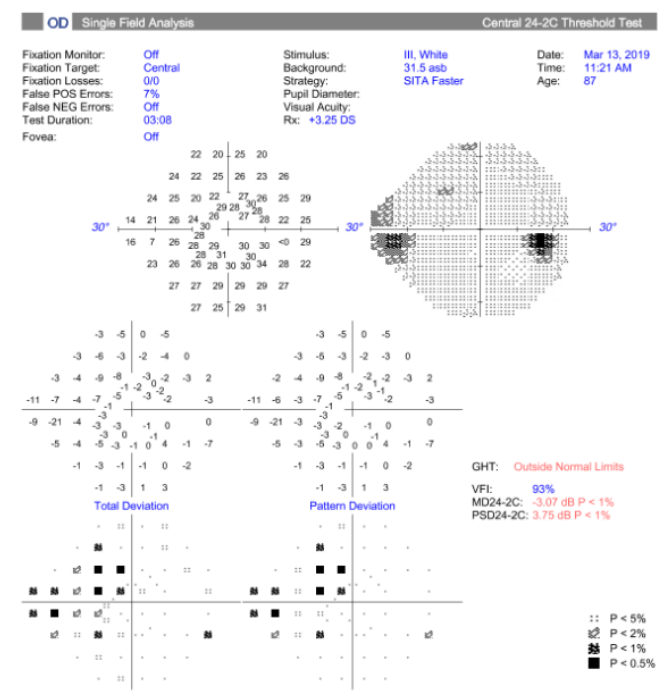

B

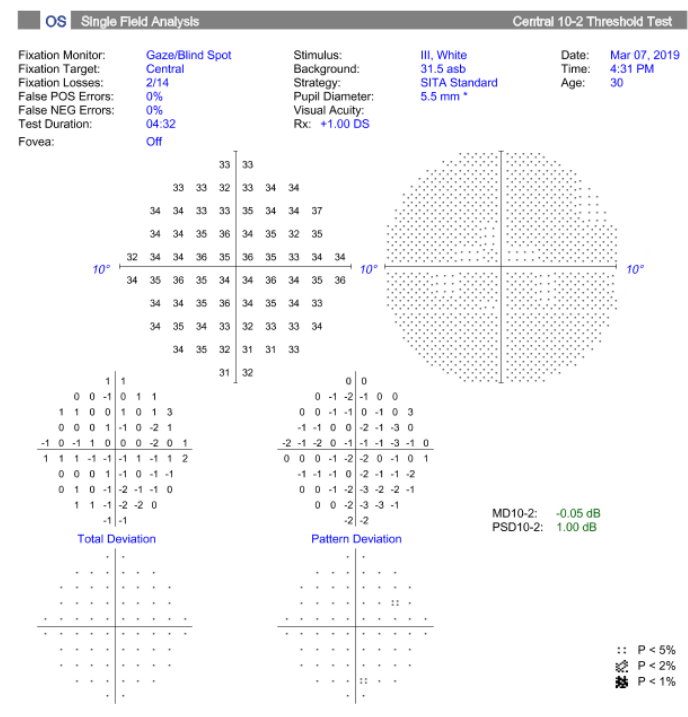

$\mathrm{D}$

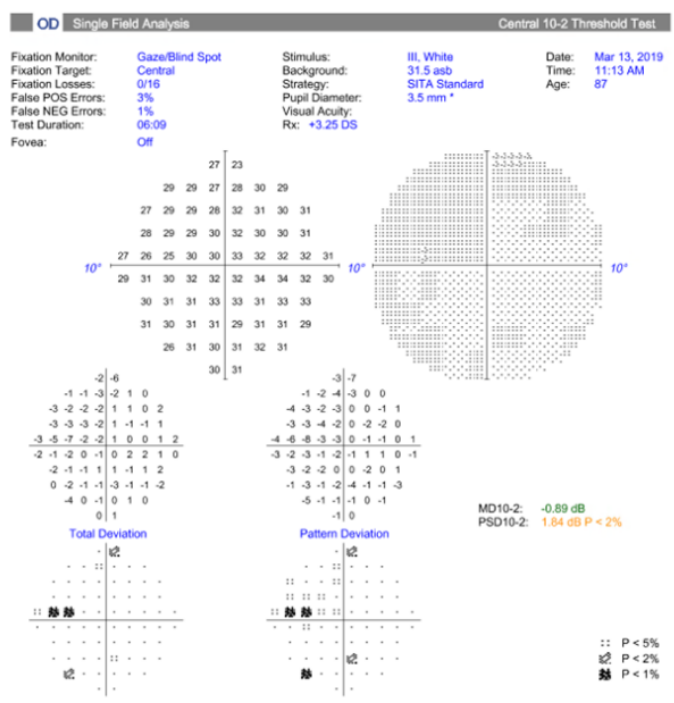

Figura 11 - A) Perimetria 24-2C de um olho saudável; B) Perimetria 10-2 do mesmo olho em A), confirmando ausência de anormalidades na região macular. C) Perimetria 24-2C de um olho com glaucoma; D) Perimetria 10-2 do mesmo olho em $\mathrm{C}$ ), confirmando anormalidades na região paracentral superior

Outro fator que limita a extrapolação destes achados relaciona-se à distribuição racial de nossa amostra. Um estudo comparativo de indivíduos de raça negra e branca demonstrou que, mesmo em indivíduos saudáveis, 
aqueles de raça negra apresentavam maior variabilidade de parâmetros de perimetria 24-2 (98). Este efeito foi, recentemente, demonstrado como capaz de afetar a capacidade de detecção da progressão funcional em indivíduos de raça negra, como detecção significativamente mais tardia ${ }^{(99)}$. Nossa amostra talvez não tivesse o poder suficiente de testar esta relação e seu efeito na detecção de progressão se os grupos raciais fossem analisados separadamente.

Outro ponto de importância é que, tanto o presente projeto (análise de progressão) como o trabalho anterior de De Moraes e colaboradores (focado no diagnóstico) $(8,11,27,31)$ não visam a substituir as medidas convencionais de estrutura (CFNR peripapilar) e função (perimetria 24-2). Estas devem ser vistas como medidas complementares. Há, no entanto, conhecimento intuitivo (também baseado em estatística) que, quanto maior o número de exames realizados, maior será a sensibilidade, seja para diagnóstico ou detecção de progressão. No entanto, esse aumento vem às custas de uma redução da especificidade. Este é um dos motivos que clínicos deveriam evitam solicitar exames em excesso para manejo de doenças crônicas, como o glaucoma. Nota-se, por exemplo, na análise frequentista do Objetivo 2 um número alto (e até inaceitável) de resultados falso-positivos resultantes da simples adição de exames otimizados para mácula. Ao se solicitar mais exames complementares (em adição aos convencionais 24-2 e fotografia de disco óptico), corre-se o risco de tratar pacientes que não têm glaucoma ou que não estão progredindo significativamente. $O$ efeito desse erro pode ser tão grave quanto o não diagnóstico da doença ou de sua progressão do ponto de vista de saúde pública. Os resultados aqui apresentados sugerem, no entanto, que do ponto de vista estatístico, o benefício de se combinar a avaliação macular aos exames convencionais (funcionais e estruturais) excede aquele decorrente do aumento de resultados falso-positivos. Ainda, a combinação de parâmetros estruturais e funcionais (aqui testados com abordagem Bayesiana) também sugere o benefício de se combinar OCT (macular e peripapilar) e a perimetria (24-2 e 10-2). Quanto ao OCT, por exemplo, a varredura macular adiciona, aproximadamente, 2 minutos na 
duração do exame, mas fornece, por sua vez, informação importante para diagnóstico e seguimento. Quanto à perimetria 10-2, no entanto, a fadiga pode representar uma limitação para sua realização na mesma visita que a perimetria 24-2. Não obstante, conforme discutido acima em relação às novas estratégias perimétricas com maior densidade de pontos no campo central (24-2C), esta limitação deverá ser superada em breve, o que poderá tornar a discussão sobre o uso da perimetria 24-2 versus 10-2 irrelevante no futuro próximo.

Deve-se considerar também que a combinação de exames nas mãos de especialistas é feita de forma diferente daquela baseada em índices sumários (como MD e CFNR). Especialistas procuram por padrões de defeito de forma topográfica que permitam distinguir resultados falsopositivos de casos de progressão real. O uso de exames otimizados para mácula tem óbvias vantagens para avaliação dessa importante área da retina, mas também por razões óbvias não permite a avaliação de áreas extramaculares onde o dano glaucomatoso, frequentemente, se inicia e pode progredir ${ }^{(100)}$. A disponibilidade de mapas funcionais e estruturais completos (combinando mácula e áreas extramaculares) permite ao clínico analisar a presença de dano glaucomatoso e sua progressão de forma mais completa e minimizando a ocorrência de resultados falso-positivos. Portanto, não só do ponto de vista estatístico, mas também do ponto de vista prático, há vantagens de se combinar abordagens convencionais àquelas otimizadas para a região macular.

Para prática clínica e em saúde pública, entretanto, futuros estudos avaliando o custo benefício da adição desses exames ainda são necessários antes de sua ampla aplicação. Por exemplo, um bom treinamento na avaliação do disco óptico em fotografias e na avaliação da perimetria 24-2 podem ter impacto semelhante ou até superior, do ponto de vista socioeconômico, aos aqui demonstrados uma vez levado em consideração o custo desses exames adicionais. 
Outra informação relevante descrita no presente estudo - e consistente com a literatura - é que a maior parte dos pacientes com ou suspeitos de glaucoma progridem a taxas lentas quando tratados adequadamente ${ }^{(42,101)}$. Usando-se o MD do 24-2, por exemplo, a taxa de progressão foi menor que $-0,20 \mathrm{~dB} / \mathrm{ano}$ na maioria dos pacientes. A esta taxa, o paciente glaucomatoso médio deste estudo (67 anos de idade na visita basal e MD de -2,0 dB) levaria 60 anos para atingir um nível de severidade funcional de $-14 \mathrm{~dB}$ (considerado significante o suficiente para considerar o indivíduo desabilitado funcionalmente ${ }^{(60)}$ ) ou 100 anos para atingir cegueira legal (MD do 24-2 de $-22 \mathrm{~dB}$, conforme a Organização Mundial de Saúde) ${ }^{(60)}$. Um dos objetivos da pesquisa clínica em glaucoma é identificar pacientes em alto risco de progressão a taxas rápidas (exemplo, $1,00 \mathrm{~dB} /$ ano $\left.^{(41)}\right)$, para que na prática clínica tratamentos mais agressivos sejam oferecidos mais precocemente a esses pacientes, conforme sugerido por Susanna et al. ${ }^{(35)}$ Métodos para identificação desses pacientes foram sugeridos por De Moraes e Susanna (42) e serão o objetivo de futuras análises, usando-se o presente banco de dados.

Outra futura direção do presente projeto é incorporar informação topográfica (e não apenas índices globais) na avaliação de progressão estrutural e funcional do glaucoma. Por exemplo, Wang et al. (102) forneceram evidência de que a espessura topográfica (local) da CCGR correlaciona-se com a perda de sensibilidade em pacientes com glaucoma. Raza et al. (103) mostraram ainda uma boa concordância quantitativa entre a espessura da CCGR e a perda de sensibilidade, quando o deslocamento das CGR em relação aos fotorreceptores perto da fóvea foi levado em consideração (Figura 12). A incorporação de dados topográficos pode ser realizada por modelos estatísticos mistos em que cada dado local (como valores de TD ou setores na CCGR macular) é incorporado dentro de uma hierarquia que leva em consideração sua autocorrelação no decorrer do tempo. Modelos Bayesianos (como ANSWERS ${ }^{\left({ }^{80}\right)}$ ) também permitem esse tipo de análise ao mesmo tempo que ajustam para correlações entre estrutura e função por setores. No presente estudo, a escolha de índices globais foi decorrente de 
sua disponibilidade nos impressos comerciais dos aparelhos, facilitando-se, assim, a aplicação dos presentes resultados na prática clínica. Além disso, apesar de se perder informação espacial com sua utilização, índices globais têm por natureza uma menor variabilidade quando comparados a medidas pontuais ou regionais (45). $\mathrm{Na}$ prática, entretanto, recomenda-se a monitorização do glaucoma, tanto com índices globais como topográficos $(104,105)$. 


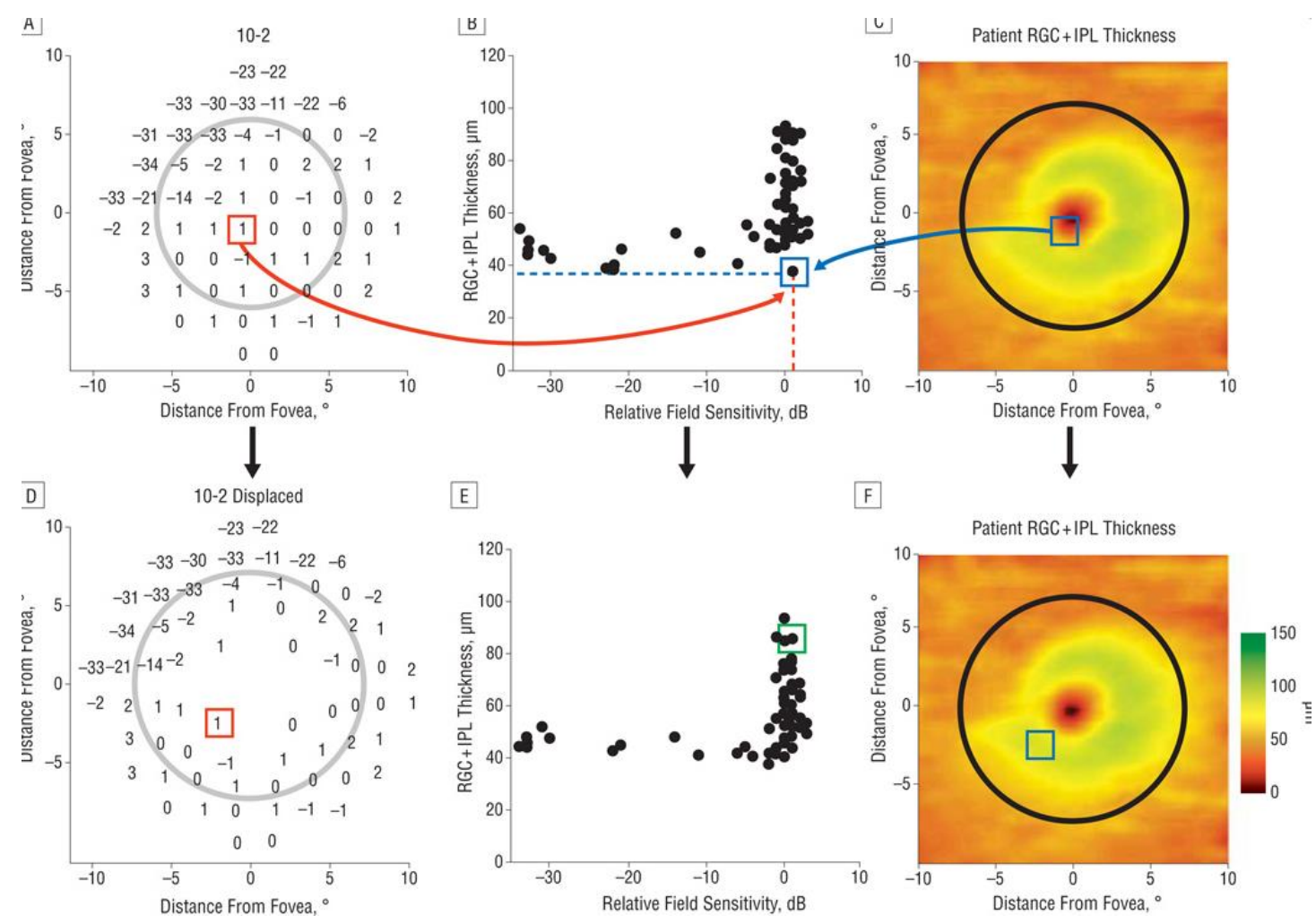

Fonte: Raza et al. (103)

Figura 12 - Estrutura-função na mácula. Um exemplo da relação estruturafunção de um paciente glaucomatoso, com uma ilustração da redução da variabilidade resultante do ajustamento para o deslocamento das células ganglionares da retina em relação aos fotorreceptores. A espessura (C) e a relação quantitativa entre todos os valores de desvio TD da perimetria 10-2 e a espessura da camada de células ganglionares + camada plexiforme externa (do inglês Retinal Ganglion Cell + Inner Plexiform [RGCP]) do paciente na região correspondente (B). Um ponto no campo visual nas coordenadas $x$, y de $1^{\circ},-1^{\circ}$ (quadrado vermelho) é mostrado com o ponto de dados correspondentes no gráfico função-estrutura (quadrado verde, parte E) e na posição correspondente na área (quadrado azul, parte B). Sem considerar o deslocamento espacial de células ganglionares, a relação entre espessura e sensibilidade é fraca (B). D-F) a relação melhora e o ponto no quadrado verde agora se encontra na distribuição dos valores da estruturafunção após a contabilização do deslocamento das células ganglionares

Em resumo, embora os resultados apresentados correspondam a uma amostra de indivíduos com dano glaucomatoso inicial e com curto tempo de seguimento, eles sugerem que a incorporação da avaliação macular na propedêutica de progressão do glaucoma tem vantagens além 
daquelas já descritas para seu diagnóstico. Além disso, sua combinação (incluindo-se dados estruturais e funcionais) pode auxiliar no manejo de pacientes com glaucoma de forma mais personalizada, com identificação mais precoce da progressão glaucomatosa, bem como uma potencial redução no custo de futuros ensaios clínicos testando novas intervenções para tratamento do glaucoma e prevenção de cegueira. 


\section{CONCLUSÕES}

(1) Parâmetros estruturais e funcionais otimizados para avaliação macular demonstraram performance superior àquela observada usando-se parâmetros convencionalmente utilizados na prática clínica;

(2) A combinação desses parâmetros demonstrou performance superior à de quando esses parâmetros (maculares ou não) foram avaliados isoladamente, mesmo após ajuste para taxa de resultados falsopositivos;

(3) Parâmetros estruturais derivados do OCT tiveram performance superior aos parâmetros funcionais derivados da perimetria acromática 24-2, mesmo após ajuste para taxa de resultados falso-positivos;

(4) Uma abordagem Bayesiana que incorpora estrutura e função pode melhorar a acurácia de medida da taxa de progressão funcional medida com o atual padrão de referência (perimetria acromática 24-2); e

(5) O uso de parâmetros estruturais ou funcionais otimizados para avaliação macular (ou sua combinação) pode aprimorar a performance para detecção da progressão glaucomatosa na prática clínica e em ensaios randomizados independente do aumento de resultados falsopositivos que se esperaria pela simples adição de mais exames complementares. 


\section{REFERÊNCIAS}




\section{REFERÊNCIAS}

1. Weinreb RN, Khaw PT. Primary open-angle glaucoma. Lancet. 2004;363(9422):1711-20.

2. Leske MC, Heijl A, Hyman L, Bengtsson B, Dong L, Yang Z. Predictors of long-term progression in the early manifest glaucoma trial. Ophthalmology. 2007;114(11):1965-72.

3. The Advanced Glaucoma Intervention Study (AGIS): 7. The relationship between control of intraocular pressure and visual field deterioration. The AGIS Investigators. Am J Ophthalmol. 2000;130(4):429-40.

4. Musch DC, Gillespie BW, Niziol LM, Lichter PR, Varma R. Intraocular pressure control and long-term visual field loss in the Collaborative Initial Glaucoma Treatment Study. Ophthalmology. 2011;118(9):1766-73.

5. The effectiveness of intraocular pressure reduction in the treatment of normal-tension glaucoma. Collaborative Normal-Tension Glaucoma Study Group. Am J Ophthalmol. 1998;126(4):498-505.

6. Gordon MO, Beiser JA, Brandt JD, Heuer DK, Higginbotham EJ, Johnson CA, et al. The Ocular Hypertension Treatment Study: baseline factors that predict the onset of primary open-angle glaucoma. Archives of Ophthalmology (Chicago, III : 1960). 2002;120(6):714-20; discussion 829-30.

7. Heijl A. Studies on computerized perimetry. Acta Ophthalmol Suppl. 1977;132:1-42. 
8. Hood DC, Raza AS, de Moraes CG, Liebmann JM, Ritch R.

Glaucomatous damage of the macula. Prog Retin Eye Res. 2013;32:1-21.

9. Drance SM. The early field defects in glaucoma. Invest Ophthalmol. 1969;8(1):84-91.

10. Langerhorst CT, Carenini LL, Bakker D, De Bie-Raakman MAC. Measurements for description of very early glaucomatous field defects. In: Wall M, Heiji A, editors. Perimetry Update 1996/1997. New York, NY: Kugler Publications; 1997. p. 67-73.

11. Traynis I, De Moraes CG, Raza AS, Liebmann JM, Ritch R, Hood DC. Prevalence and nature of early glaucomatous defects in the central 10 degrees of the visual field. JAMA Ophthalmol. 2014;132(3):291-7.

12. Park HY, Hwang BE, Shin HY, Park CK. Clinical clues to predict the presence of parafoveal scotoma on Humphrey 10-2 visual field using a Humphrey 24-2 visual field. Am J Ophthalmol. 2016;161:150-9.

13. Sullivan-Mee M, Karin Tran MT, Pensyl D, Tsan G, Katiyar S. Prevalence, features, and severity of glaucomatous visual field loss measured with the 10-2 Achromatic Threshold Visual Field Test. Am J Ophthalmol. 2016;168:40-51.

14. Schiefer U, Papageorgiou E, Sample PA, Pascual JP, Selig B, Krapp $E$, et al. Spatial pattern of glaucomatous visual field loss obtained with regionally condensed stimulus arrangements. Invest Ophthalmol Vis Sci. 2010;51(11):5685-9.

15. Curcio CA, Allen KA. Topography of ganglion cells in human retina. J Comp Neurol. 1990;300(1):5-25. 
16. McFadzean R, Brosnahan D, Hadley D, Mutlukan E. Representation of the visual field in the occipital striate cortex. $\mathrm{Br} \mathrm{J}$ Ophthalmol. $1994 ; 78(3): 185-90$.

17. Murata H, Hirasawa H, Aoyama Y, Sugisaki K, Araie M, Mayama C, et al. Identifying areas of the visual field important for quality of life in patients with glaucoma. PloS One. 2013;8(3):e58695.

18. Blumberg DM, De Moraes CG, Prager AJ, Yu Q, Al-Aswad L, Cioffi GA, et al. Association between undetected 10-2 visual field damage and vision-related quality of life in patients with glaucoma. JAMA Ophthalmol. 2017;135(7):742-7.

19. Prager AJ, Hood DC, Liebmann JM, De Moraes CG, Al-Aswad LA, Yu Q, et al. Association of glaucoma-related, optical coherence tomographymeasured macular damage with vision-related quality of life. JAMA Ophthalmol. 2017;135(7):783-8.

20. Garg A, Hood DC, Pensec N, Liebmann JM, Blumberg DM. Macular damage, as determined by structure-function staging, is associated with worse vision-related quality of life in early glaucoma. Am J Ophthalmol. 2018;194:88-94.

21. Ramulu PY, West SK, Munoz B, Jampel HD, Friedman DS. Driving cessation and driving limitation in glaucoma: the Salisbury Eye Evaluation Project. Ophthalmology. 2009;116(10):1846-53.

22. Ramulu PY, West SK, Munoz B, Jampel HD, Friedman DS. Glaucoma and reading speed: the Salisbury Eye Evaluation project. Arch Ophthalmol (Chicago, III : 1960). 2009;127(1):82-7. 
23. Baig S, Diniz-Filho A, Wu Z, Abe RY, Gracitelli CP, Cabezas E, et al. Association of fast visual field loss with risk of falling in patients with glaucoma. JAMA Ophthalmol. 2016;134(8):880-6..

24. Jampel HD, Frick KD, Janz NK, Wren PA, Musch DC, Rimal R, et al. Depression and mood indicators in newly diagnosed glaucoma patients. Am J Ophthalmol. 2007;144(2):238-44.

25. Weinreb RN, Aung T, Medeiros FA. The pathophysiology and treatment of glaucoma: a review. JAMA. 2014;311(18):1901-11.

26. Grillo LM, Wang DL, Ramachandran R, Ehrlich AC, De Moraes CG, Ritch $\mathrm{R}$, et al. The 24-2 visual field test misses central macular damage confirmed by the 10-2 visual field test and optical coherence tomography. Transl Vis Sci Technol. 2016;5(2):15.

27. Wang DL, Raza AS, de Moraes CG, Chen M, Alhadeff P, Jarukatsetphorn $\mathrm{R}$, et al. Central glaucomatous damage of the macula can be overlooked by conventional OCT retinal nerve fiber layer thickness analyses. TransI Vis Sci Technol. 2015;4(6):4.

28. Zhang C, Tatham AJ, Abe RY, Hammel N, Belghith A, Weinreb RN, et al. Macular ganglion cell inner plexiform layer thickness in glaucomatous eyes with localized retinal nerve fiber layer defects. PloS One. 2016;11(8):e0160549.

29. Tatham AJ, Medeiros FA, Zangwill LM, Weinreb RN. Strategies to improve early diagnosis in glaucoma. Prog Brain Res. 2015;221:103-33.

30. Mills RP, Budenz DL, Lee PP, Noecker RJ, Walt JG, Siegartel LR, et al. Categorizing the stage of glaucoma from pre-diagnosis to end-stage disease. Am J Ophthalmol. 2006;141(1):24-30. 
31. De Moraes CG, Sun A, Jarukasetphon R, Rajshekhar R, Shi L, Blumberg DM, et al. Association of macular visual field measurements with glaucoma staging systems. JAMA Ophthalmol. 2018 Nov 8.

32. Susanna R, Jr., Vessani RM. Staging glaucoma patient: why and how? Open Ophthalmol J. 2009;3:59-64.

33. De Moraes CG, Hood DC, Thenappan A, Girkin CA, Medeiros FA, Weinreb RN, et al. 24-2 Visual fields miss central defects shown on 10-2 tests in glaucoma suspects, ocular hypertensives, and early glaucoma. Ophthalmology. 2017;124(10):1449-56.

34. Wu Z, Medeiros FA, Weinreb RN, Zangwill LM. Performance of the 10-2 and 24-2 visual field tests for detecting central visual field abnormalities in glaucoma. Am J Ophthalmol. 2018;196:10-7.

35. Susanna R, Jr., De Moraes CG, Cioffi GA, Ritch R. Why do people (still) go blind from glaucoma? Transl Vis Sci Technol. 2015;4(2):1.

36. Weinreb RN GE. Association of International Glaucoma Societies. Glaucoma diagnosis: structure and function. Amsterdam: Kugler Publications; 2004.

37. Heijl A, Lindgren G, Olsson J. Normal variability of static perimetric threshold values across the central visual field. Arch Ophthalmol (Chicago, III : 1960). 1987;105(11):1544-9.

38. Heijl A, Lindgren A, Lindgren G. Test-retest variability in glaucomatous visual fields. Am J Ophthalmol. 1989;108(2):130-5. 
39. Artes PH, Hutchison DM, Nicolela MT, LeBlanc RP, Chauhan BC. Threshold and variability properties of matrix frequency-doubling technology and standard automated perimetry in glaucoma. Invest Ophthalmol Vis Sci. 2005;46(7):2451-7.

40. Nouri-Mahdavi K, Hoffman D, Ralli M, Caprioli J. Comparison of methods to predict visual field progression in glaucoma. Arch Ophthalmol (Chicago, III : 1960). 2007;125(9):1176-81.

41. Chauhan BC, Garway-Heath DF, Goni FJ, Rossetti L, Bengtsson B, Viswanathan AC, et al. Practical recommendations for measuring rates of visual field change in glaucoma. Br J Ophthalmol. 2008;92(4):569-73.

42. De Moraes CG, Juthani VJ, Liebmann JM, Teng CC, Tello C, Susanna R, Jr., et al. Risk factors for visual field progression in treated glaucoma. Arch Ophthalmol (Chicago, III : 1960). 2011;129(5):562-8.

43. De Moraes CG, Liebmann JM, Greenfield DS, Gardiner SK, Ritch R, Krupin $\mathrm{T}$, et al. Risk factors for visual field progression in the low-pressure glaucoma treatment study. Am J Ophthalmol. 2012;154(4):702-11.

44. Demirel S, De Moraes CG, Gardiner SK, Liebmann JM, Cioffi GA, Ritch $\mathrm{R}$, et al. The rate of visual field change in the ocular hypertension treatment study. Invest Ophthalmol Vis Sci. 2012;53(1):224-7.

45. Spry PG, Johnson CA. Identification of progressive glaucomatous visual field loss. Surv Ophthalmol. 2002;47(2):158-73.

46. Vesti E, Johnson CA, Chauhan BC. Comparison of different methods for detecting glaucomatous visual field progression. Invest Ophthalmol Vis Sci. 2003;44(9):3873-9. 
47. Otarola F, Chen A, Morales E, Yu F, Afifi A, Caprioli J. Course of glaucomatous visual field loss across the entire perimetric range. JAMA Ophthalmol. 2016;134(5):496-502.

48. Pathak M, Demirel S, Gardiner SK. Nonlinear trend analysis of longitudinal pointwise visual field sensitivity in suspected and early glaucoma. TransI Vis Sci Technol. 2015;4(1):8.

49. Wu Z, Saunders LJ, Daga FB, Diniz-Filho A, Medeiros FA. Frequency of testing to detect visual field progression derived using a longitudinal cohort of glaucoma patients. Ophthalmology. 2017;124(6):786-92.

50. De Moraes CG, Demirel S, Gardiner SK, Liebmann JM, Cioffi GA, Ritch $R$, et al. Rate of visual field progression in eyes with optic disc hemorrhages in the ocular hypertension treatment study. Arch Ophthalmol (Chicago, III : 1960). 2012;130(12):1541-6.

51. De Moraes CG, Demirel S, Gardiner SK, Liebmann JM, Cioffi GA, Ritch $R$, et al. Effect of treatment on the rate of visual field change in the ocular hypertension treatment study observation group. Invest Ophthalmol Vis Sci. 2012;53(4):1704-9.

52. de Moraes CG, Furlanetto RL, Ritch R, Liebmann JM. A new index to monitor central visual field progression in glaucoma. Ophthalmology. 2014;121(8):1531-8.

53. De Moraes CG, Jasien JV, Simon-Zoula S, Liebmann JM, Ritch R. Visual field change and 24-hour IOP-related profile with a contact lens sensor in treated glaucoma patients. Ophthalmology. 2016;123(4):744-53. 
54. De Moraes CG, Liebmann CA, Susanna R, Jr., Ritch R, Liebmann JM. Examination of the performance of different pointwise linear regression progression criteria to detect glaucomatous visual field change. Clin Exp Ophthalmol. 2012;40(4):e190-6.

55. De Moraes CG, Liebmann JM, Liebmann CA, Susanna R, Jr., Tello C, Ritch R. Visual field progression outcomes in glaucoma subtypes. Acta Ophthalmol. 2013;91(3):288-93.

56. De Moraes CG, Liebmann JM, Park SC, Teng CC, Nemiroff J, Tello $\mathrm{C}$, et al. Optic disc progression and rates of visual field change in treated glaucoma. Acta Ophthalmol. 2013;91(2):e86-91.

57. De Moraes CG, Sehi M, Greenfield DS, Chung YS, Ritch R, Liebmann JM. A validated risk calculator to assess risk and rate of visual field progression in treated glaucoma patients. Invest Ophthalmol Vis Sci. 2012;53(6):2702-7.

58. de Moraes CG, Song C, Liebmann JM, Simonson JL, Furlanetto RL, Ritch R. Defining 10-2 visual field progression criteria: exploratory and confirmatory factor analysis using pointwise linear regression. Ophthalmology. 2014;121(3):741-9.

59. Gardiner SK, Demirel S, De Moraes CG, Liebmann JM, Cioffi GA, Ritch $R$, et al. Series length used during trend analysis affects sensitivity to changes in progression rate in the ocular hypertension treatment study. Invest Ophthalmol Vis Sci. 2013;54(2):1252-9.

60. Saunders LJ, Russell RA, Kirwan JF, McNaught Al, Crabb DP. Examining visual field loss in patients in glaucoma clinics during their predicted remaining lifetime. Invest Ophthalmol Vis Sci. 2014;55(1):102-9. 
61. Su D, Park SC, Simonson JL, Liebmann JM, Ritch R. Progression pattern of initial parafoveal scotomas in glaucoma. Ophthalmology. 2013;120(3):520-7.

62. Hood DC, Nguyen M, Ehrlich AC, Raza AS, Sliesoraityte I, De Moraes CG, et al. A Test of a model of glaucomatous damage of the macula with high-density perimetry: implications for the locations of visual field test points. TransI Vis Sci Technol. 2014;3(3):5.

63. Jampel HD, Friedman D, Quigley H, Vitale S, Miller R, Knezevich F, et al. Agreement among glaucoma specialists in assessing progressive disc changes from photographs in open-angle glaucoma patients. Am J Ophthalmol. 2009;147(1):39-44.e1.

64. Lisboa R, Paranhos A, Jr., Weinreb RN, Zangwill LM, Leite MT, Medeiros FA. Comparison of different spectral domain OCT scanning protocols for diagnosing preperimetric glaucoma. Invest Ophthalmol Vis Sci. 2013;54(5):3417-25.

65. Mwanza JC, Oakley JD, Budenz DL, Anderson DR. Ability of cirrus HD-OCT optic nerve head parameters to discriminate normal from glaucomatous eyes. Ophthalmology. 2011;118(2):241-8.e1.

66. Zhang X, Loewen N, Tan O, Greenfield DS, Schuman JS, Varma R, et al. Predicting development of glaucomatous visual field conversion using baseline fourier-domain optical coherence tomography. Am J Ophthalmol. 2016;163:29-37.

67 Schulze A, Lamparter J, Pfeiffer N, Berisha F, Schmidtmann I, Hoffmann EM. Diagnostic ability of retinal ganglion cell complex, retinal nerve fiber layer, and optic nerve head measurements by Fourier-domain optical coherence tomography. Graefe's Arch Clin Exp Ophthalmol. 2011;249(7):1039-45. 
68. Michelessi M, Riva I, Martini E, Figus M, Frezzotti P, Agnifili L, et al. Macular versus nerve fibre layer versus optic nerve head imaging for diagnosing glaucoma at different stages of the disease: Multicenter Italian Glaucoma Imaging Study. Acta Ophthalmol. 2019;97(2):e207-e15.

69. Kim KE, Park KH. Macular imaging by optical coherence tomography in the diagnosis and management of glaucoma. Br J Ophthalmol. 2018;102(6):718-24.

70. Kansal V, Armstrong JJ, Pintwala R, Hutnik C. Optical coherence tomography for glaucoma diagnosis: An evidence based meta-analysis. PloS One. 2018;13(1):e0190621.

71. Zhang X, Dastiridou A, Francis BA, Tan O, Varma R, Greenfield DS, et al. Comparison of glaucoma progression detection by optical coherence tomography and visual field. Am J Ophthalmol. 2017;184:63-74.

72. Kim YK, Ha A, Na KI, Kim HJ, Jeoung JW, Park KH. Temporal relation between macular ganglion cell-inner plexiform layer loss and peripapillary retinal nerve fiber layer loss in glaucoma. Ophthalmology. 2017;124(7):1056-64.

73. Marshall HN, Andrew NH, Hassall M, Qassim A, Souzeau E, Ridge $B$, et al. Macular ganglion cell-inner plexiform layer loss precedes peripapillary retinal nerve fiber layer loss in glaucoma with lower intraocular pressure. Ophthalmology. 2019 Mar 22.pii: S0161-6420(18)32563-6.

74. Leite MT, Sakata LM, Medeiros FA. Managing glaucoma in developing countries. Arq Bras Oftalmol. 2011;74(2):83-4.

75. Elam AR, Blachley TS, Stein JD. Geographic variation in the use of diagnostic testing of patients with newly diagnosed open-angle glaucoma. Ophthalmology. 2016;123(3):522-31. 
76. Tanna AP, Bandi JR, Budenz DL, Feuer WJ, Feldman RM, Herndon LW, et al. Interobserver agreement and intraobserver reproducibility of the subjective determination of glaucomatous visual field progression. Ophthalmology. 2011;118(1):60-5.

77. Blumberg DM, De Moraes CG, Liebmann JM, Garg R, Chen C, Theventhiran A, et al. Technology and the glaucoma suspect. Invest Ophthalmol Vis Sci. 2016;57(9):80-5.

78. Medeiros FA, Zangwill LM, Girkin CA, Liebmann JM, Weinreb RN. Combining structural and functional measurements to improve estimates of rates of glaucomatous progression. Am J Ophthalmol. 2012;153(6):1197205.e1.

79. Russell RA, Malik R, Chauhan BC, Crabb DP, Garway-Heath DF. Improved estimates of visual field progression using bayesian linear regression to integrate structural information in patients with ocular hypertension. Invest Ophthalmol Vis Sci. 2012;53(6):2760-9.

80. Zhu H, Russell RA, Saunders LJ, Ceccon S, Garway-Heath DF, Crabb DP. Detecting changes in retinal function: Analysis with NonStationary Weibull Error Regression and Spatial enhancement (ANSWERS). PloS One. 2014;9(1):e85654.

81. Leite MT, Zangwill LM, Weinreb RN, Rao HL, Alencar LM, Medeiros FA. Structure-function relationships using the Cirrus spectral domain optical coherence tomograph and standard automated perimetry. J Glaucoma. 2012;21(1):49-54.

82. Kanamori A, Nakamura M, Tomioka M, Kawaka Y, Yamada Y, Negi A. Structure-function relationship among three types of spectral-domain optical coherent tomography instruments in measuring parapapillary retinal nerve fibre layer thickness. Acta Ophthalmol. 2013;91(3):e196-202. 
83. Hood DC, Kardon RH. A framework for comparing structural and functional measures of glaucomatous damage. Prog Retin Eye Res. 2007;26(6):688-710.

84. Sample PA, Girkin CA, Zangwill LM, Jain S, Racette L, Becerra LM, et al. The African Descent and Glaucoma Evaluation Study (ADAGES): design and baseline data. Arch Ophthalmol. 2009;127(9):1136-45.

85. Schmidt AF, Finan C. Linear regression and the normality assumption. J Clin Epidemiol. 2018;98:146-51.

86. Hammel N, Belghith A, Weinreb RN, Medeiros FA, Mendoza N, Zangwill LM. Comparing the rates of retinal nerve fiber layer and ganglion cell-inner plexiform layer loss in healthy eyes and in glaucoma eyes. Am J Ophthalmol. 2017;178:38-50.

87. Ledolter J, Kardon RH. Assessing trends in functional and structural characteristics: a survey of statistical methods with an example from ophthalmology. TransI Vis Sci Technol. 2018;7(5):34.

88. Pathak M, Demirel S, Gardiner SK. Nonlinear, multilevel mixedeffects approach for modeling longitudinal standard automated perimetry data in glaucoma. Invest Ophthalmol Vis Sci. 2013;54(8):5505-13.

89. Liebmann K, De Moraes CG, Liebmann JM. Measuring rates of visual field progression in linear versus nonlinear scales: implications for understanding the relationship between baseline damage and target rates of glaucoma progression. J Glaucoma. 2017;26(8):721-5.

90. Bengtsson B, Heijl A. Evaluation of a new perimetric threshold strategy, SITA, in patients with manifest and suspect glaucoma. Acta Ophthalmol Scand. 1998;76(3):268-72. 
91. Rizopoulos D. The R Package JMbayes for fitting joint models for longitudinal and time-to-event data using MCMC. Journal of Statistical Software. 2016;72(7):1-46.

92. Crabb DP, Garway-Heath DF. Intervals between visual field tests when monitoring the glaucomatous patient: wait-and-see approach. Invest Ophthalmol Vis Sci. 2012;53(6):2770-6.

93. Wu Z, Medeiros FA. Impact of different visual field testing paradigms on sample size requirements for glaucoma clinical trials. Sci Rep. 2018;8(1):4889.

94. Weinreb RN, Kaufman PL. Glaucoma research community and FDA look to the future, II: NEI/FDA Glaucoma Clinical Trial Design and Endpoints Symposium: measures of structural change and visual function. Invest Ophthalmol Vis Sci. 2011;52(11):7842-51.

95. De Moraes CG, Liebmann JM, Levin LA. Detection and measurement of clinically meaningful visual field progression in clinical trials for glaucoma. Prog Retin Eye Res. 2017;56:107-47.

96. Garway-Heath DF, Zhu H, Cheng Q, Morgan K, Frost C, Crabb DP, et al. Combining optical coherence tomography with visual field data to rapidly detect disease progression in glaucoma: a diagnostic accuracy study. Health Technol Assess (Winchester, England). 2018;22(4):1-106.

97 Abe RY, Diniz-Filho A, Zangwill LM, Gracitelli CP, Marvasti AH, Weinreb $\mathrm{RN}$, et al. The relative odds of progressing by structural and functional tests in glaucoma. Invest Ophthalmol Vis Sci. 2016;57(9):421-8. 
98. Racette L, Liebmann JM, Girkin CA, Zangwill LM, Jain S, Becerra LM, et al. African Descent and Glaucoma Evaluation Study (ADAGES): III. Ancestry differences in visual function in healthy eyes. Arch Ophthalmol (Chicago, III : 1960). 2010;128(5):551-9.

99. Gracitelli CPB, Zangwill LM, Diniz-Filho A, Abe RY, Girkin CA, Weinreb RN, et al. Detection of glaucoma progression in individuals of African descent compared with those of European descent. JAMA Ophthalmol. 2018;136(4):329-35.

100. Keltner JL, Johnson CA, Cello KE, Edwards MA, Bandermann SE, Kass MA, et al. Classification of visual field abnormalities in the ocular hypertension treatment study. Arch Ophthalmol (Chicago, III : 1960). 2003;121(5):643-50.

101. Chauhan BC, Mikelberg FS, Artes PH, Balazsi AG, LeBlanc RP, Lesk MR, et al. Canadian Glaucoma Study: 3. Impact of risk factors and intraocular pressure reduction on the rates of visual field change. Arch Ophthalmol (Chicago, III : 1960). 2010;128(10):1249-55.

102. Wang M, Hood DC, Cho JS, Ghadiali Q, De Moraes CG, Zhang X, et al. Measurement of local retinal ganglion cell layer thickness in patients with glaucoma using frequency-domain optical coherence tomography. Arch Ophthalmol (Chicago, III : 1960). 2009;127(7):875-81.

103. Raza AS, Cho J, de Moraes CG, Wang M, Zhang X, Kardon RH, et al. Retinal ganglion cell layer thickness and local visual field sensitivity in glaucoma. Arch Ophthalmol (Chicago, III : 1960). 2011;129(12):1529-36.

104. Hood DC, De Moraes CG. Four questions for every clinician diagnosing and monitoring glaucoma. J Glaucoma. 2018;27(8):657-64. 
105. Hood DC, De Moraes CG. Challenges to the common clinical paradigm for diagnosis of glaucomatous damage with oct and visual fields. Invest Ophthalmol Vis Sci. 2018;59(2):788-91. 